\title{
Development of a haploid transformation system and overexpression of Phytochrome B gene in \\ Brassica napus L.
}

\author{
Dissertation \\ to obtain the Ph.D. degree \\ in the faculty of Agricultural Sciences \\ Georg-August-University Göttingen \\ Germany
}

Presented by

Kolitha Bandara Wijesekara

Born in Kandy, Sri Lanka

Göttingen, July 2007 
D7

1. Name of referee: Prof. Dr. Heiko C. Becker

2. Name of referee: Prof. Dr. Petr Karlovsky

Date of Dissertation: 19 July 2007 


\section{Table of contents}

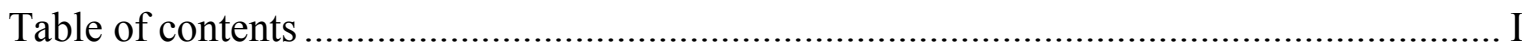

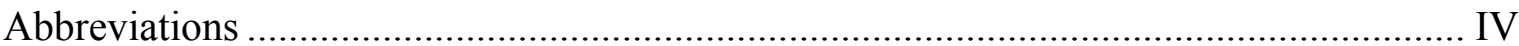

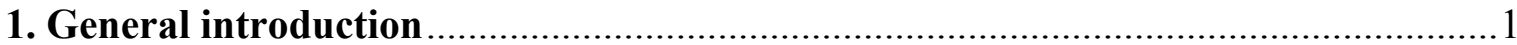

2. Transformation of haploid explants of Brassica napus L. as a rapid method to obtain

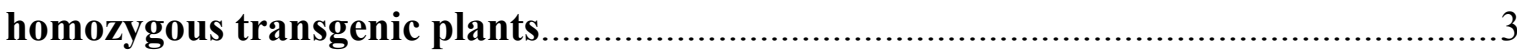

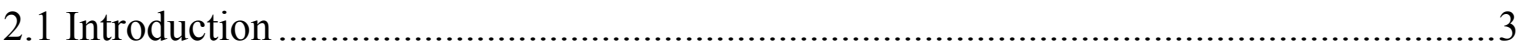

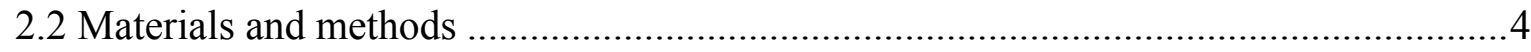

2.2.1 in vitro production and propagation of haploid plants ...........................................4

2.2.2 Analysis of ploidy level of microspore derived plants............................................5

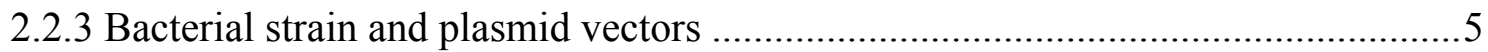

2.2.4 Preparation of basic culture media and stock solutions ........................................

2.2.5 Optimization of callus production and shoot regeneration ..................................

2.2.6 Infection and cocultivation of leaf and petiole explants ......................................

2.2.7 Selection of transformed calli and plants ........................................................... 10

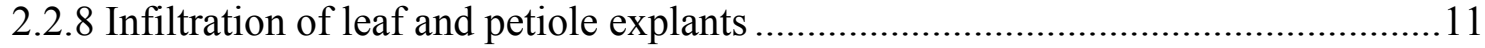

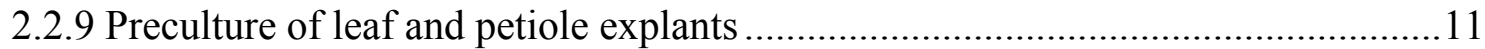

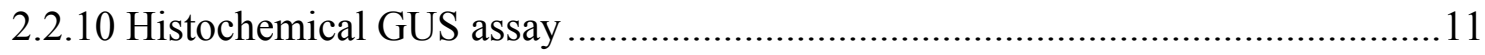

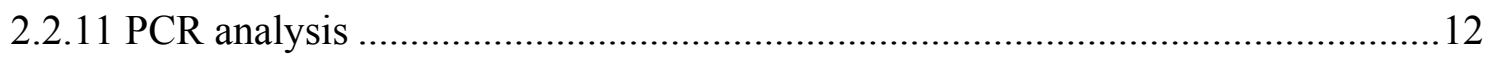

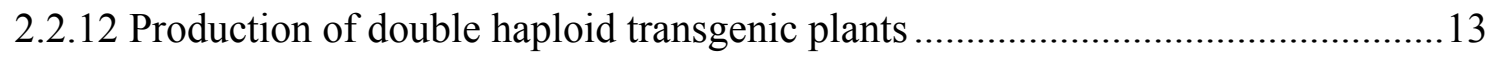

2.2.13 Experimental design and statistical analysis .................................................... 14

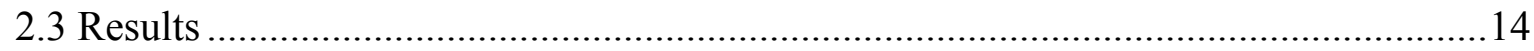

2.3.1 Optimization of callus production and shoot regeneration ................................. 14

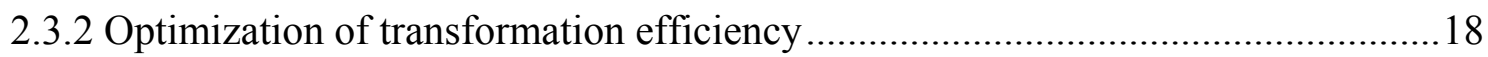

2.3.3 Effect of filter paper and preculture of explants ................................................20

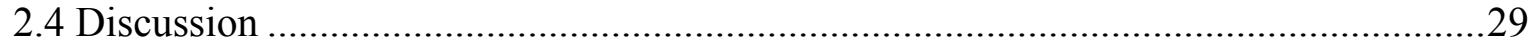


2.4.1 Optimization of callus production and shoot regeneration ................................29

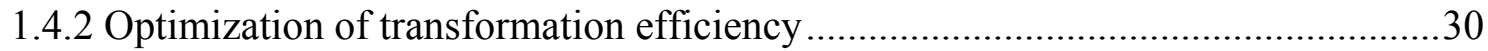

2.4.3 Advantages of using haploid plant materials for transformation ..........................33

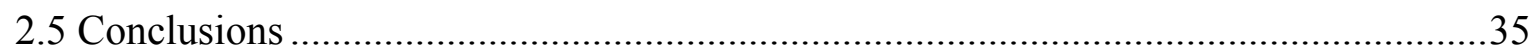

3. Overexpression of Arabidopsis phytochrome B in Brassica napus L......................36

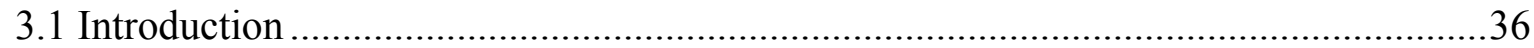

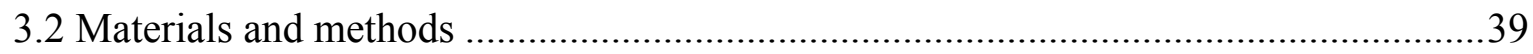

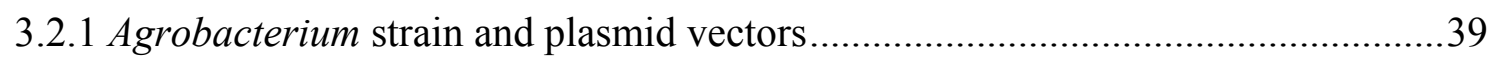

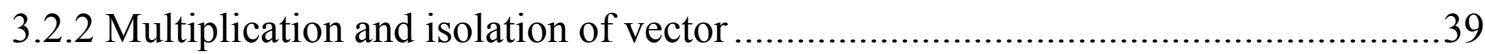

3.2.3 Preparation of competent cells of Agrobacterium tumefaciens ............................40

3.2.4 Introduction of plant expression vector into Agrobacterium tumefaciens strain ...41

3.2.5 Preparation of glycerine stocks of transformed Agrobacterium tumefaciens ........41

3.2.6 Preparation of bacterial cell suspension for transformation of plant tissues..........42

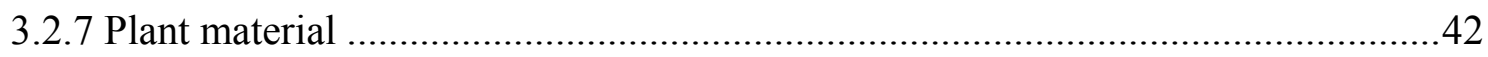

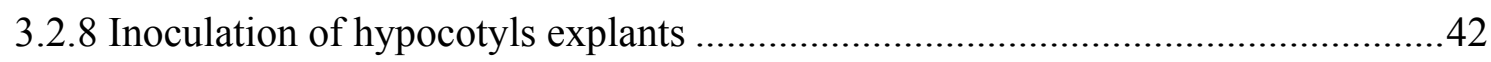

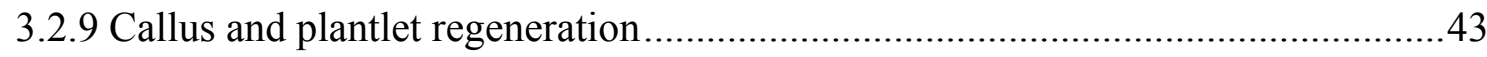

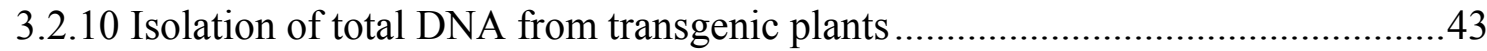

3.2.11 Determination of DNA concentration and PCR analysis.................................44

3.2.12 Morphological characterization of primary transformants ( $\mathrm{T} 1$ plants) ...............45

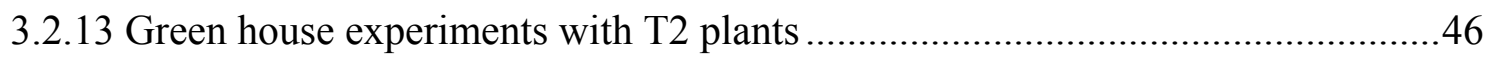

3.2.14 Measurement of hypocotyl length and kanamycin sensitivity assay ...................46

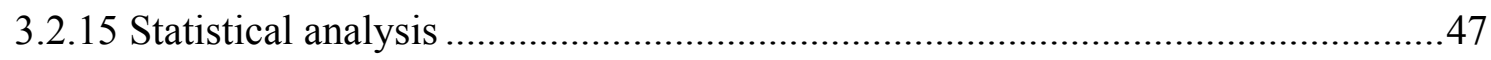

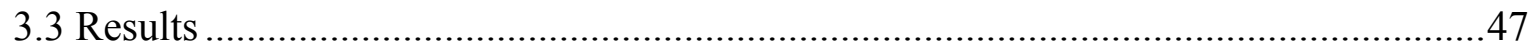

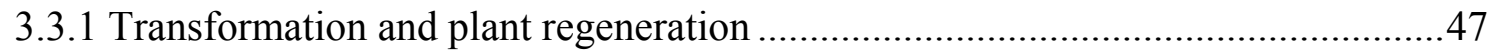

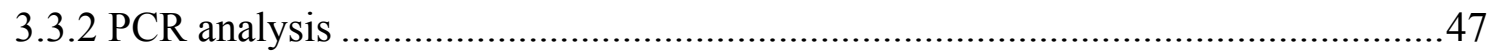

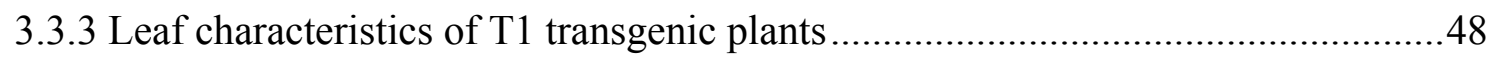

3.3.4 Morphological, yield and quality traits of $\mathrm{T} 1$ transgenic plants ..........................50

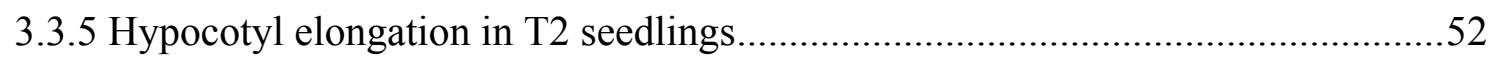

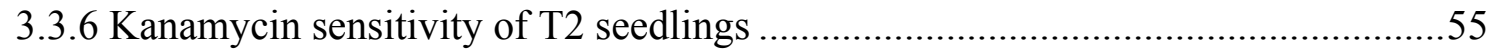




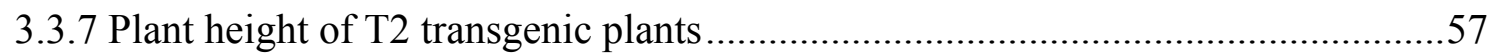

3.3.8 Bolting, first flowering and duration of flowering in $\mathrm{T} 2$ plants..........................58

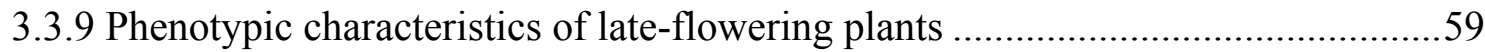

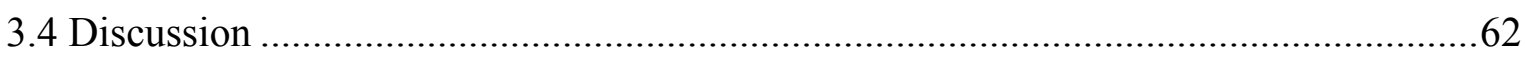

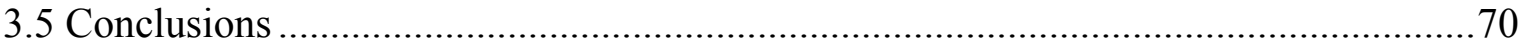

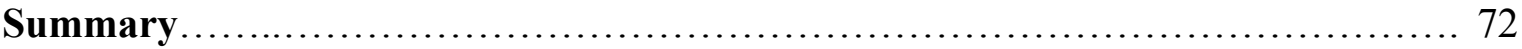

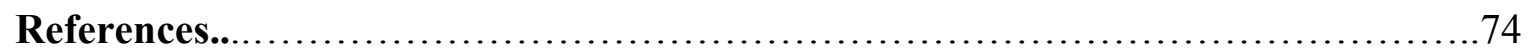

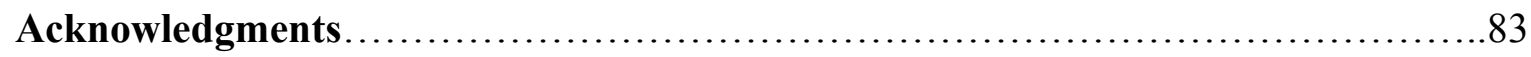

Curriculum Vitae............................................................. 85 


\section{Abbreviations}

$\mathrm{AgNO}_{3}$

ANOVA

BAP

$\mathrm{Ca}\left(\mathrm{NO}_{3}\right)_{2}$

CaMV

cDNA

DMSO

DNA

dNTPs

EDTA

GA3

GUS

IBA

$\mathrm{kb}$

LB-Medium

MES

mRNA

NAA

NIRS

OD

PCR

RNA

rpm

T-DNA

Tris
Silver nitrate

Analysis of variance

6-Benzylaminopurine

Calcium nitrate

Cauliflower mosaic virus

Complementary DNA

Dimethylsulfoxide

Deoxyribonucleic acid

Deoxynucleotide triphosphates

Ethylenediamine tetraacetic acid

Gibberellic acid

$\beta$-Glucuronidase

Indole-3- butyric acid

Kilobases

Luria-Bertani medium

Morpholinoethane sulfonic acid

Messenger Ribonucleic Acid

1-Naphthaleneacetic acid

Near infrared spectroscopy

Optical density

Polymerase chain reaction

Ribonucleic acid

Revolutions per minute

Transfer-DNA

Trishydroxymethylaminomethane 


\section{General introduction}

Brassica is the most economically important genus in the family Brassicaceae (former Cruciferae). Cultivated forms of this genus are mainly oil crops and vegetable crops. Among the Brassica crops, oilseeds have the highest economic value. The oilseed Brassicas include Brassica juncea, Brassica carinata, Brassica rapa and Brassica napus which are collectively and commonly called as oilseed rape. Varieties with low aliphatic glucosinolates and erucic acid in seed oil are referred to as canola which is most often $B$. napus. However, canola-quality B. rapa and B. juncea varieties are also available (Cardoza and Stewart 2004b). Canola oil is widely used as cooking oil and in making margarine which is very low in saturated fatty acids, making it popular among health conscious consumers. This has made canola the third most important oil crop after soybean and palm oil, in global production (FAO 2006). Canola meal, which is a leftover product after extracting oil, is used as a protein supplement in animal feed. Vegetable Brassicas are a highly diverse group of crops grown worldwide which belong mainly to Brassica oleracea, as well as B. rapa and B. napus. This group includes plants such as broccoli, Brussels sprouts, cabbage, cauliflower, collards, kale, kohlrabi, rutabaga, and turnip (Cardoza and Stewart 2004b).

Because of the high economic importance, more research has been pursued in improving breeding programs with Brassica crops. With conventional breeding techniques it takes a minimum of 8-10 generations to develop a new variety with desired traits (Cardoza and Stewart 2004a). An alternative approach of speedy trait development without resorting to conventional breeding techniques would be the use of genetic engineering and biotechnology. Genetic engineering allows transfer of foreign genes with desired traits into plants, regardless of differences in species, genera or even kingdoms. Many genetic improvements to Brassica crops with the highest impact have come from genetic transformation. Genetic approaches of Brassica napus have mainly focused on improving oil quality (Verwoert et al. 1995, Knutzon et al. 1992) and making it herbicide-tolerant (de Block et al. 1989, de Block and de Brouwer 1991) or insect tolerant (Stewart et al. 1996). Agrobacterium tumefaciens-mediated transformation is the most widely used method of gene transfer into Brassica and it is generally quite efficient and practical for most species in the genus. Frequently, Agrobacterium-mediated transformation is carried out using seedling raised hypocotyls (de Block et al. 1989), cotyledons and cotyledonary petioles 
(Moloney et al. 1989) owing to the high regeneration ability of these explants. Due to the diploid nature of seedling-raised plant materials, first generation transgenic plants would be hemizygous for the transgene. Consequently, much time and labour has to be invested to produce homozygous plants out of hemizygous plants. This study investigates the potential of using haploid leaf and petiole explants of Brassica napus plants propagated in vitro for an efficient Agrobacterium-mediated gene transfer. Use of haploid materials assures homozygous transgenic plants in one generation after colchicines treatment and also gives greater uniformity among transgenic plants due to the use of cloned plant materials.

Many current $B$. napus cultivars are prone to lodging causing high yield losses (Islam and Evans 1994). Lodging could be decreased by reducing plant height which is often achieved in B. napus by applying chemical growth regulators (Gans et al. 2000). This method is expensive and could also interfere with other endogenous plant hormones and metabolic processes (Rademacher 2000). Decrease in plant height has been observed with potatoes (Solanum tuberosum) (Thiele et al. 1999) and with tobacco (Nicotiana tabacum) (Halliday at al. 1997) after overexpression of Arabidopsis thaliana phytochromes B gene (PHYB). This study investigates the possibility of reducing plant height by overexpression of the $A$. thaliana PHYB gene in B. napus plants. 


\section{Transformation of haploid explants of Brassica napus L. as a rapid method to obtain homozygous transgenic plants}

\subsection{Introduction}

Oilseed rape (Brassica napus) is considered to be the most important crop for the production of vegetable oils in Northern Europe, Canada and in China (Downey and Röbbelen 1989). Thus Brassica napus is an important target for crop improvements. Several protocols for genetic transformation of B. napus have been reported, such as microinjection (Neuhaus et al. 1987, Miki et al. 1989), direct DNA uptake (Guerche et al. 1987, Jardinaud et al. 1993), microprojectile bombardment (Stöger et al. 1995) as well as Agrobacterium-mediated DNA transfer (Fry et al. 1987, Pua et al. 1987, de Block et al. 1989, Moloney et al. 1989, Boulter et al. 1990, Damgaard et al. 1997, Schröder et al. 1994, Stefanov et al. 1994). Out of the above mentioned transformation methods Agrobacterium tumefaciens-mediated transformation has proven to be efficient in many Brassica species. Using genetic transformation, new traits such as modifications of the oil composition (Verwoert et al. 1995, Knutzon et al. 1992), herbicide tolerance (de Block et al. 1989, de Block and de Brouwer 1991) and altered protein composition (Kohno-Murase et al. 1995, Altenbach et al. 1992) have been successfully introduced into this crop.

A wide range of target explants of B. napus, including hypocotyl segments (Radke et al. 1988, de Block et al. 1989, Cardoza and Stewart 2003, Khan et al. 2003), cotyledonary petioles (Moloney et al. 1989), thin cell layers (Charest et al. 1988), stem segments (Fry et al. 1987), peduncle segments (Eapen and George 1997) and isolated protoplasts from hypocotyls and mesophyll cells (Thomzik and Hain 1990, Wang et al. 2005) have been transformed using Agrobacterium tumefaciens with varying successes in different laboratories. Often these target explants and cells have been obtained from in vitro grown seedlings. Owing to the diploid character of these plant materials, first generation transgenic plants (T1) will necessarily be hemizygous for the transformed gene. From the hemizygous loci, the transformed gene would segregate in accordance with Mendelian inheritance in the successive generations. Frequently, transformation with Agrobacterium tumefaciens results in insertion of multiple copies of the transgene. When multiple unlinked transgenic copies are present in hemizygous plants, much time and labour has to be invested to produce homozygous plants by repeated selfing or by applying the doubled haploid technology. Conversely, molecular characterization of the transgene copy number 
and determination of homo-/ hemizygous state is laborious and not always giving conclusive results.

The use of haploid cells and tissue explants could provide an alternative approach for efficient transformation of oilseed rape. This seems tempting because haploid transgenic plants will become in one step homozygous diploid after colchicine treatment. The transformation of haploid microspores has been reported using the particle gun (Fukuoka et al. 1998) and Agrobacterium (Pechan 1989). However, the microspore culture system is very sensitive and the results have been shown to be difficult to reproduce. An alternative to this sensitive system is the use of explants from haploid plants obtained from microspore culture, for Agrobacterium transformation. This study investigates the potential of using haploid leaf and petiole explants of Brassica napus plants propagated in vitro for an efficient Agrobacterium-mediated gene transfer.

\subsection{Materials and Methods}

\subsection{1 in vitro production and propagation of haploid plants}

French spring rapeseed cv. Drakkar plants were grown in a controlled environmental chamber at $17 \pm 2{ }^{\circ} \mathrm{C}$ and a photoperiod of $16 / 8 \mathrm{hrs}$ day/night. Unopened flower buds of 2-3 $\mathrm{mm}$ in length (which corresponds to late uninucleate stage of pollen development), were obtained from the main raceme of these plants. Microspore isolation was carried out according to the method described by Fletcher et al. (1998). Isolated microspores were cultured in liquid NLN medium containing vitamins, macro, and micro elements (Duchefa, Netherlands) and supplemented with $500 \mathrm{mg} / \mathrm{l} \mathrm{Ca}\left(\mathrm{NO}_{3}\right)_{2}$ and $13 \%$ sucrose. The $\mathrm{pH}$ was adjusted to 5.8 and the medium was filter-sterilized. Immediately after microspore isolation, microspores were given a heat shock by placing culture plates in an oven at $32{ }^{\circ} \mathrm{C}$ for $48 \mathrm{hrs}$ in darkness. Thereafter, culture plates were transferred onto a slow rotating shaker $(40 \mathrm{rpm})$ and provided with a photoperiod of $16 / 8 \mathrm{hrs}$ day/night at $25{ }^{\circ} \mathrm{C}$. Wellgrown cotyledonary embryos (after 25-28 days from microspore isolation) were transferred onto solid MS medium, where regeneration of embryos into plantlets and root formation was achieved in additional 30 days' time. 
Plantlets obtained were analysed for their ploidy level (see below) and afterwards selected haploid plantlets were clonally propagated in vitro by transferring the top shoots or stem segments of 1-2 $\mathrm{cm}$ in length bearing an auxiliary bud, into agar-solidified hormone-free Murashige and Skoog (1962) basal medium (MS) supplemented with 2\% sucrose. Shoots were grown at $25{ }^{\circ} \mathrm{C}$ with a day length of $16 \mathrm{~h}$. A continuous supply of plantlets was obtained by regular sub-culturing of excised shoot/stem segments on fresh MS medium in every three to four weeks intervals. Leaves and petiole segments obtained from these plants were used as explants in transformation experiments.

\subsubsection{Analysis of ploidy level of microspore-derived plants}

Fresh young leaf samples (about $1 \mathrm{~cm}^{2}$ ) from microspore-derived plantlets were chopped separately using a sharp razorblade in $200 \mu \mathrm{l}$ of staining solution that contained $1 \mathrm{mg} / \mathrm{l}$ of DAPI (4,6-diamino-2-phenyl-indole). Then the re-suspended solution was passed through a $50 \mu \mathrm{m}$ nylon filter (Nybolt) and diluted with additional $800 \mu \mathrm{l}$ of staining solution. After that the sample was inserted into the Partec Cell Analyser PAS-II (Partec GmbH, Munster) equipped with a mercury lamp. Data was plotted on a semi-logarithmic scale where the histogram peaks are distributed along the abscissa. Leaf samples taken from seedling-raised B. napus plants were used as the diploid standard.

\subsubsection{Bacterial strain and plasmid vectors}

The binary plasmid system of Agrobacterium tumefaciens strains ATHV Rif ${ }^{\mathrm{R}}$ and AGL0 (see Table 2.1) containing binary vectors pPNGUS (provided by Dr. Michael Wallbraun, Centrum Grüne Gentechnik, DLR Rheinpfalz, 67435 Neustadt/Wstr.) and pAK-UGI 9-1 (provided by Dr. Christian Möllers) respectively, were used for transformation. 
Table 2.1. Agrobacterium strains used in transformation

\begin{tabular}{lcclcr}
\hline $\begin{array}{l}\text { Agrobacterium } \\
\text { strain }\end{array}$ & \multicolumn{2}{c}{ Chromosomal } & & $\begin{array}{c}\text { Helper/Vir- } \\
\text { plasmid }\end{array}$ & Reference \\
\cline { 2 - 3 } & background & marker gene* & & \\
\hline ATHV Rif & C58 & rif & pEHA101 & Hellens et al. 2000 \\
AGL0 & C58 & rif & pTiBo542 $\Delta \mathrm{T}-$ & Lazo et al. 1991 \\
& & & DNA &
\end{tabular}

* Antibiotic resistance gene used to select for that strain of Agrobacterium or Ti plasmid Abbreviations: rif, rifampicin resistant

T-DNA region of binary vectors contained chimeric gene construct of NPTII gene coding for neomycin phosphotransferase (which allows for the selection of plants resistant to kanamycin) and $\beta$-glucuronidase (GUS-Intron) as reporter gene. GUS-Intron reporter gene does not express GUS activity in A. tumefaciens cells. Plasmid, transgenes, promoters, terminators, and selection antibiotics in bacteria and in plant were as listed in Table 2.2.

Table 2.2. Binary plasmid, transgenes and selection antibiotics in bacteria and in plants

\begin{tabular}{lllc}
\hline Binary plasmid & \multicolumn{1}{c}{ Transgenes } & \multicolumn{2}{c}{ Antibiotic selection } \\
\cline { 3 - 4 } & (Promoter-Gene-Terminator) & in bacteria & in plants \\
\hline pPNGUS & Pnos-NPTII-Tnos & Streptomycin & Kanamycin \\
& PCaMV35S-GUSi-T35S & Spectinomycin & \\
pAK-UGI 9-1 & PCaMV35S-NPTII-T35S & Streptomycin & Kanamycin \\
& PUbi-GUSi-Tnos & Spectinomycin & \\
\hline
\end{tabular}

Abbreviations: PCaMV35S, cauliflower mosaic virus 35S gene promoter sequence; T35S, terminator sequence of $35 \mathrm{~S}$ gene; PUbi, sunflower ubiquitin promoter sequence; Pnos, nopaline synthase gene promoter sequence; Tnos, nopaline synthase gene terminator sequence; GUSi, $\beta$-glucuronidase gene sequence with an intron (Vancanneyt et al. 1990); NPTII, neomycin phosphotransferase gene sequence. 
2.2.4 Preparation of basic culture media, stock solutions of phytohormones, antibiotics and other reagents

Stock solutions of heat-labile phytohormones, antibiotics and other reagents were prepared beforehand, filter-sterilized and stored in $1 \mathrm{ml}$ aliquots in Eppendorf tubes at $-20{ }^{\circ} \mathrm{C}$ (see Table 2.3 and 2.4). Basic culture media such as, MS (Murashige and Skoog 1962) and DKW medium (Driver and Kuniyuki 1984) were prepared in advance and stored in $500 \mathrm{ml}$ blue capped bottles (Scott) until use. Solid media were heated up in a microwave oven to melt. After cooling the medium to about $40-45^{\circ} \mathrm{C}$, heat labile compounds were added one after the other at desired concentrations with swirling in between, before pouring the medium into sterile petri dishes.

Table 2.3. Stock solutions of antibiotics used for selection in bacteria and in plants

\begin{tabular}{llll}
\hline Antibiotic & Chem. Co. & Stock solution & Final concentration \\
\hline Streptomycin & Duchefa & $100 \mathrm{mg} / \mathrm{ml}\left({\left.\text { in } \mathrm{H}_{2} \mathrm{O}\right)}_{3}\right.$ & $300 \mathrm{mg} / 1$ \\
Spectinomycin & Duchefa & $\left.100 \mathrm{mg} / \mathrm{ml} \mathrm{(in} \mathrm{H}_{2} \mathrm{O}\right)$ & $100 \mathrm{mg} / 1$ \\
Carbenicillin & Duchefa & $50 \mathrm{mg} / \mathrm{ml}\left({\left.\text { in } \mathrm{H}_{2} \mathrm{O}\right)}_{500 \mathrm{mg} / 1}\right.$ & $35 \mathrm{or} 50 \mathrm{mg} / 1$ \\
Kanamycin & Duchefa & $\left.500 \mathrm{mg} / \mathrm{ml} \mathrm{(in} \mathrm{H}_{2} \mathrm{O}\right)$ & $50 \mathrm{mg} / 1$ \\
Rifampicin & Duchefa & $100 \mathrm{mg} / \mathrm{ml} \mathrm{(in} \mathrm{DMSO})$ & \\
\hline
\end{tabular}

Table 2.4. Stock solutions of phytormones and reagents used in callus induction (CIM) and regeneration medium (DKW)

\begin{tabular}{llll}
\hline Chemical & Chem. Co. & Stock solution & Final conc. \\
\hline $\mathrm{AgNO}_{3}$ & Riedel & $5 \mathrm{mg} / \mathrm{ml}\left(\right.$ in $\left.\mathrm{H}_{2} \mathrm{O}\right)$ & $5 \mathrm{mg} / \mathrm{l}$ \\
Acetosyringone & Roth & $10 \mathrm{mM}($ in DMSO; $19.6 \mathrm{mg}$ in $10 \mathrm{ml})$ & $100 \mu \mathrm{M} / 1$ \\
$\mathrm{BAP}$ & Duchefa & $2 \mathrm{mg} / \mathrm{ml}\left(\right.$ solvent, $1 \mathrm{M} \mathrm{NaOH}$, diluent $\left.\mathrm{H}_{2} \mathrm{O}\right)$ & $2 \mathrm{mg} / \mathrm{l}$ \\
$\mathrm{GA}_{3}$ & Sigma & $1 \mathrm{mg} / \mathrm{ml}\left(\right.$ solvent EtOH, diluent $\left.\mathrm{H}_{2} \mathrm{O}\right)$ & $0.1 \mathrm{mg} / 1$ \\
$\mathrm{IBA}$ & Duchefa & $1 \mathrm{mg} / \mathrm{ml}\left(1 \mathrm{M} \mathrm{NaOH}\right.$, diluent $\left.\mathrm{H}_{2} \mathrm{O}\right)$ & $0.1 \mathrm{mg} / 1$ \\
$\mathrm{NAA}$ & Duchefa & $1 \mathrm{mg} / \mathrm{ml}\left(1 \mathrm{M} \mathrm{KOH}\right.$, diluent $\left.\mathrm{H}_{2} \mathrm{O}\right)$ & $0.1 \mathrm{mg} / 1$ \\
Picloram & Duchefa & $1 \mathrm{mg} / \mathrm{ml}\left(\right.$ in $\left.\mathrm{H}_{2} \mathrm{O}\right)$ & $0.01 \mathrm{mg} / 1$ \\
\hline
\end{tabular}


Table 2.5. Composition of culture media

\begin{tabular}{|c|c|c|}
\hline Medium & Application & Composition for $1 \mathrm{~L}$ of medium \\
\hline YEB & Growth of $A$. tumefaciens & $\begin{array}{l}1 \mathrm{~g} / \mathrm{l} \text { Yeast extract, } 5 \mathrm{~g} / 1 \mathrm{Meat} \text { extract, } 5 \mathrm{~g} / \mathrm{l} \\
\text { Peptone (Casein), } 0.5 \mathrm{~g} / 1 \mathrm{MgSO} 4 \cdot 7 \mathrm{H} 2 \mathrm{O}, 5 \\
\mathrm{~g} / 1 \text { Sucrose, } \mathrm{pH} 7.4\end{array}$ \\
\hline $\begin{array}{l}\text { CIM } \\
\text { (standard) }\end{array}$ & $\begin{array}{l}\text { Liquid: Infection, co- } \\
\text { cultivation, washing }\end{array}$ & $\begin{array}{l}5.3 \mathrm{~g} / \mathrm{l} \mathrm{MS} \text { media-mix powder (Duchefa, } \\
\text { Netherlands), } 300 \mathrm{mg} / 1 \text { Myo-Inositol, } 500 \\
\mathrm{mg} / 1 \mathrm{MES}, 2 \mathrm{mg} / 1 \mathrm{BAP}, 0.001 \mathrm{mg} / 1 \text { Picloram, } \\
5 \mathrm{mg} / 1 \mathrm{AgNO} 3,20 \mathrm{~g} / 1 \text { sucrose, } \mathrm{pH} \text { 5.7. Solid } \\
\text { medium: } 5.4 \mathrm{~g} / 1 \text { agarose }\end{array}$ \\
\hline $\begin{array}{l}\text { CIM-L } \\
\text { (for leaf } \\
\text { explants) }\end{array}$ & $\begin{array}{l}\text { Liquid: Pre-culture of leaf } \\
\text { explants, infection, co- } \\
\text { cultivation, washing } \\
\text { Solid: Callus induction } \\
\text { with leaf explants }\end{array}$ & $\begin{array}{l}5.3 \mathrm{~g} / \mathrm{l} \mathrm{MS} \text { media-mix powder (Duchefa, } \\
\text { Netherlands), } 300 \mathrm{mg} / 1 \text { Myo-Inositol, } 500 \\
\mathrm{mg} / 1 \mathrm{MES}, 2 \mathrm{mg} / 1 \mathrm{BAP}, 0.1 \mathrm{mg} / 1 \mathrm{NAA}, 0.1 \\
\mathrm{mg} / 1 \mathrm{GA}_{3}, 5 \mathrm{mg} / 1 \mathrm{AgNO} 3,20 \mathrm{~g} / 1 \text { sucrose, } \mathrm{pH} \\
\text { 5.7 Solid medium: } 5.4 \mathrm{~g} / 1 \text { agarose }\end{array}$ \\
\hline $\begin{array}{l}\text { CIM-P } \\
\text { (for petiole } \\
\text { explants) }\end{array}$ & $\begin{array}{l}\text { Liquid: Pre-culture of } \\
\text { petiole explants, infection, } \\
\text { co-cultivation, washing } \\
\text { Solid: Callus induction } \\
\text { with petiole explants }\end{array}$ & $\begin{array}{l}5.3 \mathrm{~g} / \mathrm{l} \mathrm{MS} \text { media-mix powder (Duchefa, } \\
\text { Netherlands), } 300 \mathrm{mg} / 1 \text { Myo-Inositol, } 500 \\
\mathrm{mg} / \mathrm{MES}, 2 \mathrm{mg} / 1 \mathrm{BAP}, 0.01 \mathrm{mg} / 1 \text { Picloram, } \\
5 \mathrm{mg} / 1 \mathrm{AgNO} 3,20 \mathrm{~g} / 1 \text { sucrose, } \mathrm{pH} 5.7 \text { Solid } \\
\text { medium: } 5.4 \mathrm{~g} / 1 \text { agarose }\end{array}$ \\
\hline $\begin{array}{l}\text { DKW } \\
\text { (standard) }\end{array}$ & $\begin{array}{l}\text { Shoot regeneration } \\
\text { (organogenesis) }\end{array}$ & $\begin{array}{l}5.3 \mathrm{~g} / 1 \mathrm{DKW} \text { medium-mix powder (Duchefa, } \\
\text { Netherlands), } 20 \mathrm{~g} / 1 \text { Sucrose, } 1 \mathrm{mg} / 1 \mathrm{BAP} \text {, } \\
0.01 \mathrm{mg} / 1 \mathrm{IBA}, 0.01 \mathrm{mg} / 1 \mathrm{GA} 3,5 \mathrm{mg} / 1 \\
\text { AgNO3, } 5.4 \mathrm{~g} / 1 \text { agarose, } \mathrm{pH} 5.7\end{array}$ \\
\hline $\begin{array}{l}\text { DKW } \\
\text { (modified) }\end{array}$ & $\begin{array}{l}\text { Shoot regeneration } \\
\text { (organogenesis) }\end{array}$ & $\begin{array}{l}5.3 \mathrm{~g} / 1 \mathrm{DKW} \text { medium-mix powder (Duchefa, } \\
\text { Netherlands), } 20 \mathrm{~g} / 1 \mathrm{Sucrose}, 1 \mathrm{mg} / 1 \mathrm{BAP} \text {, } \\
0.1 \mathrm{mg} / 1 \mathrm{IBA}, 0.1 \mathrm{mg} / \mathrm{GA} 3,5 \mathrm{mg} / 1 \mathrm{AgNO} \text {, } \\
5.4 \mathrm{~g} / 1 \text { agarose, pH } 5.7\end{array}$ \\
\hline MS (basal) & $\begin{array}{l}\text { Shoot elongation and } \\
\text { rooting }\end{array}$ & $\begin{array}{l}5.3 \mathrm{~g} / \mathrm{l} \mathrm{MS} \text { media-mix powder (Duchefa, } \\
\text { Netherlands), } 20 \mathrm{~g} / 1 \text { sucrose, } 5 \mathrm{~g} / 1 \text { agar, } \mathrm{pH} \\
5.8\end{array}$ \\
\hline
\end{tabular}


2.2.5 Optimization of callus production and shoot regeneration from leaf and petiole explants

In early experiments, transformation and plant regeneration conditions were carried out according to a standard protocol for hypocotyl segments developed by de Block et al. (1989) and modified by Hüsken et al. (2005). Almost no transformed callus production was obtained with leaf explants using this protocol while poor callus production was achieved with petiole explants. Therefore experiments to optimize callus regeneration were carried out with varying hormone combinations and concentrations.

Picloram concentration of callus induction medium (CIM, see Table 2.5 for composition) in the standard protocol was increased five, ten and twenty times, while keeping the other components of the medium unchanged. Leaves and petioles were obtained from 3-4 weeks old in vitro grown plants and were cut into squares of $0.5 \mathrm{~cm}^{2}$ (leaves) and segments of 0.5 $0.7 \mathrm{~mm}$ in length (petioles) using a sharp scalpel. Twenty explants of leaf /or petiole were cultured in a single petri dish (which was considered as a replicate) and every treatment was replicated four times within a single experiment. Culture plates were sealed with micropore tapes and incubated in a growth chamber under constant light at $22{ }^{\circ} \mathrm{C}$. Callus production was determined by assigning a score (from 1 to 5) to each petri dish, after four weeks from culture initiation. Yet, no reasonable increase in callus production was obtained with leaf explants when cultured on CIM medium with increased picloram concentration. Therefore, three different hormone combinations were tried with leaf explants. Experimental design and determination of callus production after four weeks, was as described in the above experiment. Shoot regeneration from green callus was achieved in DKW medium in the standard protocol; however the obtained shoot regeneration frequencies were low. Therefore concentration of phytohormones IBA and $\mathrm{GA}_{3}$ was increased by five, ten, and twenty times than the concentrations used in the standard protocol. Shoot regeneration efficiency was determined for each treatment combination, after six weeks of culture in the regeneration medium.

\subsubsection{Infection and cocultivation of leaf and petiole explants}

A single Agrobacterium colony formed on freshly streaked selective agar plate (with selective antibiotics) was inoculated into $4 \mathrm{ml}$ of YEB (Yeast Extract Broth) medium (Grimley et al. 1986) with $300 \mathrm{mg} / 1$ streptomycin, $100 \mathrm{mg} / 1$ spectinomycin and $100 \mu \mathrm{M}$ 
acetosyringone, and grown overnight at $27^{\circ} \mathrm{C}$ on a shaker rotating at $200 \mathrm{rpm}$ in the dark. An aliquot of $100 \mu \mathrm{l}$ from this solution was used to inoculate $40 \mathrm{ml}$ of YEB medium supplemented with $300 \mathrm{mg} / \mathrm{l}$ of streptomycin, $100 \mathrm{mg} / \mathrm{l}$ spectinomycin and $100 \mu \mathrm{M}$ acetosyringone, in a $100 \mathrm{ml}$ Erlenmeyer flask and cultured as above over night. Bacterial solution was then centrifuged in $50 \mathrm{ml}$ sterile plastic centrifuge tubes (Corning) at 6000 rpm for $10 \mathrm{~min}$ and the pellet was re-suspended in $3 \mathrm{ml}$ of liquid CIM. Before cocultivation, $\mathrm{OD}_{600}$ was measured and adjusted to a final optical density of 0.8-1.0 with approximately $1 \times 10^{9}$ bacterial cells/ $\mathrm{ml}$ in liquid CIM supplemented with $100 \mu \mathrm{M}$ acetosyringone. This preparation was used for the inoculation of explants. Excised leaf and petiole segment (squares of $0.5 \mathrm{~cm}^{2}$ and segments of $5-10 \mathrm{~mm}$ ) were inoculated separately with Agrobacterium suspension in a sterile Petri dish, for $40 \mathrm{~min}$ at room temperature with gentle shaking. The segments were subsequently blotted and were co-cultivated on sterile filter papers placed over liquid CIM medium, in a sterile plastic petri dish $(9 \mathrm{~cm})$. The number of segments cultured in a single petri dish was 25 . Petri dishes were sealed with micropore tape $(3 \mathrm{M})$ and incubated for 2 days in a growth chamber under constant light at $22{ }^{\circ} \mathrm{C}$.

\subsubsection{Selection of transformed calli and plants}

After two days coculture with Agrobacterium and prior to transfer to the selection medium, leaf and petiole segments were washed three times with liquid CIM medium and the final washing was with liquid CIM medium containing $500 \mathrm{mg} / 1$ carbenicillin for $30 \mathrm{~min}$. Segments were briefly dried on sterile filter papers and transferred individually to solid CIM-L/ or CIM-P medium supplemented with $500 \mathrm{mg} / 1$ carbenicillin and $35 \mathrm{mg} / \mathrm{l}$ or 50 $\mathrm{mg} / \mathrm{l}$ kanamycin. Culture plates were sealed with micropore tape and incubated in a growth chamber at $22^{\circ} \mathrm{C}$ under continuous light. After 4 weeks on the selection medium, regenerated green calli formed on the explants were separated and transferred individually onto agarose solidified DKW (modified) medium (see Table 2.5 for the composition) supplemented with $500 \mathrm{mg} / \mathrm{l}$ carbenicillin, $35 \mathrm{mg} / 1$ or $50 \mathrm{mg} / \mathrm{l} \mathrm{kanamycin}$ and incubated in a growth chamber at $22^{\circ} \mathrm{C}$ under continuous light. After 6 additional weeks, elongated green shoots (putative transformants) longer than $1 \mathrm{~cm}$ were separated from calli and transferred to Magenta boxes containing solid MS medium supplemented with $500 \mathrm{mg} / \mathrm{l}$ carbenicillin and 35/or $50 \mathrm{mg} / \mathrm{l} \mathrm{kanamycin}$. Three to four shoots were cultured per jar and incubated in a growth chamber at $22^{\circ} \mathrm{C}$ under continuous light to allow shoot elongation and rooting. Culture plates were scored after 4 weeks from coculture to determine the 
percentage of explants with green calli regeneration. Green calli and shoots were further screened for the activity of GUS gene using histochemical GUS assay (see below).

\subsubsection{Infiltration of leaf and petiole explants}

As one pre-treatment, vacuum infiltration of leaf/petiole explants was performed. Excised leaf and petiole explants were collected separately in a $50 \mathrm{ml}$ centrifuge tubes (Corning) containing liquid CIM-medium with Agrobacterium. Tubes were placed in a vacuum chamber and the vacuum was held for 1-2 min with a pressure ranging from 25 to $27 \mathrm{~mm}$ Hg. Next, the vacuum was slowly released and the tubes were placed on a slow rotating shaker at $80 \mathrm{rpm}$ for $40 \mathrm{~min}$. The subsequent tissue culture procedure was the same as for those non infiltrated explants.

\subsubsection{Preculture of leaf and petiole explants}

It was observed that during two days co-cultivation period, a considerable percentage of leaf explants (approximately 25-30 \%) displayed tissue browning and sign of wilting and necrosis, due to stress exerted by Agrobacterium. Therefore, intact leaves and petioles were subjected to two days preculture period on $8.5 \mathrm{~cm}$ sterile filter papers (MN 440, MachereyNagel), soaked with liquid CIM-L/or CIM-P medium (see Table 2.5 for media composition) supplemented with $100 \mu \mathrm{M}$ acetosyringone as a means of hardening the fragile tissue explants, prior to sectioning and subsequent inoculation with Agrobacterium. In control experiments, explants were inoculated directly with Agrobacterium without a pre-culture period on $8.5 \mathrm{~cm}$ sterile filter papers, soaked with liquid CIM-L/or CIM-P medium. In a similar experiment, whole leaves and petioles were subjected to a two days preculture period on agarose solidified CIM-L/or CIM-P medium before sectioning and cocultivation with Agrobacterium to determine the effects of liquid and solid medium on preculture of tissue explants.

\subsubsection{Histochemical GUS assay}

Histochemical GUS assay was carried out as described by Jefferson (1987). Tissue samples taken from putative transformed calli and plantlets were dipped in GUS assay solution containing $50 \mathrm{mM}$ sodium phosphate buffer (pH 7.0), $10 \mathrm{mM}$ EDTA, 0.1\% Triton-X-100, $0.1 \%$ sarcosyl, $10 \mathrm{mM}$ 2-mercapto-ethanol and 1mM X-gluc (5-bromo-4-chloro-3-indolyl- 
$\beta$-D-glucuronide cyclohexylammonium salt) substrate (X-gluc dissolved in dimethyl sulfoxide) and incubated at $37{ }^{\circ} \mathrm{C}$ overnight. Chlorophyll in tissue samples was de-stained by rinsing them with $70 \%$ ethanol.

\subsubsection{PCR analysis}

Total DNA was extracted from young leaves of kanamycin resistant plantlets using DNeasy Plant Mini Kit (Qiagen) according to the manufacturer's instruction manual. A sample of 25 ng template DNA was amplified with a thermal cycler-480 (Perkin Elmer, Norwalk, USA) (see below for the composition of PCR mixture and the program used for the PCR reaction) using specific primer combinations for NPTII and GUS genes (primer combinations used were as listed in Table 2.6). Amplified products were separated in a $1.5 \%(\mathrm{w} / \mathrm{v})$ agarose gel in $1 \mathrm{x}$ TAE buffer at $120 \mathrm{~V}$ for two hours, stained with ethidium bromide, visualized under an ultra violet illuminator and recorded with a gel documenter.

Table 2.6. Primers and expected amplification length

\begin{tabular}{lll}
\hline Primer Sequence & Fragment length
\end{tabular}

GUS-fw. $\quad 5^{`}$-CCCTTATGTTACGTCCTGTAGAAACCC -3` 1000 bp

GUS-rev. 5'- CCAATCCAGTCCATTTAATGCGTGGTCG -3`

NPT-II-fw. 5’-ATCGGGAGCGGCGATACCGTA-3` 700 bp

NPT-II-rev. 5'-GAGGCT ATT CGG CTATGACTG-3`

fw. Forward primer, rev. Reverse primer 


\section{PCR reaction mixture}

Component

Template-DNA

10x PCR-Puffer

$\mathrm{MgCl} 2$

Forward-Primer

Reverse-Primer

dNTPs

Taq-Polymerase

$\mathrm{H}_{2} \mathrm{O}$ (HPL)

Total volume
Volume

$1 \mu 1$

$2.5 \mu 1$

$1.5 \mu 1$

$1.0 \mu 1$

$1.0 \mu 1$

$0.5 \mu 1$

$0.5 \mu 1$

Adjusted

$25 \mu 1$

\section{Concentration}

$(25 \mathrm{ng} / \mu \mathrm{l})$

$25 \mathrm{mM}$

$10 \mu \mathrm{M}$

$10 \mu \mathrm{M}$

$1.25 \mathrm{mM}$

$1.25 \mathrm{U} / \mu \mathrm{l}$

\section{The program for the PCR reaction}

1x Denaturing

35x Denaturing

Primer annealing temperature

$$
\begin{aligned}
& \text { for NPTII primers } \\
& \text { for GUS primers }
\end{aligned}
$$

Extension

$$
\begin{aligned}
& 3 \text { min at } 95^{\circ} \mathrm{C} \\
& 1 \text { min at } 95^{\circ} \mathrm{C}
\end{aligned}
$$

$$
\begin{aligned}
& 1 \mathrm{~min} \text { at } 54^{\circ} \mathrm{C} \\
& 1 \mathrm{~min} \text { at } 60^{\circ} \mathrm{C}
\end{aligned}
$$$$
2 \min \text { at } 72{ }^{\circ} \mathrm{C}
$$

\subsubsection{Production of double haploid transgenic plants}

To produce double haploid plants, top shoot and stem segments with an auxiliary shoot bud, obtained from haploid transformed plants were treated in vitro with colchicine. Top shoots (with primordial leaves only) and stem segments ( 1 $\mathrm{cm}$ in length) were dipped in MS liquid medium supplemented with $500 \mathrm{mg} / \mathrm{l}(1252 \mu \mathrm{M})$ colchicines in a $100 \mathrm{ml}$ sterile flask and cultured for $24 \mathrm{hrs}$ on a shaker revolving at $200 \mathrm{rpm}$. After treatment time, segments were washed three times thoroughly with liquid MS medium, briefly dried on a sterile filter paper and cultured on agar solidified MS medium for further growth and rooting. Well grown plantlets with active root growth were transferred into soil (top earth 3 : 1 compost) in $6 \mathrm{~cm} \times 6 \mathrm{~cm}$ black plastic pots and placed in a controlled climate chamber for 4-5 days at $17{ }^{\circ} \mathrm{C}$ with a photoperiod of $16 / 8$ day/night. After that, plants were transferred into the green house and kept under humid conditions for another week. Finally the plants were planted in 11 (length) $\mathrm{cm}$ x 9 (width) $\mathrm{cm}$ black plastic pots with same soil mixture and grown to maturity. 


\subsubsection{Experimental design and statistical analysis}

Experiments were repeated four times, unless otherwise stated. Each experiment consisted of at least four petri dishes with each 25 leaf/or petiole explants per explant type, treatment and application. Analysis of variance was based on means of those petri dishes and was performed by the PLABSTAT software (Utz 2001) using the following model:

$$
\mathrm{Y}_{i j k l}=\mu+e_{i}+t_{j}+s_{k}+r_{l}+e t_{i j}+e s_{i k}+t s_{j k}+e r_{i l}+t r_{j l}+s r_{k l}+e t s_{i j k}+\varepsilon_{i j k l}
$$

where: $Y_{i j k l}$ was observation of explant $i$ at treatment $j$ at application $\mathrm{k}$ in experiment $l ; \mu$ was the general mean; $e_{i}, t_{j}, s_{k}$ and $r_{l}$ were the effects of explant $i$, treatment $j$, application $k$ and experiment $l$, respectively, along with their respective interactions. $\varepsilon_{i j k l}$ was the residual error. The explant type, treatments, and applications were considered as fixed variables. Some experiments had only a treatment and no application. For those experiments the above mentioned model was adapted accordingly. For multiple mean comparisons Duncan's multiple range test at $\mathrm{P}=0.05$ was applied using the Stat-Graphics Plus for Windows 3.0 (Statistical Graphics Corp. 1997).

\subsection{Results}

\subsubsection{Experiments to optimize callus production and shoot regeneration from leaf and petiole explants}

Early experiments conducted with the transformation protocol described by Hüsken et al. (2005) for diploid hypocotyls segments, resulted in poor callus production with petiole explants, but failed to produce any calli with leaf explants (data not shown). Therefore experiments to optimize callus induction and regeneration were carried out with varying hormone combinations and concentrations. Increase in picloram concentration by ten times than the concentration used in the standard protocol (while keeping the other components unchanged), has resulted in optimal callus production with petiole explants (Fig. 2.1). Based on these results, a modified callus induction medium for petiole explants was defined, termed as CIM-P (see Table 2.5 for medium composition) and was used in all subsequent experiments conducted with petiole explants. 


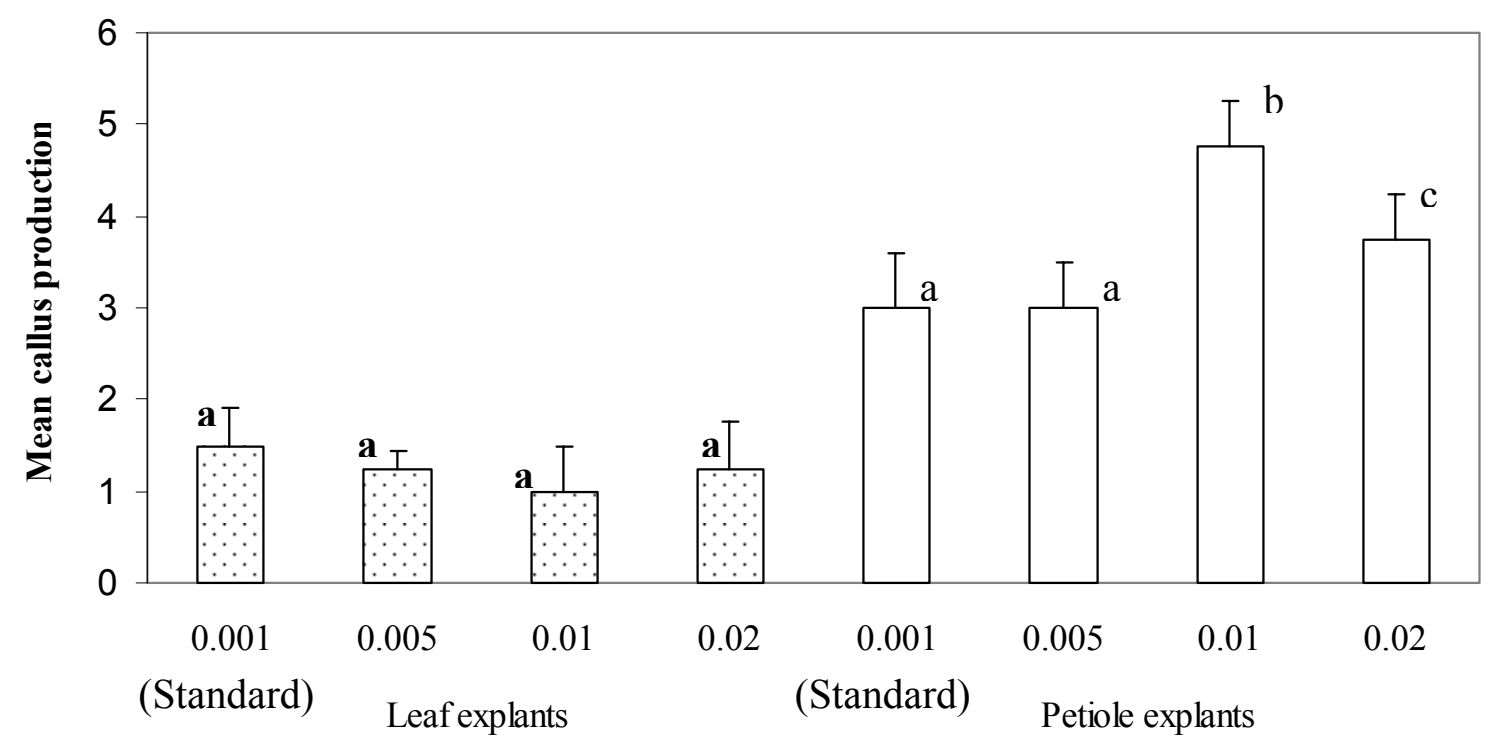

Picloram concentration (mg/l)

$1=$ No callus production, $2=$ Very poor callus production, $3=$ Poor callus production, 4=Good callus production, $5=$ Very good callus production

Fig 2.1. Effect of picloram concentration on callus production with leaf and petiole explants of haploid B. napus. Columns denoted by the same letter are not significantly different at $\mathrm{P}=0.05$ according to Duncan's multiple range test. Results represent means from one experiment with four replications (Petri dishes) with each a sample size of 20 explants. Multiple comparisons of leaf (bold letters) and petiole explants are independent of each other. Vertical bars represent the standard error.

Yet, no or very poor callus production was achieved with leaf explants at all the concentrations of picloram tested (Fig. 2.1). Callus production with leaf explants was significantly increased when BAP concentration was reduced from $2 \mathrm{mg} / \mathrm{l}$ to $1 \mathrm{mg} / \mathrm{l}$ and picloram was replaced by $0.1 \mathrm{mg} / 1 \mathrm{NAA}$ and $\mathrm{GA}_{3}$ (Fig 2.2). This hormone combination was chosen for subsequent experiments with leaf explants and termed CIM-L (see Table 2.5 for medium composition). Leaf explants with a part of the mid rib had a positive effect on callus production (Fig 2.2). 


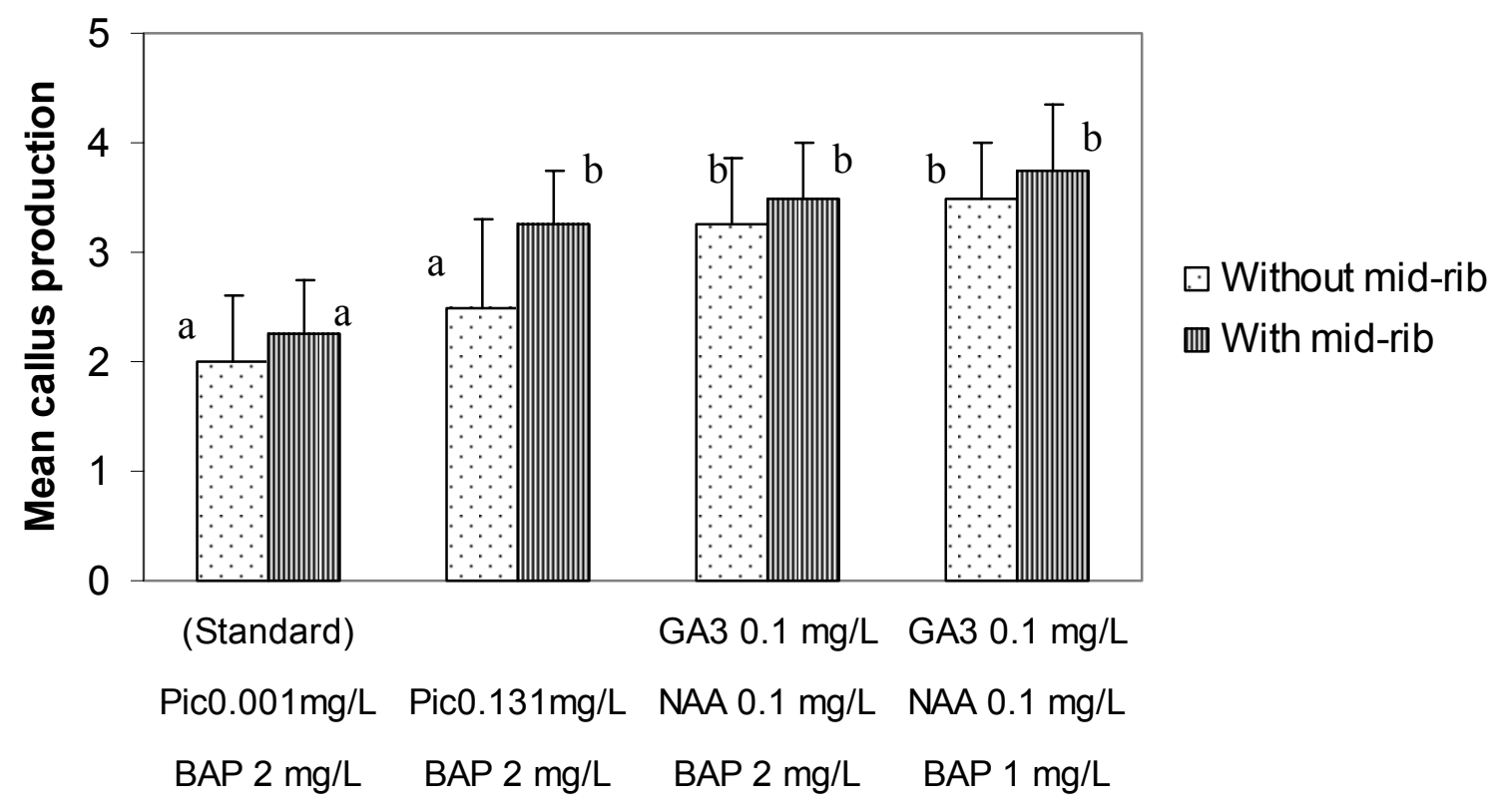

Hormone combinations

$1=$ No callus production, $2=$ Very poor callus production, $3=$ Poor callus production, 4=Good callus production, $5=$ Very good callus production

Fig 2.2. Effect of different combinations of phytohormones on callus production with leaf explants. Columns denoted by the same letter are not significantly different at $\mathrm{P}=0.05$ according to Duncan's multiple range test. Results represent means from one experiment with four replications (Petri dishes) with each a sample size of 20 explants. Vertical bars represent the standard error

Shoot regeneration medium (DKW) of the standard protocol resulted in poor shoot regeneration from green calli of leaf and petiole explants. To increase shoot regeneration frequency from green calli, concentrations of IBA and $\mathrm{GA}_{3}$ were increased by five, ten and twenty times than the concentrations used in the standard protocol, while keeping the other components unchanged. Increased phytohormone concentration and origin of callus had a significant effect on shoot regeneration. Calli derived from leaf explants produced a significantly higher number of shoots per callus cultured than those calli with petiole origin (Table 2.7 and Fig. 2.3). Ten times increase in both IBA and $\mathrm{GA}_{3}$ resulted in significantly higher shoot regeneration from green calli obtained from both leaf and petiole explants (Fig. 2.3). Based on these results, a modified shoot regeneration medium was defined and termed as DKW (modified) and used for all subsequent experiments (see Table 2.5 for medium composition). 
Table 2.7. Analysis of variance results for the effect of a phytohormone treatment on shoot regeneration from 8-10 weeks old callus cultures derived from leaf and petiole explants of haploid B. napus. (No. of shoots regenerated per cultured callus)

\begin{tabular}{llllll}
\hline Source & DF & MS & Var. cp & F & LSD5 \\
\hline Explant type & 1 & 1.210 & 0.0366 & $30.66^{* *}$ & 0.10 \\
Hormone concentration & 3 & 1.574 & 0.0959 & $39.89^{* *}$ & 0.15 \\
Experiment & 7 & 0.210 & 0.0214 & $5.34^{* *}$ & 0.30 \\
Explant type x Hormone con. & 3 & 0.023 & -0.002 & 0.6 & 0.21 \\
Residual error & 21 & 0.039 & 0.039 & & \\
\hline
\end{tabular}

${ }^{* *}$ significant at $\mathrm{p}=0.01,{ }^{*}$ significant at $\mathrm{p}=0.05$

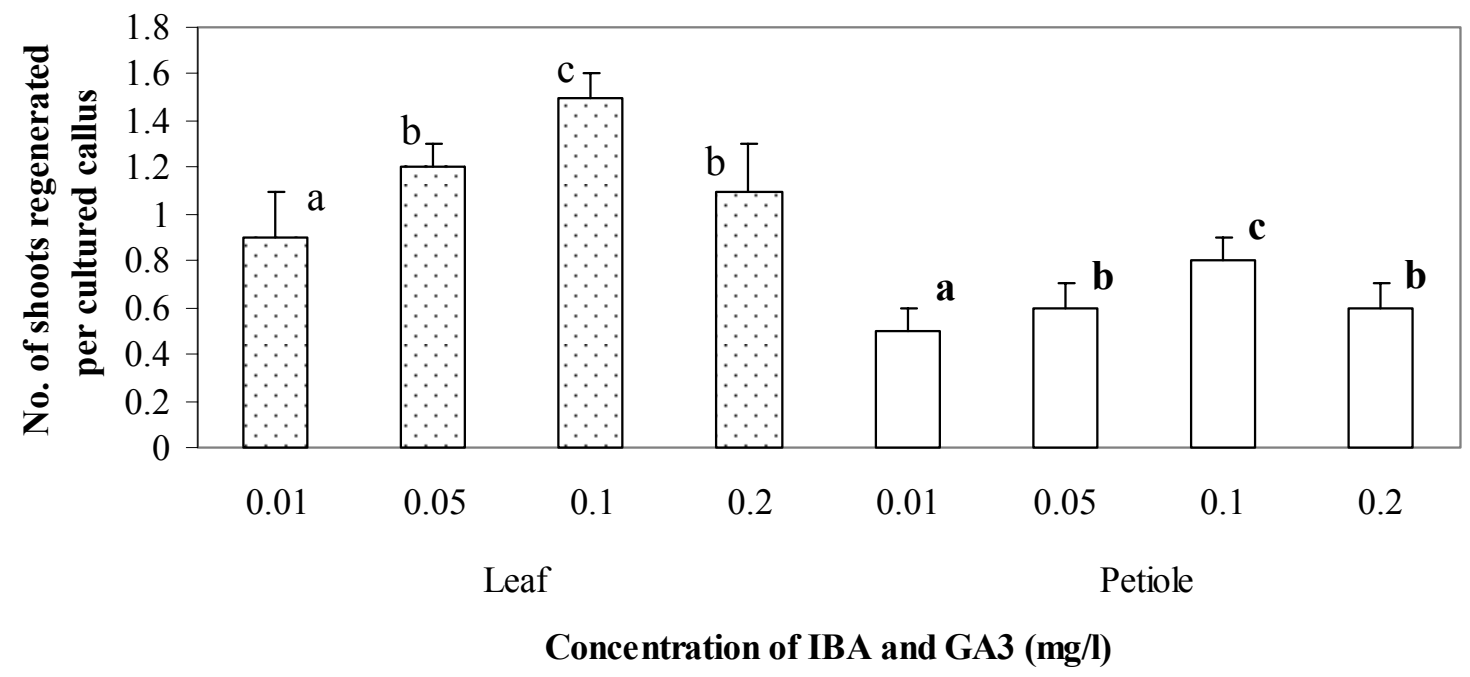

Fig 2.3. Effect of phytohormones on shoot regeneration in 8-10 weeks old callus cultures derived from leaf and petiole explants of haploid B. napus. Columns denoted by the same letter are not significantly different at $\mathrm{P}=0.05$ according to Duncan's multiple range test. Multiple comparisons of leaf and petiole (bold letters) are independent of each other. Vertical bars represent the standard error. 
Upon culture in DKW (modified) medium, 53.3\% of calli derived from leaf explants produced shoots after six weeks of culture while $40.9 \%$ of calli derived from petiole explants produced shoots after the same time period in culture (Table 2.8). When transferred into the solid MS medium, $92.7 \%$ of shoots of leaf origin and $90.5 \%$ of shoots of petiole origin rooted and became plantlets. $96 \%$ of plantlets of leaf origin and $92 \%$ of plantlets of petiole origin were found to be haploid after analysis of ploidy of 25 randomly selected plantlets (Table 2.8).

Table 2.8. Shoot regeneration from calli derived from leaf and petiole explants on DKW (modified) medium with $0.1 \mathrm{mg} / 1 \mathrm{IBA}$ and $0.1 \mathrm{mg} / 1 \mathrm{GA} 3$ hormone combination

\begin{tabular}{|l|c|c|c|c|c|c|}
\hline $\begin{array}{l}\text { Callus } \\
\text { origin }\end{array}$ & $\begin{array}{c}\text { No. of } \\
\text { calli } \\
\text { cultured }\end{array}$ & $\begin{array}{c}\text { Shoot } \\
\text { initiating } \\
\text { calli }\end{array}$ & $\begin{array}{c}\text { Regeneration } \\
\text { efficiency } \\
(\%)\end{array}$ & $\begin{array}{c}\text { No. of } \\
\text { shoots } \\
\text { regenerated }\end{array}$ & $\begin{array}{c}\text { Number of } \\
\text { plantlets } \\
\text { obtained }\end{array}$ & $\begin{array}{c}\% \text { of } \\
\text { haploid } \\
\text { plantlets }\end{array}$ \\
\hline Leaf & 45 & 24 & 53.3 & 67 & 55 & 96.0 \\
\hline Petiole & 88 & 36 & 40.9 & 72 & 53 & 92.0 \\
\hline
\end{tabular}

\subsubsection{Optimization of transformation efficiency}

\section{Vacuum infiltration of explants}

Histochemical GUS assay was performed after one week from infitration with 50 randomly selected leaf and petiole explants (infiltated and noninfiltated). Vacuum infiltration of leaf and petiole explants (prior to two days cocultivation) with a Agrobacterium tumefaciens cell suspension (strain AGL0 pAK-UGI 9-1) has resulted in an increased number of explants with blue transformed areas $\left(\mathrm{GUS}^{+}\right.$explants) as well as the number of blue transformed spots (or GUS ${ }^{+}$spots) per explant (Table 2.9). Vacuum infiltration of leaf explants resulted in $22 \%$ increase in $\mathrm{GUS}^{+}$explants when compared with the non infiltrated leaf explants while petiole explants showed an increase of $12 \%$ in $\mathrm{GUS}^{+}$explants after vacuum infiltration (Table 2.9). Infiltration has increased the number of $\mathrm{GUS}^{+}$spots in both explant types in general, however leaf explants showed the highest number of $\mathrm{GUS}^{+}$spots. 
The number of GUS ${ }^{+}$spots exceeded over 20 for some infiltrated leaf explants ( see Fig 2.6d at page 27).

However, infiltration with Agrobacterium suspension did not increase the percentage of explants with putatively transformed green callus (Table 2.10 and Fig. 2.4).

Table 2.9. Results of histochemical GUS assay of infiltrated and noninfiltrated leaf and petiole explants

\begin{tabular}{lcccc}
\hline $\begin{array}{l}\text { Explant } \\
\text { type }\end{array}$ & $\begin{array}{l}\text { No. of explants } \\
\text { examined }\end{array}$ & Infiltration & $\begin{array}{l}\text { Percentage of } \\
\text { GUS }^{+} \text {explants }\end{array}$ & $\begin{array}{c}\text { Mean number of GUS } \\
\text { spots per explant }\end{array}$ \\
\hline Leaf & 50 & with & 54 & $13.8 \mathrm{a}$ \\
& 50 & without & 32 & $7.0 \mathrm{~b}$ \\
Petiole & 50 & with & 34 & $7.2 \mathrm{~b}$ \\
& 50 & without & 22 & $5.7 \mathrm{c}$ \\
\hline
\end{tabular}

\footnotetext{
${ }^{\S}$ Histochemical GUS assay was performed one week after infiltration with Agrobacterium. Means with the same letters are not significantly different at $\mathrm{P}=0.05$ according to Duncan's multiple range test.
}

Table 2.10. Analysis of variance results for the effect of Agrobacterium infiltration of explants on the percentage green callus production of leaf and petiole explants with and without kanamycin selection, as determined after four weeks of culture in callus induction medium.

\begin{tabular}{llllll}
\hline Source & DF & MS & Var. cp & F & LSD5 \\
\hline Explant type & 1 & 4027.66 & 124.67 & $105.54^{* *}$ & 3.18 \\
Infiltration & 1 & 0.353 & -1.181 & 0.01 & 3.18 \\
Kanamycin & 1 & 33659.00 & 1050.82 & $882.03^{* *}$ & 3.18 \\
Experiment & 7 & 353.74 & 39.44 & $9.23^{*}$ & 6.36 \\
Explant x Infiltration & 1 & 220.69 & 11.40 & $5.78^{*}$ & 9.00 \\
Explant x Kanamycin & 1 & 4676.65 & 289.90 & $122.55^{* *}$ & 4.50 \\
Infiltration x Kanamycin & 1 & 48.38 & 0.638 & 1.27 & 4.50 \\
Residual error & 25 & 38.16 & 38.16 & & \\
\hline$* *$
\end{tabular}

significant at $\mathrm{p}=0.01,{ }^{*}$ significant at $\mathrm{p}=0.05$ 
Interaction effects explant type $\mathrm{x}$ infiltration were small and not significant. In other words, infiltrated and non-infiltrated explants were found to be equally competent in their ability to produce green calli in the presence of kanamycin. The results also show that the pressure exerted on tissue explants ( 25 to $27 \mathrm{~mm} \mathrm{Hg}$ ) during vacuum infiltration was not destructive to the tender tissue explants. Significant effects were also found for the explant type and for the interaction effects Explant type x Kanamycin treatment.

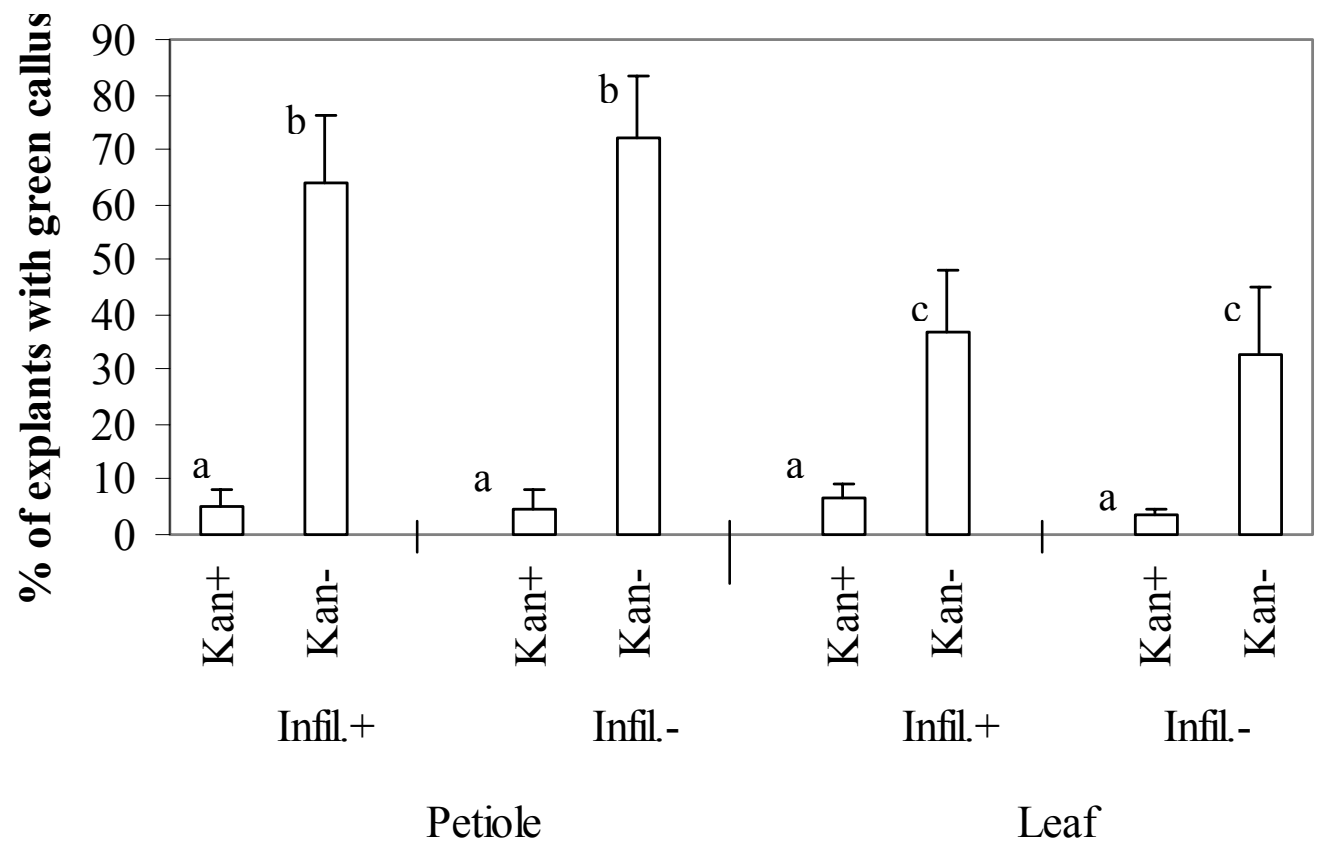

Treatment combinations

Fig 2.4. Effect of infiltration of explants with a bacterial cell suspension (AGL0 pAK-UGI 9-1) on percentage green callus production of leaf and petiole explants with (Kan+) and without (Kan-) $35 \mathrm{mg} / 1$ kanamycin selection, after four weeks of culture in callus induction medium. Columns denoted by the same letter are not significantly different at $\mathrm{P}=0.05$ according to Duncan's multiple range test. Vertical bars represent the standard error

\subsubsection{Effect of filter paper and preculture of explants}

It has been obverved in early transformation experiments (conducted with the standard protocol) that, as many as $30 \%$ of leaf explants died after the cocultivation period of two days, due to tissue browning and development of necrotic areas on cultured explants. Similarly, about $10 \%$ of petiole explants also died during the same culture period due to tissue browning and necrosis (data not shown). Therefore, a two days preculture treatment 
was given to intact leaves and petioles before sectioning into segments and subsequent coculture, as a means of hardening the tender tissue explants against stress exerted by Agrobacterium. Preculture was performed either on filter papers soaked with liquid CIML/or CIM-P, or on solid medium. Explant type, preculture and type of medium (liquid or solid) had significant effect on tissue browning and necrosis as determined after two days from coculture (Table 2.11). Interaction effects Preculture $\mathrm{x}$ Explant type were comparatively large.

Table 2.11. Analysis of variance results for the effect of a two days preculture treatment on tissue browning and necrosis of leaf and petiole explants during cocultivation with Agrobacterium in liquid or solid medium and on percentage of explants with green callus, after four weeks from coculture (50 mg/l kanamycin selection)

\begin{tabular}{|c|c|c|c|c|c|c|}
\hline \multirow[t]{2}{*}{ Source } & \multicolumn{3}{|c|}{$\begin{array}{l}\text { Tissue browning/or necrosis } \\
\text { (after two days from } \\
\text { coculture) }\end{array}$} & \multicolumn{3}{|c|}{$\begin{array}{l}\% \text { of explants with green } \\
\text { callus (after four weeks from } \\
\text { coculture) }\end{array}$} \\
\hline & $\mathrm{DF}$ & Var. cp & $\bar{F}$ & DF & Var. cp & $\mathrm{F}$ \\
\hline Explant type & 1 & 46.47 & $254.66^{* *}$ & 1 & 7.92 & $247.19 * *$ \\
\hline Medium (liquid/solid) & 1 & 6.07 & $28.03 * *$ & 1 & 0.16 & $5.83 *$ \\
\hline Preculture & 1 & 35.05 & $156.95 * *$ & 1 & 0.09 & $3.69+$ \\
\hline Experiments & 3 & 0.20 & 0.40 & 3 & 0.10 & $2.61+$ \\
\hline Preculture x Med. & 1 & 2.65 & $7.21 *$ & 1 & 1.66 & $26.78 * *$ \\
\hline Preculture $\mathrm{x}$ Explant & 1 & 21.17 & $48.09 * *$ & 1 & 1.11 & $18.39 * *$ \\
\hline Explant x Med. & 1 & 11.80 & $27.25+$ & 1 & 1.35 & $21.92 * *$ \\
\hline Residual error & 12 & 3.59 & & 12 & 0.54 & \\
\hline
\end{tabular}

significant at $\mathrm{p}=0.01,{ }^{*}$ significant at $\mathrm{p}=0.05$

Preculture of explants in liquid or in solid medium before coculture with Agrobacterium significantly reduced the tissue necrosis and explant death in both explant types. Preculture on filter papers soaked with liquid medium had the highest significant effect on both explant types to bring down the tissue necrosis when compared with preculture on solid medium (Table 2.12). Preculture on filter papers in liquid medium reduced necrosis of leaf explants by $65 \%$, while the reduction of necrosis of petiole explants was $35 \%$. Even without two days preculture period, leaf explants cocultivated with Agrobacterium on filter 
papers soaked with liquid medium, significantly reduced the necrosis of cultured explants by $33 \%$. However, this beneficial effect by liquid culture medium was not significant for petiole explants (Table 2.12). Preculture had an positive effect on green callus (or putative transformed callus) regeneration from leaf and petiole explants, cultured for four weeks in callus induction medium with $50 \mathrm{mg} / \mathrm{l}$ kanamycin selection. Based on these results, two days preculture and cocultivation of explants with Agrobacterium on filter papers soaked with liquid medium, was adapted for all the subsequent transformation experiments.

Table 2.12. Effect of two days preculture treatment on tissue browning/or tissue death during cocultivation with Agrobacterium, and on green callus regeneration with $50 \mathrm{mg} / 1$ kanamycin selection. Means denoted by the same letter are not significantly different at $\mathrm{P}=0.05$ according to Duncan's multiple range test.

\begin{tabular}{ccccc}
\hline Explant & Preculture & Medium & $\begin{array}{l}\text { Browning or tissue } \\
\text { death after two days } \\
\text { of cocultivation (\%) }\end{array}$ & $\begin{array}{l}\text { Explants with green } \\
\text { callus after four weeks of } \\
\text { culture under } 50 \mathrm{mg} / 1 \\
\text { kanamycin selection (\%) }\end{array}$ \\
\hline L & + & CIM-L (lq.) & $11.0 \mathrm{a}$ & $5.4 \mathrm{a}$ \\
L & + & CIM-L (s) & $15.0 \mathrm{~b}$ & $2.5 \mathrm{~b}$ \\
L & - & CIM-L (lq.) & $21.0 \mathrm{c}$ & $5.0 \mathrm{a}$ \\
L & - & CIM-L (s) & $31.1 \mathrm{~d}$ & $4.2 \mathrm{c}$ \\
P & + & CIM-P (lq.) & $7.2 \mathrm{e}$ & $9.5 \mathrm{~d}$ \\
P & + & CIM-P (s) & $6.7 \mathrm{e}$ & $8.6 \mathrm{e}$ \\
P & - & CIM-P (lq.) & $11.0 \mathrm{a}$ & $5.4 \mathrm{a}$ \\
P & - & CIM-P (s) & $10.4 \mathrm{a}$ & $8.5 \mathrm{e}$
\end{tabular}

Abbreviations: lq: liquid medium, s: solid medium, L: leaf explants, P: petiole explants, $(+)$ with two days preculture period, (-) without preculture

\section{Effect of Agrobacterium strain/plasmid and acetosyringone}

The Agrobacterium strain (ATHV Rif ${ }^{\mathrm{R}}$ pPNGUS and AGL0pAK-UGI 9-1), the explant type and the addition of $100 \mu \mathrm{M}$ of acetosyringone in the culture medium (CIM-L /or CIMP) during the two days preculture and two days of cocultivation with Agrobacterium had a significant effect on the percentage of explants with green callus on both explants types in the presence of $50 \mathrm{mg} / \mathrm{l}$ kanamycin selection (Table 2.13 and Fig. 2.5). Agrobacterium 
strain, acetosyringone, and type of explant had significant individual effects and combine effects on green callus production (Fig. 2.5). Strain AGL0 harbouring plant transformation vector AK-UGI 9-1 resulted in a significantly higher number of kanamycin resistant green calli for both explants types than strain ATHVpPNGUS (Fig. 2.5). Acetosyringone had a significant effect on explant type and Agrobacterium strain. Use of acetosyringone increased the green callus production of petiole explants by $35 \%$ and leaf explants by $36 \%$ (when compared with the corresponding controls without acetosyringone) after coculture with AGL0pAK-UGI 9-1. Explants inoculated with ATHVpPNGUS, the increase in green callus production due to acetosyringone was $12 \%$ for petiole explants and $16 \%$ for leaf explants (Fig 2.5). Type of explant had a distinct outcome on kanamycin resistant green callus production, where petiole explants produced significantly higher number of calli than leaf explants in all the treatment combinations tested. According to the results obtained with this experiment, $100 \mu \mathrm{M}$ of acetosyringone was used in the culture medium during two days preculture and two days cocultivation period and transformation was carried out with Agrobacterium strain AGL0pAK-UGI 9-1 in all subsequent transformation experiments.

Table 2.13. Analysis of variance results for the percentage of leaf/petiole explants with green callus in dependence on the Agrobacterium strain/plasmid and a treatment with acetosyringone

\begin{tabular}{llllll}
\hline Source & DF & MS & Var.cp. & F & LSD5 \\
\hline Agrobacterium strain & 1 & 87.12 & 5.41 & $176.89^{* *}$ & 0.54 \\
Explant type & 1 & 158.42 & 9.87 & $321.67 * *$ & 0.54 \\
Acetosyringone & 1 & 26.64 & 1.63 & $54.10^{* *}$ & 0.54 \\
Experiments & 3 & 4.46 & 0.49 & $9.07 * *$ & 0.76 \\
Agro. Strain x Explant type & 1 & 39.60 & 4.88 & $80.42^{* *}$ & 0.76 \\
Acetosyringone x Explant type & 1 & 12.5 & 1.27 & $25.38^{* *}$ & 0.76 \\
Acetosyringone x Agro. strain & 1 & 4.5 & 0.46 & $9.14^{*}$ & 0.76 \\
Residual error & 12 & 0.49 & 0.49 & & \\
${ }^{* * *}$ significant at $\mathrm{p}=0.01{ }^{*}$ significant at $\mathrm{p}=0.05$ & & & &
\end{tabular}




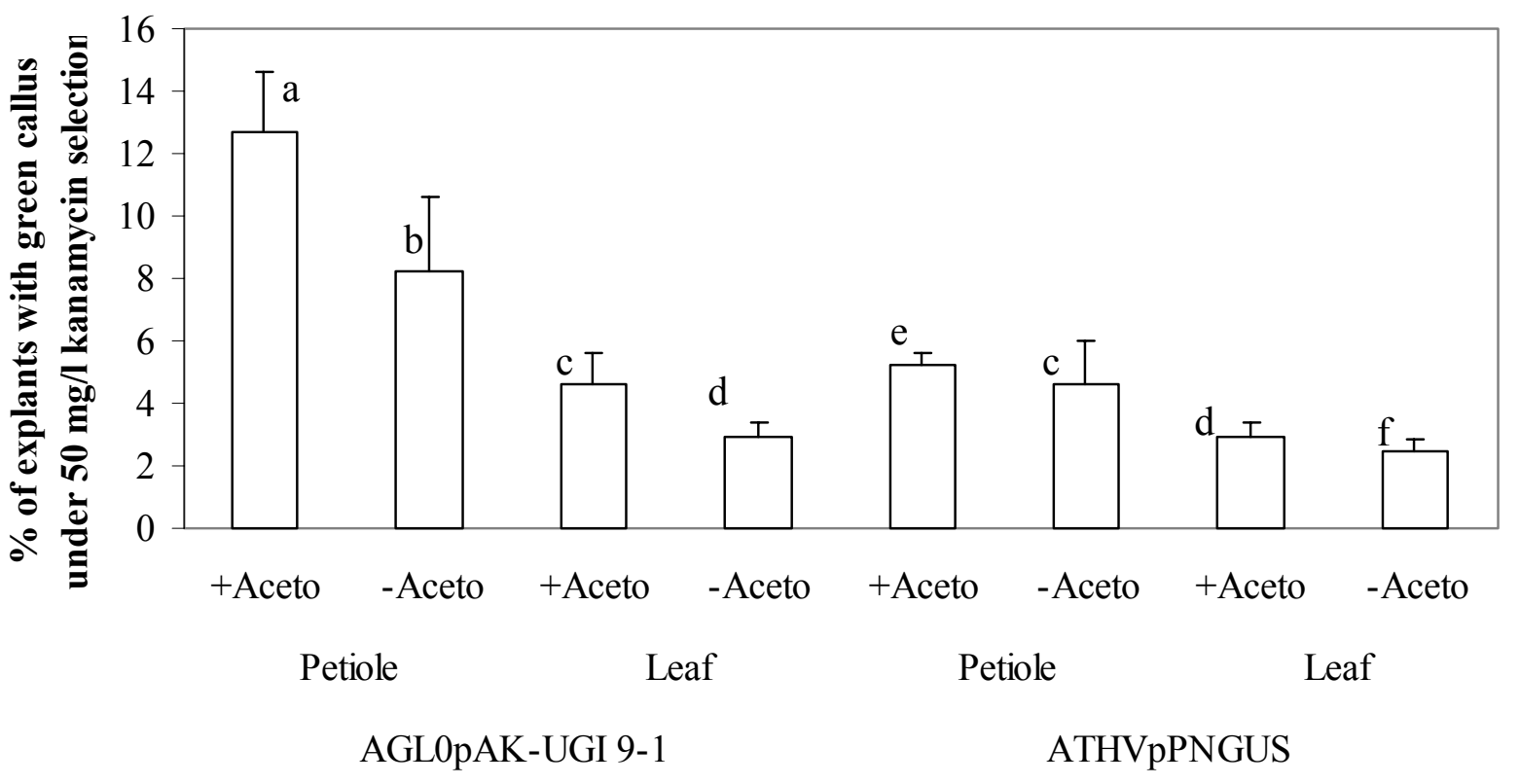

Treatment combinations

Fig 2.5. Effect of Agrobacterium strain/plasmid and use of $100 \mu \mathrm{M}$ of acetosyringone in the culture medium during two days preculture and cocultivation with Agrobacterium. Green callus production of cultured leaf and petiole explants under $50 \mathrm{mg} / \mathrm{l} \mathrm{kanamycin}$ selection was recorded after four weeks from coculture. Columns denoted by the same letter are not significantly different at $\mathrm{P}=0.05$ according to Duncan's multiple range test. Vertical bars represent the standard error.

\section{Transformation of leaf and petiole explants using modified transformation protocol}

Based on the results of above experiments to optimize callus regeneration, organogenesis and transformation efficiency, a modified protocol has been established to obtain transformed plants with haploid leaf and petiole explants using Agrobacterium strain AGL0pAK-UGI 9-1. Green callus was induced in the improved callus induction medium (CIM-L and CIM-P) after four weeks from coculture with Agrobacterium, under $50 \mathrm{mg} / 1$ kanamycin selection. Callus originated mainly from the cut ends or at wounded sites as a result of handling with the forceps. In leaf explants, most of the callus originated from the cut edges of leaf veins. Putative transformed callus sectors were green in colour and healthy, while the non-transformed callus sectors turned whitish or turned necrotic due to the kanamycin toxicity (Fig 2.5a and Fig 2.6a). Out of 625 cocultured leaf explants 31 (5\%) produced calli with green sectors while out of 675 cocultured petiole explants $60(9 \%)$ developed green callus sectors (Table 2.14). 
Table 2.14. Transformation efficiency of haploid leaf and petiole explants of B. napus cv. Drakkar transformed with Agrobacterium strain AGL0pAK-UGI 9-1 with two days preculture.

\begin{tabular}{|c|c|c|c|c|c|}
\hline Explant & $\begin{array}{l}\text { No. } \\
\text { explants }\end{array}$ & $\begin{array}{l}\text { No. of } \\
\operatorname{Kan}^{R} \text { green }\end{array}$ & $\begin{array}{l}\text { No. of } \operatorname{Kan}^{\mathrm{R}} \\
\text { shoots }\end{array}$ & $\begin{array}{l}\text { No. of rooted } \\
\text { shoots in }\end{array}$ & $\begin{array}{l}\text { Transformation } \\
\text { efficiency (TE) }\end{array}$ \\
\hline & cocultured & callus & regenerated & MS+Kan. 50 & $(\%)$ \\
\hline
\end{tabular}

$\begin{array}{llllll}\text { Leaf } & 625 & 31 & 18 & 2 & 1.8\end{array}$

$\begin{array}{llllll}\text { Petiole } & 675 & 60 & 28 & 6 & 2.9\end{array}$

\footnotetext{
Abbreviations, $\mathrm{Kan}^{\mathrm{R}}$ : Kanamycin resistant, MS+Kan. 50: MS medium supplimented with $50 \mathrm{mg} / \mathrm{l} \mathrm{kanamycin.}$

$\mathrm{TE}=$ number of kanamycin resistant shoots $\mathrm{x}$ 100/number of explants cocultured
}

GUS assay conducted with representative explants with green callus showed that, all leaf explants assessed and $90 \%$ of petiole explants assessed were having transformed sectors. This suggest that selection with $50 \mathrm{~g} / \mathrm{l}$ kanamycin was adequate to eliminate possible escapes or non-transformed callus, in early stages of callus proliferation. Green shoot buds (GSBs) became visible as miniature protuberances on green callus sectors after second week of culture in DKW (modified) medium and by the fourth week well developed GSBs could be seen. In additional two weeks time, shoots with 2-3 primodial leaves ranging from 5 to $10 \mathrm{~mm}$ in length were observed (Fig 2.5c and Fig 2.6c). 


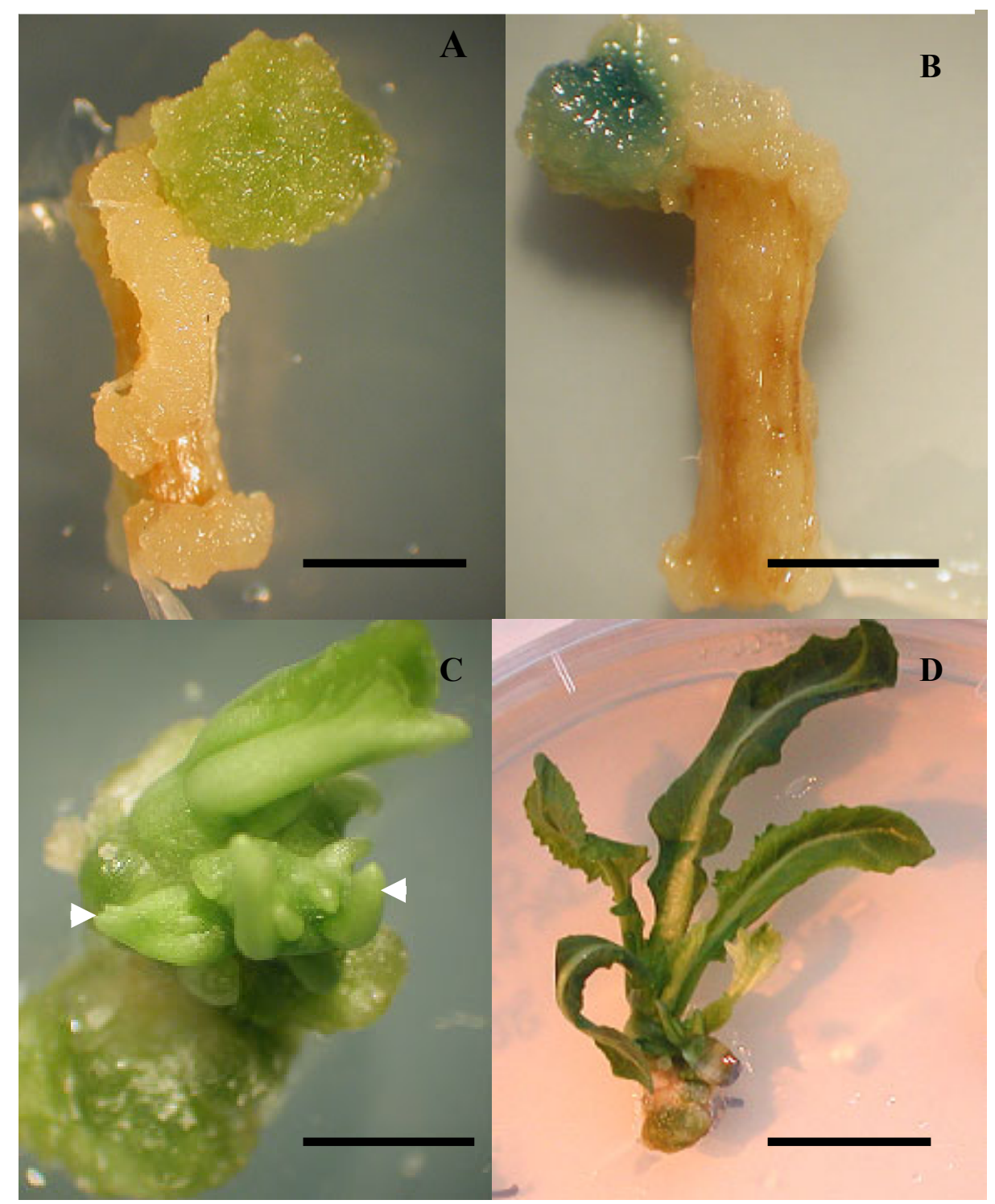

Fig 2.5. Shoot regeneration from kanamycin resistant callus derived from petiole explants inoculated with $A$. tumefaciens strain AGL0 pAK-UGI 9-1.

(A) Green callus regeneration from the cut surface of the petiole, after four weeks of culture in CIM-P medium under $50 \mathrm{mg} / 1$ kanamycin selection. (B) Petiole explant with GUS ${ }^{+}$ callus (blue colour). The light areas on the explant are non-transformed callus tissues. (C) Formation of green shoot buds (arrow heads) and shoots regeneration from green callus cultured in DKW (modified) medium (with $50 \mathrm{mg} / \mathrm{l}$ kanamycin selection) after 6-8 weeks from coculture. (D) A well developed kanamycin resistant shoot, after 10 weeks from inoculation. (Scale bar $=5 \mathrm{~mm})$ 


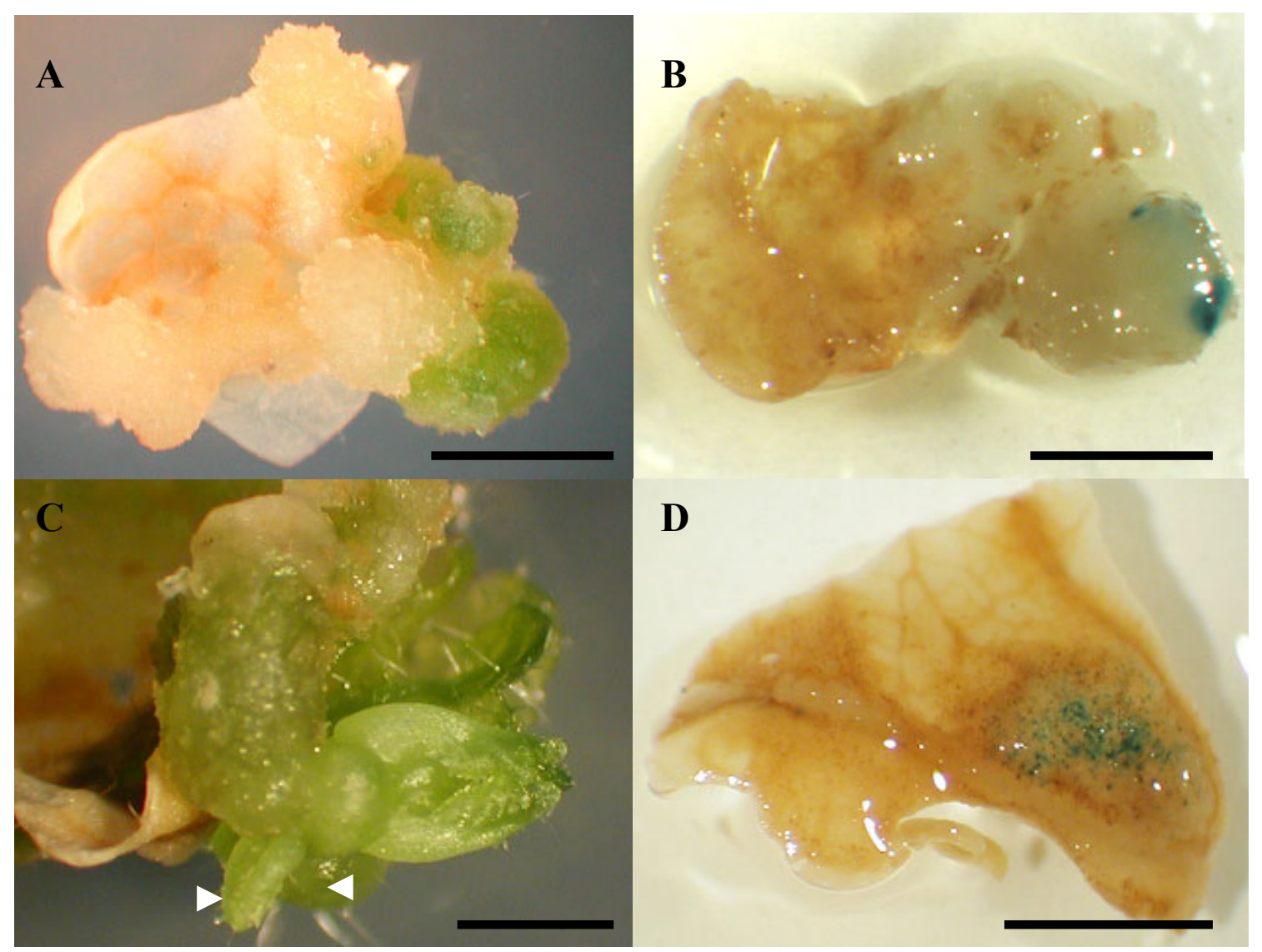

Fig 2.6. Histochemical GUS assay and shoot regeneration from kanamycin resistant callus derived from leaf explants inoculated with A. tumefaciens strain AGL0 pAK-UGI 9-1.

(A) Green callus regeneration from leaf explant, after four weeks of culture in CIM-L medium with $50 \mathrm{mg} / \mathrm{l}$ kanamycin selection. (B) Leaf explant with GUS+ callus (blue colour). The light areas on the explant are non-transformed callus tissues. (C) Formation of green shoot buds (arrow heads) and shoot regeneration from green callus cultured in DKW (modified) medium (with $50 \mathrm{mg} / 1$ kanamycin), after 6-8 weeks from coculture. (D) A leaf explant subjected to GUS assay after one week from vacuum infiltration with $A$. tumefaciens cell suspension. Note the numerous blue transformed spots in the leaf blade. $($ Scale bar $=5 \mathrm{~mm})$

$35 \%$ of green calli of leaf origin (11 out of 31 transferred) produced shoots in DKW (modified) medium while $30 \%$ of calli of petiole origin (18 out of 60 transferred) responded by producing shoots. Conversion of GSBs into well developed shoots was $72 \%$ for the calli of leaf origin and $64 \%$ for the calli of petiole origin. Both types of calli underwent the successive developmental stages of shoot organogenesis either simultaneously or without a noteworthy difference in time. No stuctural or morphological dissimilarity was observed between regenerated shoots of leaf and petiole origin. 
Upon transfer to MS (basal) with $50 \mathrm{mg} / \mathrm{l}$ kanamycin, 11 shoots of leaf origin and 19 shoots of petiole origin showed further growth and remained green. Two shoots of leaf origin and six shoots of petiole origin rooted in MS (basal) with $50 \mathrm{mg} / \mathrm{l} \mathrm{kanamycin}$ and developed into plantlets (Table 2.14).

\section{Ploidy, GUS assay, and PCR analysis of putative transformed plants}

Analysis of ploidy of rooted plants showed that all of them were haploids. Histochemical GUS assay performed with rooted putative transformed plants were all found to be negative. Amplification of template DNA extracted from four rooted plantlets in $50 \mathrm{mg} / \mathrm{l}$ kanamycin containing MS medium and five kanamycin resistant plantlets (they did not produce roots in MS with kanamycin, but in MS without kanamycin) with GUS primers resulted in an expected $1000 \mathrm{bp}$ fragment for all the plantlets tested and for the plasmid pAK-UGI 9-1, which was the positive control. No amplification was obtained with DNA from non transgenic control plant (Fig. 2.7).

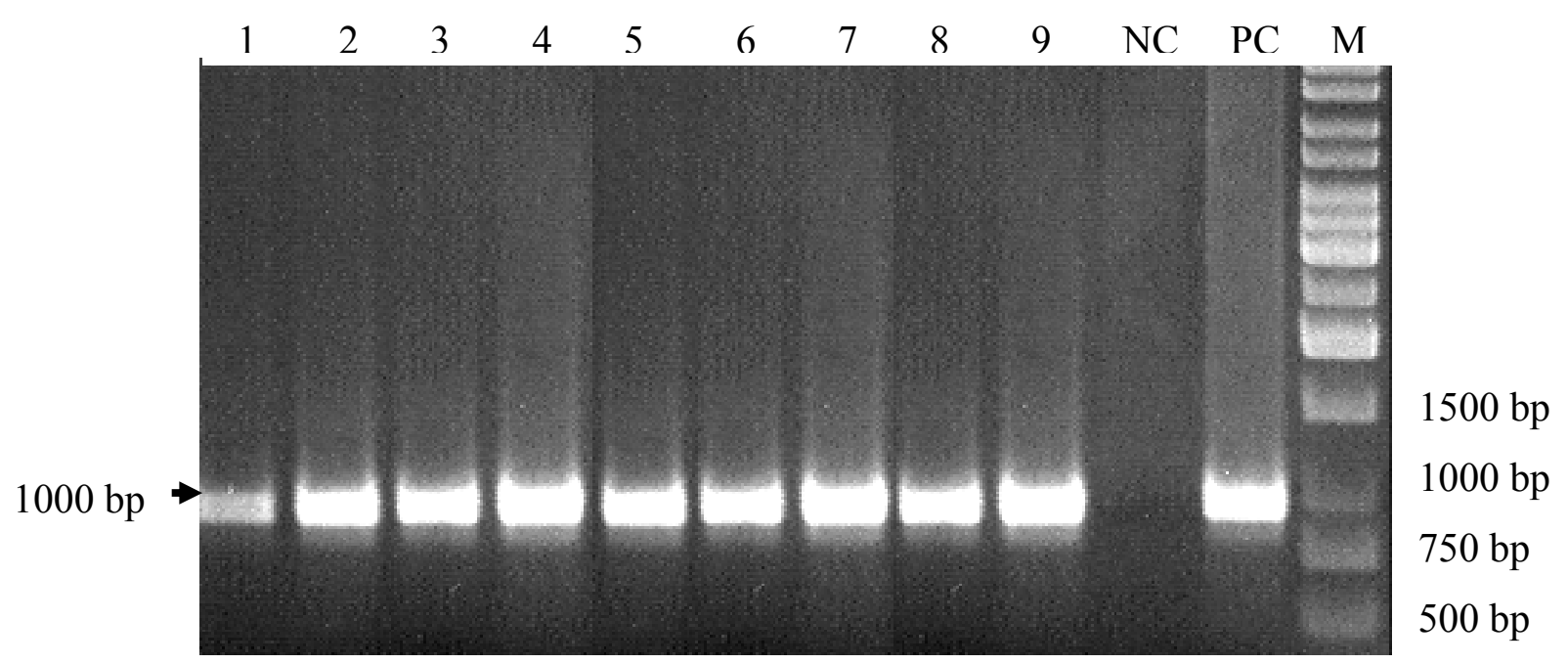

Fig. 2.7. PCR detection of GUS gene in Brassica napus cv. Drakkar transformed with binary vector system of $A$. tumefaciens strain AGL0 pAK-UGI 9-1.

Lanes 1-9: Kanamycin resistance T1 plants (1-4: T1 plants rooted in MS medium with 50 mg/1 Kanamycin, 5-9: Kanamycin resistant T1 plants rooted in MS medium without 50 mg/l kanamycin), NC: non-transformed plant as the negative control, PC: plasmid pAKUGI 9-1 as the positive control, M: DNA size marker. 
Similarly, amplification of total DNA with NPTII primers resulted in an expected band of $700 \mathrm{bp}$ with all the putative transgenic plants and with positive control (plasmid pAK-UGI 9-1) while no amplification product was obtained with non transgenic control plant (data not shown). Culture of leaf samples taken from PCR positive plants in YEB medium confirmed that plants were not contaminated with Agrobacterium.

\subsection{Discussion}

\subsubsection{Optimization of callus production and shoot regeneration}

One of the main prerequisites of a successful plant transformation protocol is the development of an efficient regeneration system from those specific tissues that can be infected by Agrobacterium. Tissue culture requirements to achieve better plant regeneration from a given tissue explant could vary among cultivars or even genotypes (Kazan et al. 1997). Therefore, it would be difficult to adapt a previously described transformation protocol to another system as it is, without modifications and improvements. Efficient plant regeneration from leaves of B. napus has been reported (Dunwell 1981, Akasaka-Kennedy et al. 2005), however, a successful plant transformation using these protocols hitherto is not known. Development of a plant regeneration protocol alone may not necessarily guarantee a successful transformation with that protocol. Stress exerted by Agrobacterium during coculture and detrimental effects by selective agents such as kanamycin and hygromycin may greatly influence the plant regeneration frequency. Therefore, it is important to test the developed plant regeneration protocol under the conditions required in a standard transformation procedure and keep on introducing improvements to the protocol to achieve better transformation efficiency.

This study is a simultaneous approach to develop an efficient plant regeneration protocol for haploid leaf and petiole explants and to regenerate transformed plants from infected tissue explants using Agrobacterium-mediated gene transfer method. With this protocol plant regeneration from leaf and petiole explants had been achieved in two phases: a callus regeneration phase and a shoot regeneration phase. Callus regeneration was achieved in defined callus induction media with specific hormone combinations for leaf and petiole explants. The optimal callus production was achieved with leaf explants in CIM-L medium

while CIM-P medium gave the optimal callus production with petiole explants. Shoot organogenesis from green transformed calli was achieved in DKW (modified) medium 
where $53 \%$ of leaf derived calli and $41 \%$ of petiole derived calli produced shoots. $96 \%$ of plantlets derived from leaf explants and $92 \%$ of plantlets derived from petiole explants remained haploid (Table 2.8). It is important that regenerated plantlets remain haploid in order to produce homozygous double haploid transgenic plants. Silver nitrate $\left(\mathrm{AgNO}_{3}\right)$ which is a potent ethylene inhibitor was added in $5 \mathrm{mg} / \mathrm{l}$ concentration to both callus induction (CIM) medium as well as to organogenesis medium (DKW) taking into consideration the previous reports of improved organogenesis with Brassica napus in the presence of $\mathrm{AgNO}_{3}$. Addition of $\mathrm{AgNO}_{3}$ has significantly increased the green bud formation and shoots regeneration from rapeseed leaves (Akasaka-Kennedy et al. 2005). Medium supplemented with $\mathrm{AgNO}_{3}$ has also resulted in high shoot regeneration in B. napus with hypocotyls segments (Schröder et al. 1994, Eapen and George 1997, Cardoza and Stewart 2003) and mesophyll protoplasts (Hu et al. 1999).

\subsubsection{Optimization of transformation efficiency}

\section{Effect of filter paper, preculture of explants and the use of acetosyringone}

In this study, leaf explants were found to be very sensitive to cocultivation with Agrobacterium and turned necrotic very easily. For petiole explants, the tissue necrosis was not as high as for leaf explants (which was $\sim 30 \%$ ) but remained at a considerable percentage of $\sim 10 \%$. Tissue necrosis was surmounted in this study by preculture of whole leaves with petioles in CIM for two days, before sectioning into segments and coculture with Agrobacterium. Preculture was found to be more effective on filter papers soaked in liquid CIM than in solid medium. Filter paper acts in this case as a paper wick connecting the medium and cultured explants and thus allowing an efficient supply of essential nutrients to the tissue explants and keep cultured explants moist all the time to avoid a possible dehydration or wilting. Tissue necrosis of leaf explants could be reduced by $65 \%$ after two days preculture on filter papers (Table 2.12). Considering the positive effects of using filter papers on liquid medium, cocultivation was also carried out on filter papers soaked in liquid medium. Preconditioning of hypocotyl explants for $72 \mathrm{~h}$ before cocultivation with Agrobacterium has resulted in a higher number of transgenic plants in $B$. napus (Cardosa and Stewart 2003). Cocultivation of explants on filter paper has increased the transformation efficiency from $10 \%$ to more than $20 \%$ for cotyledonary petioles in $B$. carinata (Babic et al. 1998). Wounding of tissue explants before inoculation with Agrobacterium has been considered to be necessary for the release of vir-genes inducing phenolic compounds (Binns 1990). Therefore, preculture in this study was performed with 
intact leaves and petiole explants, unlike preculture of cut hypocotyl segments as reported by Cardosa and Stewart (2003). Precultured explants were dissected into segments just before coculture with Agrobacterium. This simple modification allows the release of virinducing compounds at the time of Agrobacterium infection and also prevents a possible tissue browning due to early release of phenolic compounds. Other than wound released plant phenolic compounds, chemicals such as acetosyringone is also found to be enhancing the ability of Agrobacterium tumefaciens to transform host plants, thus incorporated either in culture medium used for cocultivation of Agrobacterium with plant tissue explants (Godwin et al. 1991, Henzi et al. 2000) or alternatively has been used to precondition tissue explants prior to inoculation with Agrobacterium (Guivarc'h et al.1993). In this study, the use of $100 \mu \mathrm{M}$ of acetosyringone during preculture and coculture with Agrobacterium resulted in a significant increase in putative transformed callus production in both explant types; petioles and leaves. However, the beneficial effects of acetosyringone apparently fluctuate along with Agrobacterium strain and plasmid that has been used to inoculate tissue explants. Differences in induced virulence amongst different Agrobacterium-strains after cocultivation with $200 \mu \mathrm{M}$ with acetosyringone have been reported by Godwin et al. (1991). Improved transformation efficiency after inclusion of acetosyringone in coculture medium has been reported in B. oleracea (Henzi et al. 2000, Tsukayaki et al. 2002), B. campestris (Zhang et al. 2000), B. napus and in B. juncea (Charest et al. 1989).

\section{Infiltration of tissue explants}

Infiltration of leaf and petiole segments with Agrobacterium cell suspension has increased the number of transformed sectors per explant (as confirmed by GUS assay after one week from coculture), but majority of these transformed sectors did not proliferate into green callus. Consequently tissue infiltration in this study did not help to increase the number of explants with transformed callus. It could be possible that not all of those transformed cells at the beginning, have the equal capacity to proliferate and develop into callus. Differential callus proliferating ability of leaf tissue cells of B. napus has been reported (AkasakaKennedy et al. 2005) where cells of vascular parenchyma cells exhibited the highest proliferation and callus production ability. This observation is in agreement with the findings of this study where most of the transformed callus originated from the cut edges of leaf veins. GUS staining of infiltrated leaf explants showed that most of the transformed cells were in the middle of the leaf blade and not in the vascular regions with higher regeneration ability (Fig. 2.6d). It could be important to have a higher number of 
transformed cells with ability to undergo cell proliferation in order to achieve a higher number of transgenic calli.

Using the protocol developed in this study, transformed calli expressing GUS gene were obtained from haploid leaf and petiole explants after coculture with Agrobacterium tumefaciens strain AGL0 pAK-UGI 9-1. Kanamycin resistant transformed plants with NPTII and GUS genes (confirmed by PCR) have been obtained after organogenesis of transformed calli. A transformation efficiency (TE) of 1.8 was obtained with leaf explants and TE of 2.9 was obtained with petiole explants $(\mathrm{TE}=$ number of kanamycin resistant shoots x 100/ total number of explants cultured). Nevertheless, rooting was achieved only with 8 kanamycin resistant shoots when cultured in MS with $50 \mathrm{mg} / 1 \mathrm{kanamycin}$ (2 leaforigin plantlets and 6 petiole-origin plantlets). PCR amplification with DNA from four rooted shoots and five non-rooted but kanamycin resistant shoots (they rooted in MS without kanamycin) confirmed the presence of both transgenes (NPTII and GUS) in all plantlets tested. Healthy shoots that displayed an active growth under $50 \mathrm{mg} / \mathrm{l} \mathrm{kanamycin}$ selection could therefore be considered as transformed, even though they failed to produce roots in the presence of kanamycin. Transformation efficiency in this study was determined taking the number of kanamycin resistant shoots into consideration and not the number of rooted shoots (Table 2.14). These kanamycin resistant but non-rooted shoots in the presence of kanamycin readily produced roots upon transfer to hormone-free solid MS without kanamycin. Surprisingly none of the kanamycin resistant shoots gave positive results after GUS assay, suggesting a possible GUS gene inactivation. It has been revealed in several reports that, transgenes can undergo silencing after integration into host genome (Ingelbecht et al. 1994, Matzke et al. 1994, Balandin and Castresana 1997, Vaucheret et al. 1998). Suppression of the expression of transgene could happen transcriptionally or posttranscriptionally (Vaucheret et al. 1998). Methylation of promoters and gene sequence has been related to transgene silencing in several cases (Kilby et al. 1992, Matzke et al. 1994, Balandin and Castresana 1997). Transgene silencing could either be transmitted stably through several generations or could be meiotically reversible (Vaucheret et al. 1998). In many cases post-transcriptional gene silencing has shown to be developmentally regulated and not heritable. In transgenic tobacco, silencing of a $\beta-1,3$-glucanase has been overcome during seed formation (Balandin and Castresana 1997). In a similar situation, transgenic double haploid plants of $B$. napus produced after inoculation of microspore-derived embryos with Agrobacterium, failed to express the transgene (NPTII) in primary 
transformants, but restored NPTII activity has been observed with seed raised plants of T2 generation (Swanson and Erickson 1989). In this study, GUS expression was observed with callus of both leaf and petiole origin and GUS gene silencing was observed only with regenerated shoots and plantlets. This could therefore be a case of developmentally regulated or post-transcriptional gene silencing. Rooted plants in kanamycin have already been treated with colchicine to produce double haploid transgenic plants and are currently in the process of acclimatization. T2 plant generation would be analyzed to determine whether GUS activity is restored after meiosis and seed set. Expression of an integrated transgene could be established by studying either mRNA (to determine whether gene is transcribed) or protein accumulation (to determine whether mRNA is translated to produce a protein). RNA analysis could provide useful information on transcript accumulation and stability and is often used when protein analysis (western blot or ELISA) is not possible. Molecular techniques such as RT-PCR (Reverse Transcriptase PCR) could be used as a rapid and reliable method to establish the presence or absence of a specific transcript. RTPCR technique utilizes extracted mRNA (or total RNA) from transformed plants to produce copies of cDNA (complementary DNA) of the transgene in the presence of enzyme reverse transcriptase. Analysis of putative transformed plants with RT-PCR could therefore be an important future perspective of this project.

\subsubsection{Advantages of using haploid plant materials for transformation}

One of the main advantages of haploid transformation is that, the transformants will have the transgene permanently fixed (homozygous after cholchicine doubling). Successful transformations via Agrobacterium using microspore-derived embryos have been achieved with Brassica napus (Swanson and Erickson 1989), Nicotiana tabaccum and Datura innoxia (Sangwan at al. 1993). Although reported to be successful, one major disadvantage commonly shared in these works is that, no assessment has been made to establish the ploidy of haploid embryos before cocultivation with Agrobacterium. If those embryos used for cocultivation turned out to be autodiplodized, which is a common phenomenon amongst microspore-derived embryos (Möllers et al. 1994), they would inevitably produce hemizygous transgenic plants. From the hemizygous loci, transgene would segregate following Mendelian genetics.

Use of haploid plant material as in this study could shorten the time taken to obtain fertile transgenic plants with B. napus cv. Drakkar when compared with diploid plant materials (Fig. 2.8). 


\begin{tabular}{|c|c|c|c|}
\hline Haploid system & $\begin{array}{c}\text { Time } \\
\text { (weeks) }\end{array}$ & Diploid system & $\begin{array}{c}\text { Time } \\
\text { (weeks) }\end{array}$ \\
\hline $\begin{array}{l}\text { Transformation experiments and } \\
\text { plantlet regeneration }\end{array}$ & 16 & $\begin{array}{l}\text { Transformation experiments } \\
\text { and plantlet regeneration }\end{array}$ & 16 \\
\hline $\begin{array}{l}\text { Colchicine treatment, transfer } \\
\text { into green house }\end{array}$ & 2 & $\begin{array}{l}\text { Acclimatization and transfer } \\
\text { into green house }\end{array}$ & 2 \\
\hline $\begin{array}{l}\text { Delay due to colchicine } \\
\text { treatment }\end{array}$ & 4 & $\begin{array}{l}\text { Harvest seeds of } \mathrm{T} 1 \\
\text { hemizygous transgenic plants }\end{array}$ & 16 \\
\hline $\begin{array}{l}\text { Harvest seeds from homozygous } \\
\text { transgenic DH plant } \\
\downarrow\end{array}$ & 16 & $\begin{array}{l}\text { Segregation analysis with } \mathrm{T} 2 \\
\text { plant population }\end{array}$ & 16 \\
\hline $\begin{array}{l}\text { Replicated trials with } \\
\text { homozygous T2 plants }\end{array}$ & & $\begin{array}{l}\text { Replicated trials with T3 } \\
\text { plants (homozygous?) }\end{array}$ & \\
\hline Estimated time & 9.5 months & & 12.5 months \\
\hline
\end{tabular}

Fig. 2.8. Comparison of the time required for the production of homozygous transgenic plants using haploid and diploid explants as starting material

Therefore, use of haploid materials should accelerate transgenic breeding programs with oilseed rape. On the other hand, use of clonally propagated plant materials assures high genetic uniformity among transformed plants. Transformed plants will differ from their non transgenic counterparts only at the transformed loci. This would be a definite advantage in morphological and physiological studies that requires a high degree of genetic uniformity amongst transgenic plants. However, transformation protocol described in this study needs establishment of haploid plants via microspore culture beforehand, which could take up to 3 to 4 months. Once produced, haploid transgenic plants should be made diploid to obtain fertile transgenic plants (by colchicine treatment), which takes 3 to 4 weeks before the establishment of plants in the green house. Colchicine treatment to produce double haploids at best results in 20-50\% doubling rate (Möllers et al. 1994) and could lead to chimera formation or polyploidization. Haploid plant regeneration protocol described in this study resulted in relatively higher shoot regeneration efficiency $53 \%$ for leaf derived calli and $41 \%$ for petiole derived calli without Agrobacterium infection. Nevertheless, the transformation efficiency achieved with haploid leaf (1.8\%) and petiole (2.9\%) explants 
was still low when compared with transformation efficiency of $3.6 \%$ in the standard protocol by Hüsken et al. (2005). However, the difference in starting plant materials could not be ruled out in this comparison, where standard protocol uses diploid hypocotyl explants while current study uses vegetative plant materials such as leaf and petioles. Seedling-raised hypocotyl and cotyledonary explants are shown to yield high regeneration efficiencies in Agrobacterium mediated transformation of B. napus (Moloney et al. 1989, Khan et al. 2003). Transformation frequencies obtained with leaf and petiole explants in this study could not be directly compared since there is no report available to our knowledge for a successful transformation using these plant materials in B. napus.

\subsection{Conclusions}

This study has established a working protocol to obtain callus and plant regeneration with haploid plant material of B. napus cv. Drakkar. Transgenic calli expressing GUS activity were obtained with leaf and petiole explants after coculture with Agrobacterium tumefaciens. Kanamycin resistant haploid transgenic plants were regenerated from callus produced on leaf and petiole explants with kanamycin selection. The presence of selectable marker gene (NPTII) and reporter gene $(G U S)$ in putative transformed plants was confirmed with PCR. Expression of GUS gene was not detected with plants which were found to be kanamycin resistant and PCR positive for the GUS gene. Whether meiosis could restore the GUS gene activity could be established by studying double haploid transformed plants in the T2 generation. Haploid transformation should produce genetically uniform plants differing only at the transgenic loci and enable easy evaluation of physiological and agronomical effects caused by the introduced gene. Haploid transformation is relatively fast and avoids formation of hemizygous transformants. The transformation method described in this study could be extended to other important crops in Brassicaceae, Solanaceae and Poaceae in which pollen embryogenesis has already been established. 


\section{Overexpression of Arabidopsis phytochrome B in Brassica napus L.}

\subsection{Introduction}

Plant development is strongly influenced by environmental factors. Sunlight is perhaps the most decisive abiotic factor that influences the growth and development of plants. Plants possess at least two types of photoreceptors: red (R) and far-red (FR) light absorbing phytochromes and the UV-A/blue light-absorbing cryptochromes, whose primary physiological role is the acquisition of signals from the light environment (Ballaré 1999). The phytochrome family of photoreceptors plays a vital role in modifying the developmental and physiological responses of plants to the changing light environment (Smith and Whitelam 1997). The phytochrome molecule is a dimer of two identical apoproteins of approximately $120 \mathrm{kD}$, each covalently attached to a linear tetrapyrrole pigment called chromophore (Furuya 1993, Rockwell et al. 2006). Chromophore is synthesized in chloroplasts and assembled with apoproteins in the cytosol, forming the inactive red light absorbing Pr conformation of phytochromes. Pr form is considered as biologically inactive and is converted to an active Pfr form upon absorption of red light. $\mathrm{Pr}$ and Pfr forms are inter-convertible by sequential absorption of R and FR light (Quail 1991). Under daylight conditions (which is rich in red light), phytochrome is mostly converted to the Pfr form. Pfr form is unstable compared to Pr form and is converted slowly back to $\mathrm{Pr}$ form under high FR conditions or at darkness (Smith 1995). Plants absorb red light for photosynthesis and reflect and transmit FR. Therefore, conversion of Pfr into Pr could also occur under the shade of neighbouring plants. This conversion triggers a series of plant responses called shade avoidance responses such as promotion of stem elongation, reduction in leaf thickness, reduced chlorophyll content, increased apical dominance, reduced branching and accelerated flowering (Casal et al. 1987, Halliday et al. 1994, Smith and Whitelam 1997). Shade avoidance responses help plants to beat the competition exerted by other pants and is solely stimulated by reduction in R: FR ratio, which occurs under dense plant populations (Smith and Whitelam 1997). Hence the primary, if not solely, physiological function of plant phytochrome seems perception of changes in R to FR ratio and let the plant detect shade and presence of neighbouring plants.

Evidence suggests the existence of multiple, distinct, but structurally conserved species of phytochromes of which, the apoproteins are encoded by a small family of divergent genes (Quail 1991, Furuya 1993 and Smith 1995). In the model plant Arabidopsis thaliana, five genes encoding five distinct phytochromes (phyA to phyE) have been identified and cDNA 
of all five have been sequenced and characterized (Sharrock and Quail 1989, Clack et al. 1994). The polypeptides encoded by $P H Y B$ and $P H Y D$ genes share approximately $80 \%$ amino acid sequence identity and are more related to PHYE with approximately 55\% identity than they are to either the PHYA or PHYC proteins (with approximately $47 \%$ identity) (Mathews and Sharrock 1997). The different phytochrome family members were shown to have distinct, sometimes overlapping and even antagonistic roles in mediating $\mathrm{R}$ and FR effects on plant development (Smith et al. 1997, Whitelam and Devlin 1997). Depending on the stability of Pfr state, two pools of phytochromes could be identified; light labile and light stable phytochromes (Furuya 1993, Smith 1995). Phytotochrome A (phyA) is light labile and accumulates predominantly in etiolated plant tissues while phytochromes $\mathrm{B}$ (phyB) and phytochrome $\mathrm{C}$ (phyC) are relatively light stable, with phyB accumulating as the major phytochrome in light grown or in green tissues (Somers et al. 1991).

Much of the existing knowledge on distinct roles by individual phytochromes in plant development has come from studying mutants that are null for a particular phytochrome or from analysis of transgenic plants overexpressing a particular member of phytochromes (Whitelam and Harberd 1994, Smith 1995, Greef 1996, Smith and Whitelam 1997). Mutants that are deficient in a particular phytochrome exhibit a light-insensitivity under irradiation conditions in which that phytochrome is functional under normal circumstances. Likewise, transgenic plants that overexpress a particular phytochrome display lighthypersensitivity under the same irradiation condition (Halliday et al. 1997). Mutants lacking phyB or functional form of it, such as hy3 (now phyB) mutant in Arabidopsis (Reed 1993), ein mutant in Brassica rapa (Devlin et al. 1997) and tri mutant in tomato (van Tuinen et al. 1995) are insensitive to red light while transgenic Arabidopsis plants overexpressing an oat $P H Y B$ cDNA are hypersensitive to red light for the same morphological responses (Wagner et al. 1991, Nagatani et al. 1993). Light grown ein mutant seedlings of B. rapa demonstrated an elongated hypocotyl phenotype similar to phyB mutant of Arabidopsis which also showed elongated and early flowering phenotype, typical of shade avoidance responses of wild type seedlings grown under a low R/FR ratio or end of the day FR treatment (Devlin et al. 1997, Reed et al. 1993). These observations suggest that phyB plays a predominant role in mediating plant responses to vegetational shade. However, evidences are emerging to suggest the participation of other phytochromes (such as phyC) in shade avoidance responses (Smith and Whitelam 1997). In response to shade, plants allocate more assimilates for stem elongation at the expense of leaf and root development and resort to accelerated flowering that results in reduced seed set, truncated 
fruit development and low rate of seed germination (Halliday et al. 1994). An alternative transgenic approach to achieve improved agricultural productivity with crop plants has been suggested by overexpression of phytochrome genes, PHYA and PHYB (Smith 1992, Robson and Smith 1997). Overexpression of phytochrome genes effectively disables the shade avoidance responses of plants under dense populations and this may lead to higher proportion of assimilates been allocated to economically important plant parts (Smith 1995). Overexpression of oat (Avena sativa) PHYB cDNA in tobacco (Nicotiana tabacum) has resulted in a reduced stem growth and a greater stem to fresh leaf biomass ratio at high planting densities resulting up to $20 \%$ improvement in harvest index in the field (Robson et al. 1996). Overexpression of Arabidopsis PHYB cDNA in potato (Solanum tuberosum) has resulted in semidwarf plants with higher photosynthetic performance, longer lifespan of transgenic plants and greater biomass production and tuber yields (Thiele et al. 1999).

Oilseed rape (Brassica napus L.), a natural amphidiploid derived by hybridization of $B$. rapa and $B$. oleracea, is a renowned crop worldwide as edible oil as well as a source of protein animal feed. Thus oilseed rape is an important target for crop improvements. Lodging or the collapse of plants and pods falling below the cutter level at harvest is a serious problem in oilseed rape. Many current B. napus cultivars are prone to lodging and should lodging occur early in the crop season during flowering or siliques development, high yield losses could be anticipated (Islam and Evans 1994). Lodging could be decreased by reducing plant height which is often achieved in $B$. napus applying chemical growth regulators (Gans et al. 2000). However, this could be counterproductive since growth regulators are also found to be interfering with other endogenous plant hormones and metabolic processes (Rademacher 2000). Furthermore, success with growth regulators on plant height depends on the time of application, and late applications may leave high amounts of chemical residues in the grain yields (Gans et al. 2000). Two dwarf mutants; rapid cycling dwarf (Zanewich et al. 1991) and bzh (Foisset et al. 1995) have been identified in B. napus. However, these mutants are known to possess several undesirable pleiotropic effects and their field performance are not yet been well documented (Muangprom et al. 2006).

Reduced plant height observed with potato (Thiele et al. 1999) and with tobacco (Halliday at al. 1997), as a consequence of overexpression of Arabidopsis PHYB cDNA, may provide useful alternative for $B$. napus to achieve shorter plants which under field conditions would reduce lodging. This study reports the morphological and physiological implications of phyB overexpression in transgenic B. napus plants. This study was carried out with diploid 
plant material because the haploid transformation protocol described in chapter one was not fully established and optimized at the beginning of this study.

\subsection{Materials and methods}

\subsubsection{Agrobacterium strain and plasmid vectors}

The binary plasmid system of Agrobacterium tumefaciens strain C58C1 ATHV Rif ${ }^{\mathrm{R}}$ containing the helper plasmid pEHA101 and the binary vector p35SA.thPhyB was used for transformation. The plant expression vector p35SA.thPhyB (derived from pBIN19), harbours the Arabidopsis thaliana PHYB gene under the control of CaMV35S promoter and the NPTII gene under the control of the nos promoter on the T-DNA (Fig.3.1).

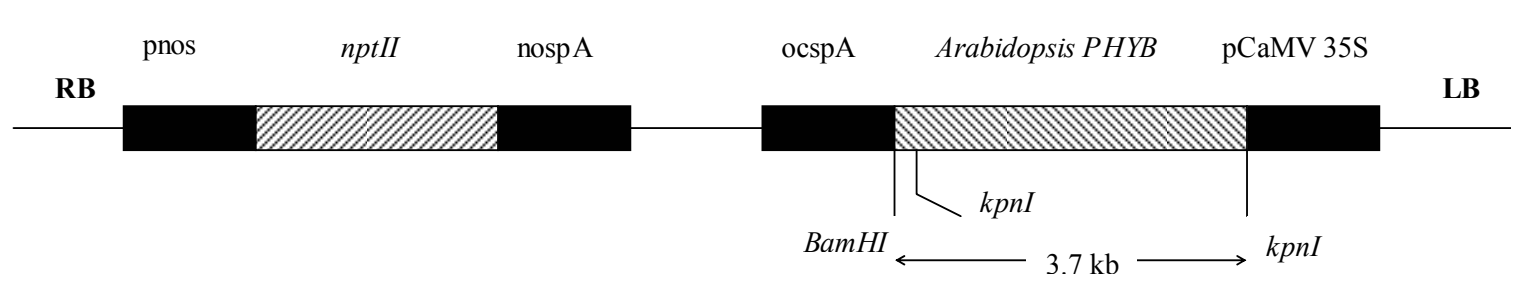

Fig. 3.1 Schematic diagram of the T-DNA region of the binary vector p35SA.thPhyB. Vector contains the coding region of the neomycin phosphotransferase gene (NPTII) under the control of nos promoter and coding region of the Arabidopsis PHYB regulated by CaMV35S promoter and pAOCS terminator of octopine synthase gene. LB, RB, Left and right border sequences from the vector T-DNA.

\subsubsection{Multiplication and isolation of vector}

The vector was introduced first into Escherichia coli strain XL1-Blue (Bullock et al. 1987) by electroporation and multiplied. E. coli was grown in $10 \mathrm{ml}$ of LB medium (see Table 3.1 for the composition) supplemented with $50 \mathrm{mg} / \mathrm{l}$ kanamycin and $100 \mathrm{mg} / \mathrm{l}$ rifampicillin (Sigma) at $37^{\circ} \mathrm{C}$ for $12-16$ hours with shaking at $200 \mathrm{rpm}$ on a rotary shaker. Bacteria cells were pelletted by centrifugation for $1 \mathrm{~min}$ at $10,000 \mathrm{x}$ g in several $1.5 \mathrm{ml}$ microcentrifuge 
tubes and the supernatant was discarded. Plasmid was re-isolated from these bacterial cells using E.Z.N.A Plasmid Miniprep Kit 1 (Classic Line) (PQLab Biotechnologie GmbH) according to the manufacturer's instruction manual. Isolated plasmid was collected in TE buffer (pH 8.0) and stored at $4{ }^{\circ} \mathrm{C}$ until use.

Table 3.1. Composition of culture media

\begin{tabular}{|c|c|c|}
\hline Medium & Application & Composition for $1 \mathrm{~L}$ of medium \\
\hline YEB & Growth of $A$. tumefaciens & $\begin{array}{l}1 \mathrm{~g} / 1 \text { Yeast extract, } 5 \mathrm{~g} / 1 \text { Meat extract, } 5 \mathrm{~g} / 1 \\
\text { Peptone (Casein), } 0.5 \mathrm{~g} / 1 \mathrm{MgSO} 4 \cdot 7 \mathrm{H} 2 \mathrm{O}, 5 \\
\mathrm{~g} / 1 \text { sucrose, } \mathrm{pH} 7.4\end{array}$ \\
\hline LB & Growth of E. coli & $\begin{array}{l}1 \mathrm{~g} / 1 \mathrm{Y} \text { east extract, } 5 \mathrm{~g} / 1 \text { Peptone (Casein), } 10 \\
\mathrm{~g} / 1 \mathrm{NaCl}, \mathrm{pH} 7.0-7.5\end{array}$ \\
\hline CIM & $\begin{array}{l}\text { Liquid: Infection, co- } \\
\text { cultivation, washing }\end{array}$ & $\begin{array}{l}5.3 \mathrm{~g} / 1 \mathrm{MS} \text { media-mix powder (Duchefa, } \\
\text { Netherlands), } 300 \mathrm{mg} / 1 \text { Myo-Inositol, } 500 \\
\text { mg/l MES, } 2 \mathrm{mg} / 1 \mathrm{BAP}, 0.001 \mathrm{mg} / 1 \text { Picloram, } \\
5 \mathrm{mg} / 1 \mathrm{AgNO} 3,20 \mathrm{~g} / 1 \text { sucrose, } \mathrm{pH} \text { 5.7. Solid } \\
\text { medium: } 5.4 \mathrm{~g} / 1 \text { agarose }\end{array}$ \\
\hline DKW & $\begin{array}{l}\text { Shoot regeneration } \\
\text { (organogenesis) }\end{array}$ & $\begin{array}{l}5.3 \mathrm{~g} / \mathrm{l} \mathrm{DKW} \text { medium-mix powder (Duchefa, } \\
\text { Netherlands), } 20 \mathrm{~g} / 1 \text { sucrose, } 1 \mathrm{mg} / 1 \text { BAP, } \\
0.01 \mathrm{mg} / 1 \text { IBA, } 0.01 \mathrm{mg} / 1 \text { GA3, } 5 \mathrm{mg} / 1 \\
\text { AgNO3, } 5.4 \mathrm{~g} / 1 \text { agarose, } \mathrm{pH} 5.7\end{array}$ \\
\hline
\end{tabular}

\subsubsection{Preparation of competent cells of Agrobacterium tumefaciens}

$4 \mathrm{ml}$ of YEB medium was inoculated with $40 \mu \mathrm{l}$ of bacteria suspension (from stock culture) in a $40 \mathrm{ml}$ conical flask and grown at $27{ }^{\circ} \mathrm{C}$ for 8 hours with shaking (200 rpm). Next, this liquid was transferred into $400 \mathrm{ml}$ of YEB medium (see Table 3.1 for the composition) in a $1000 \mathrm{ml}$ conical flask and grown overnight under the same growth conditions as before. Optical density of the bacterial suspension was measured at OD $600 \mathrm{~nm}$ and adjusted to 0.5-0.8. After that, the suspension was placed on ice for $15 \mathrm{~min}$ and centrifuged at 4000 
$\mathrm{rpm}$ at $4{ }^{\circ} \mathrm{C}$ for $15 \mathrm{~min}$. Supernatant was discarded and the bacterial pellet was kept on ice to cool down to $4{ }^{\circ} \mathrm{C}$. Pellet was re-suspended in $400 \mathrm{ml}$ of cold water (pre-cooled to $4{ }^{\circ} \mathrm{C}$ ) and centrifuged at $4000 \mathrm{rpm}$ for $15 \mathrm{~min}$. Supernatant was discarded, pellet was resuspended in $200 \mathrm{ml}$ of pre-cooled water at $4{ }^{\circ} \mathrm{C}$ and centrifuged at $4000 \mathrm{rpm}$ for $15 \mathrm{~min}$. The pellet was re-suspended in $8 \mathrm{ml}$ of Glycerine (filter sterilized and pre-cooled to $4{ }^{\circ} \mathrm{C}$ ) and centrifuged at $4000 \mathrm{rpm}$ for $15 \mathrm{~min}$. Finally, the pellet was re-suspended in $0.8-1.2 \mathrm{ml}$ of Glycerine (filter sterilized and pre-cooled to $4{ }^{\circ} \mathrm{C}$ ) distributed into $1.5 \mathrm{ml}$ microcentrifuge tubes ( $40 \mu \mathrm{l}$ of bacterial suspension in each), immediately cooled down with liquid nitrogen and stored at $-70^{\circ} \mathrm{C}$.

\subsubsection{Introduction of plant expression vector into Agrobacterium tumefaciens strain}

$40 \mu \mathrm{l}$ of bacterial cell suspension was mixed with $1 \mu \mathrm{l}$ of isolated plasmid in TE buffer (concentration 10-100 ng/ $\mu \mathrm{l}$ ), mixed well, and placed on ice for $1 \mathrm{~min}$. This liquid was then transferred into a sterilized plastic cuvette and subjected to an electric pulse of $2.5 \mathrm{kV}$ (at $200 \Omega$ ) using a pulsar (BioRad, USA). After that, liquid was transferred into a sterilized 15 $\mathrm{ml}$ centrifuge tube, added $450 \mu \mathrm{l}$ of YEB medium, mixed well and incubate at $27^{\circ} \mathrm{C}$ for 3 hours with shaking at $200 \mathrm{rpm} .200 \mu \mathrm{l}$ aliquots from this suspension was transferred onto selection plates (containing 25-30 ml of agar solidified YEB medium with $50 \mathrm{mg} / \mathrm{l}$ kanamycin and $50 \mathrm{mg} / 1$ rifampicillin in $90 \mathrm{~mm}$ Petri dishes), spread well, and incubated at $27{ }^{\circ} \mathrm{C}$ for 3 days. Transformed bacterial cells were obtained from isolated single colonies and grown further in new selection plates for several times before establishing stock cultures with them.

\subsubsection{Preparation of glycerine stocks of transformed Agrobacterium tumefaciens}

$4 \mathrm{ml}$ of YEB medium with selective agents $(50 \mathrm{mg} / \mathrm{l}$ kanamycin and $50 \mathrm{mg} / \mathrm{l}$ rifampicillin) was inoculated with transformed Agrobacterium cells obtained from an well isolated colony on the selection medium, and grown overnight at $27{ }^{\circ} \mathrm{C}$ with shaking. $150 \mu \mathrm{l}$ aliquots of overnight grown bacterial suspension was distributed among $1.5 \mathrm{ml}$ microcentrifuge tubes containing $85 \mu \mathrm{l}$ of filter sterilized glycerine, mixed well, immediately cooled with liquid nitrogen and stored at $-70{ }^{\circ} \mathrm{C}$. 


\subsubsection{Preparation of bacterial cell suspension for transformation of plant tissues}

A single bacterial colony formed on solid YEB selection medium was inoculated into $4 \mathrm{ml}$ of YEB medium with selective antibiotics and $10 \mu \mathrm{M}$ acetosyringone and grown overnight at $27^{\circ} \mathrm{C}$ on a shaker rotating at $200 \mathrm{rpm} .100 \mu \mathrm{l}$ aliquot of this solution was added into 40 $\mathrm{ml}$ of fresh YEB medium with selective antibiotics and $100 \mu \mathrm{M}$ acetosyringone and grown overnight under the same conditions as above. The bacteria suspension was centrifuged at $6000 \mathrm{rpm}$ for $10 \mathrm{~min}$ and the pellet was re-suspended in liquid callus induction medium (CIM), consisting of MS salts and vitamins (see Table 3.1 for the composition), and diluted to a bacterial cell density of $1 \times 10^{9}$ cells/ $\mathrm{ml}$. This preparation was left for 3 hours at room temperature and subsequently used for inoculation of plant tissues.

\subsubsection{Plant material}

Hypocotyl explants obtained from in vitro grown seedlings of spring oilseed rape Brassica napus cultivar Drakkar, (Serasem Company, France) was used for transformation experiments. Seeds were surface sterilized with $5 \%(\mathrm{w} / \mathrm{v})$ solution of $\mathrm{Ca}(\mathrm{OCl}) 2$ for $30 \mathrm{~min}$ with continuous shaking in a $50 \mathrm{ml}$ sterile bottle (Duran). After that seeds were rinsed three times thoroughly with sterile distilled water and dried on sterile filter papers. Sterilized seeds were plated onto agar solidified MS (basal) medium in $9 \mathrm{~cm}$ Petri dishes and grown in vitro at $25^{\circ} \mathrm{C}$ and $16 / 8$ hours day/night photoperiod provided by cool fluorescent tubes (Osram, Germany) for 5-6 days.

\subsubsection{Inoculation of hypocotyls explants}

Hypocotyls of in vitro grown seedlings were cut into 5-7 $\mathrm{mm}$ segments under aseptic conditions and inoculated with Agrobacterium cell suspension in a sterile Petri dish placed on a slow rotating shaker at $80 \mathrm{rpm}$ for $40 \mathrm{~min}$ at room temperature. Segments were briefly dried on sterile filter papers and transferred onto CIM medium solidified with $5 \mathrm{~g} / \mathrm{l}$ agarose in $9 \mathrm{~cm}$ Petri dishes. Plates were sealed with Micropore tape (3M) and incubated for two days at $22^{\circ} \mathrm{C}$. After two days of co-cultivation the segments were washed tree times with liquid CIM medium and the final washing was with $500 \mathrm{mg} / \mathrm{l}$ carbenicillin. Segments were briefly dried on sterile filter paper and transferred onto fresh solid CIM selection medium supplemented with $500 \mathrm{mg} / \mathrm{l}$ carbenicillin and $35 \mathrm{mg} / 1$ kanamycin. The number of segments cultured in a single Petri dish was 25. Plates were sealed with Micropore tape and incubated at $22^{\circ} \mathrm{C}$ under continuous light for four weeks. 


\subsubsection{Callus and plantlet regeneration}

The number of green calli formed on hypocotyls explants in selection medium after four weeks were recorded separately for each Petri dish and expressed as a percentage value. Green calli were then separated from the explants and transferred onto DKW medium (see Table 3.1 for the composition) supplemented with $500 \mathrm{mg} / \mathrm{l}$ carbenicillin und $50 \mathrm{mg} / \mathrm{l}$ kanamycin. Plates were incubated at $22{ }^{\circ} \mathrm{C}$ under continuous light condition and calli were transferred onto fresh medium in every 2-3 weeks intervals. Regenerated green shoots were separated from callus masses and transferred onto hormone free agar solidified MS medium supplemented with $500 \mathrm{mg} / 1$ carbenicillin und $50 \mathrm{mg} / \mathrm{l} \mathrm{kanamycin,} \mathrm{in} \mathrm{which} \mathrm{rooting} \mathrm{and}$ plantlet regeneration were achieved. Well grown plantlets were transferred into soil (top earth 3: 1 compost) in $6 \mathrm{~cm} \times 6 \mathrm{~cm}$ black plastic pots and placed in a controlled climate chamber for $4-5$ days at $17{ }^{\circ} \mathrm{C}$ with a photoperiod of $16 / 8$ hours day/night. After that, plants were transferred to the greenhouse and kept under humid conditions for another week. Finally the plants were planted in $11 \mathrm{~cm}$ (length) $\mathrm{x} 9 \mathrm{~cm}$ (width) black plastic pots with same soil mixture and grown to maturity.

\subsubsection{Isolation of total DNA from transgenic plants}

$100 \mathrm{mg}$ fresh weight of young leaves obtained from putative transformed plants was used as starting material for DNA isolation. Harvested plant tissue samples were immediately frozen in liquid nitrogen and stored at $-70{ }^{\circ} \mathrm{C}$ in microcentrifuge tubes until use. Tissue samples were crushed in liquid nitrogen to obtain a fine powder using a mechanical mixture mill with a plastic pestle. Isolation of total DNA was done using DNeasy Plant Mini Kit (Qiagen $\mathrm{GmbH}$ ) following the manufacturer's instruction manual. $400 \mu \mathrm{l}$ of buffer AP1 and $4 \mu \mathrm{l}$ of RNase (a stock solution of $100 \mathrm{mg} / \mathrm{l}$ ) were added into ground tissue sample and vortexed vigorously. Next, the mixture was incubated at $65{ }^{\circ} \mathrm{C}$ for $10 \mathrm{~min}$ to achieve lyses of cells while mixing 2-3 times during incubation by inverting the tube. $130 \mu 1$ of AP2 solution was added to the tube, mixed well, and incubated on ice for $5 \mathrm{~min}$. Mixture was then transferred into QIAshredder spin column and centrifuged at full speed of the microcentrifuge. This step binds DNA to the spin column and in the following step bound DNA was eluted with $50 \mu \mathrm{l}$ of $\mathrm{AE}$ buffer (preheated to $65^{\circ} \mathrm{C}$ ) into a fresh $1.5 \mathrm{ml}$ microcentrifuge tube and stored at $4{ }^{\circ} \mathrm{C}$ until further use. 


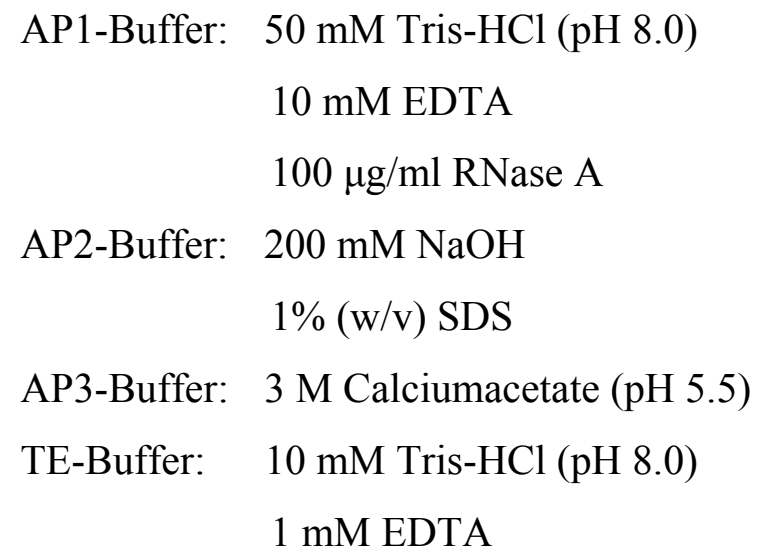

\subsubsection{Determination of DNA concentration and PCR analysis}

Fluorometer was turned on $20 \mathrm{~min}$ before to allow the instrument to warm up. Gain and MED (medium) was adjusted to read 00000. 0.1 $\mathrm{g} / \mathrm{ml}$ Hoechst 33258 (Bio-Rad) dye was prepared by mixing $1.4 \mu \mathrm{l}$ of dye (stock solution of $1 \mathrm{mg} / \mathrm{ml}$ ), $1.4 \mu \mathrm{l}$ of 10x TEN buffer and $12.6 \mathrm{ml}$ of sterile distilled water. Standard solutions of 20, 50 100, 200, 500 and $1000 \mathrm{ng}$ DNA were prepared by mixing calf thymus DNA from stock solutions of 100 and $10 \mu \mathrm{g} / \mathrm{ml}$ with $2 \mathrm{ml}$ of $0.1 \mu \mathrm{g} / \mathrm{ml}$ Hoechst dye. Machine was calibrated using these samples at ambient temperature. $2 \mu \mathrm{l}$ extracted total DNA from transformed plants was mixed with $2 \mathrm{ml}$ of 0.1 $\mu \mathrm{g} / \mathrm{ml}$ Hoechst dye in a clean cuvette, inserted into the machine and relative fluorescence unit (RFU) was recorded. The final DNA concentration for each sample was determined by dividing the RFU value by 2 (since $2 \mu$ of extracted DNA was initially mixed with the dye).

PCR was performed in a reaction mixture containing about $25 \mathrm{ng}$ plant genomic DNA, 125 $\mu \mathrm{M}$ of each dNTP, $10 \mu \mathrm{M}$ of each primer and $1.25 \mathrm{U} / \mu \mathrm{l}$ of Taq-polymerase. PCR analysis was carried out under standard conditions with 1 min denaturation, 1 min annealing, and 2min extension at $94^{\circ} \mathrm{C}, 60^{\circ} \mathrm{C}$ and $72^{\circ} \mathrm{C}$, respectively, for 35 cycles. The sequences of the PCR primers were as listed in Table 3.2. Primer design for A. thaliana PHYB gene was done by the web based Primer3 program (http://frodo.wi.mit.edu). Search was started with CaMV35S and $P H Y B$ gene coding sequence as the query. Designed primer pair amplifies the CaMV35S promoter and part of the $P H Y B$ gene. Amplified products were separated in a $1.5 \%(w / v)$ agarose gel in $1 \mathrm{x}$ TAE buffer at $120 \mathrm{~V}$ for two hours, stained with ethidium bromide, visualized under an ultra violet illuminator and recorded with a gel documenter. 
Table 3.2. Primers and expected amplification length

\begin{tabular}{|c|c|c|}
\hline Primer & Sequence & Fragment length \\
\hline $35 S-x P H Y B$-fw. & 5`- ATGGGTGCAGGTGGAAGAATG -3` & $800 \mathrm{bp}$ \\
\hline $35 S$ PHY B-rev. & 5`- TTCTTTCACCATCATCATATCC-3’ & \\
\hline$N P T-I I$-fw. & 5'-ATCGGGAGCGGCGATACCGTA-3’ & $700 \mathrm{bp}$ \\
\hline NPT-II-rev. & 5'-GAGGCTATTCGGCTATGACTG-3’ & \\
\hline
\end{tabular}

fw. Forward primer, rev. Reverse primer

\subsubsection{Morphological characterization of primary transformants (T1 plants)}

Out of 21 putative transformed plants regenerated (with $50 \mathrm{mg} / \mathrm{l} \mathrm{kanamycin} \mathrm{selection)} \mathrm{two}$ transgenic lines, 5 and 9 were selected for further experiments on the basis of showing bands with both $n p t \mathrm{II}$ and $P H Y B$ primers. Ten in vitro propagated clones of each line (5 and 9) and ten non transformed plants (hypocotyl raised) were established in the greenhouse in $11 \mathrm{~cm}$ (length) x $9 \mathrm{~cm}$ (width) plastic pots and grown to maturity under long day conditions (from Sep 06 to Dec 06). Transformed and non transformed plants used in this experiment were simultaneously raised and have gone through similar in vitro and in vivo culture phases. Transgenic plants were compared with control plants in randomized experiment for morphological, phenological, and agronomical traits.

Plant height was measured from the soil to the apex with a ruler at bolting, at first flowering and at maturity. Date of flowering was recorded after daily observations for each plant and expressed as the number of days taken from sowing to appearance of the first open flower. Leaf thickness was measured with a micrometer at four random points on leaf blades of $3^{\text {rd }}$ and $4^{\text {th }}$ leaf (from plant apex). Fresh leaf weight per $\mathrm{cm}^{2}$ was determined by measuring four randomly cut leaf discs of $1 \mathrm{~cm}^{2}$ from $3^{\text {rd }}$ and $4^{\text {th }}$ leaves of each plant.

Chlorophyll content was measured at bolting and at flowering for each plant with a chlorophyll meter (SPAD-502, Konica Minolta sensing, Inc.). Chlorophyll content of three randomly selected plants from two primary transgenic lines, T5(1) and T9(1) and from three corresponding control plants was recorded in weekly intervals from the time of 
transfer into the greenhouse until plants attained maturity (marked by siliques turning from green to yellowish brown).

\subsubsection{Greenhouse experiments with $\mathrm{T} 2$ plants}

The main shoot of T1 plants was self pollinated to produce T2 seeds. Around $200 \mathrm{~T} 2$ seeds from each transgenic line T5 and T9 were sown alongside with 40 non-transgenic seeds in the greenhouse. Hypocotyl length of the growing seedlings was recorded at the first and second week after sowing. All seedlings (206) from line 5 were grown into maturity. 50 shortest and 50 tallest seedlings were selected from line T9 after two weeks and grown into maturity. All plants were grown in $11 \mathrm{~cm}$ (length) x $9 \mathrm{~cm}$ (width) plastic pots (containing a mixture of top earth 3 : compost 1) and arranged in randomized experiment so that two nontransgenic control plants were present in each row.

\subsubsection{Measurement of hypocotyl length and kanamycin sensitivity assay of T2 seedlings}

A sample of 100 seeds obtained from each of the self pollinated transgenic T5 and T9 plants and from a corresponding control plant were grown separately in vitro for 7 days in complete darkness or in white light (at 16/8 hrs day/night light photoperiod), after which hypocotyl length was determined for each seedling. Next, the apical shoot (with a small part of the hypocotyl) was cut from all seedlings and cultured separately in solid MS medium (basal) supplemented with $100 \mathrm{mg} / \mathrm{l} \mathrm{kanamycin}$ and grown for four weeks under 16/8 hours day/night light condition. Those shoot apexes which showed continuous growth (with adventitious root formation) were recorded as kanamycin resistant $\left(\mathrm{Kan}^{\mathrm{R}}\right)$ and those shoots died without further growth as kanamycin sensitive $\left(\operatorname{Kan}^{\mathrm{S}}\right)$. Total DNA was extracted from ten selected shortest seedlings, ten intermediately tall seedlings and ten tallest seedlings, of a seven days old in vitro grown seedling population of 100, from transgenic line T5 and amplified with $P H Y B$ primers to determine the inheritance of $P H Y B$ gene. Similarly, total DNA from 20 selected shortest and 20 tallest greenhouse grown plants of T5(2) and T9(2) populations (selection criterion was the seedling height after one week) was isolated and amplified with $P H Y B$ primers to determine the inheritance of phyB gene. 


\subsubsection{Statistical analysis}

Statistical analysis of data was performed using the Stat-Graphics Plus for Windows 3.0 software (Statistical Graphics Corp. 1997). Data were presented as means and standard deviation separately for transgenic and non-transgenic plants for a given trait. Means were separated using Duncan's multiple range test at $\mathrm{P}=0.05$.

\subsection{Results}

\subsubsection{Transformation and plant regeneration}

Sixteen putative transformed clones, named T1(1) to T16(1), were obtained (with $50 \mathrm{mg} / \mathrm{l}$ kanamycin selection) from 1335 infected hypocotyl segments which corresponds to a mean transformation efficiency of $1.2 \%$.

\subsubsection{PCR analysis}

PCR analysis of the total DNA extracted from the 16 putative transformed plants confirmed the presence of both NPTII and PHYB genes in two transgenic clones, T5(1) and T9(1). These two transgenic clones were selected to be used in further studies. Amplification of total DNA with the NPTII primers gave a $700 \mathrm{bp}$ band for the clone T5 and T9 and for plasmid p35SA.thPhyB which was the positive control (PC), (Fig. 3.2b). When the PHYB primers were used for amplification, an $800 \mathrm{bp}$ band was observed for the same clones and the plasmid p35SA.thPhyB (Fig. 3.2a). No bands were obtained with an untransformed plant used as the negative control (NC). 

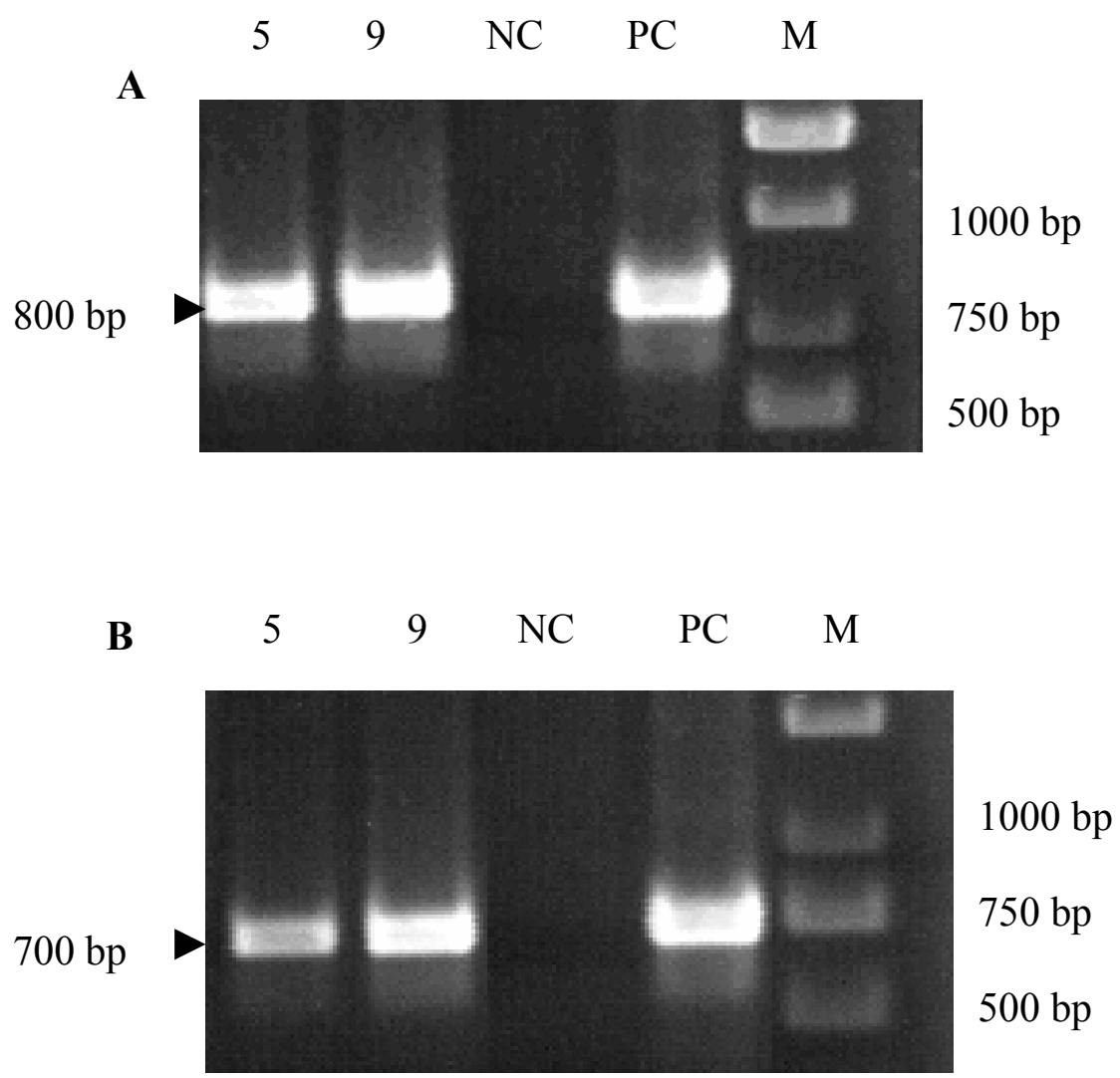

Figure 3.2. PCR analysis of DNA amplified with Arabidopsis PHYB primers (A) and NPTII primers (B).

Lanes: 5 and 9: DNA from transgenic plants T5(1) and T9(1), NC: DNA from an untransformed plant (negative control), PC: DNA from plasmid p35SA.thPhyB (positive control) M: DNA size marker

\subsubsection{Leaf characteristics of $\mathrm{T} 1$ transgenic plants}

Average number of leaves per plant at bolting was significantly higher in transgenic plants. However, the size of leaves was significantly smaller than those of controls (Table 3.3). Fresh leaf weight and thickness of leaves for transgenic plants was significantly higher than controls, while no significant difference was observed between the two transgenic lines for the same traits. 
Table 3.3. Leaf characteristics of transgenic (T1) and non-transgenic plants at the time of bolting

\begin{tabular}{|c|c|c|c|c|}
\hline Parameter & $\mathrm{T} 5(1)$ & T9(1) & Control & $\mathrm{n} / \mathrm{n}^{a}$ \\
\hline \multirow[t]{2}{*}{ Average number of leaves } & $9.3^{*}$ & $9.6^{*}$ & 8 & 10 \\
\hline & $(1.2)$ & (1.4) & $(1.1)$ & \\
\hline \multirow[t]{2}{*}{ Leaf length $(\mathrm{cm})$} & $11.4^{*}$ & $10.8^{*}$ & 13.0 & 10 \\
\hline & $(1.3)$ & $(0.7)$ & $(1.2)$ & \\
\hline \multirow[t]{2}{*}{ Leaf width $(\mathrm{cm})$} & $9.4^{*}$ & $8.6^{*}$ & 11.5 & \\
\hline & $(0.6)$ & $(0.3)$ & $(1.6)$ & \\
\hline \multirow[t]{2}{*}{ Chlorophyll content } & $45.9^{*}$ & $45.2 *$ & 42.9 & $100 / 10$ \\
\hline & $(3.9)$ & $(2.2)$ & $(1.7)$ & \\
\hline \multirow[t]{2}{*}{ Fresh leaf weight $(\mathrm{mg} / \mathrm{cm} 2)^{b}$} & $28.8 *$ & $28.3 *$ & 26.6 & $40 / 10$ \\
\hline & $(1.5)$ & $(1.5)$ & $(1.9)$ & \\
\hline \multirow[t]{2}{*}{ Leaf thickness $(\mu m)^{b}$} & $277^{*}$ & $274^{*}$ & 263 & $40 / 10$ \\
\hline & $(10)$ & (9) & (7) & \\
\hline
\end{tabular}

Data are means and standard deviations given in brackets

All data are recorded at the time of bolting, ${ }^{a}$ Number of samples/ number of individual plants, ${ }^{b}$ data are from the $3^{\text {rd }}$ and $4^{\text {th }}$ leaves from the apex, ${ }^{*}$ denotes a statistically significant difference from the control at $\mathrm{P}=0.05$

Chlorophyll content was measured at different stages of development to study the course of maturation and senescence of transgenic plants. Leaf chlorophyll content of transgenic plants increased sharply during/from the second and/to fourth week and reached a maximum at around bolting. Immediately after first flowering (approx. 40 days), senescence started simultaneously for transgenic and non-transgenic plants. Thereafter, leaf chlorophyll content of control plants decreased almost linearly while chlorophyll degradation in transgenic plants was at a decelerated rate (Fig. 3.3). 


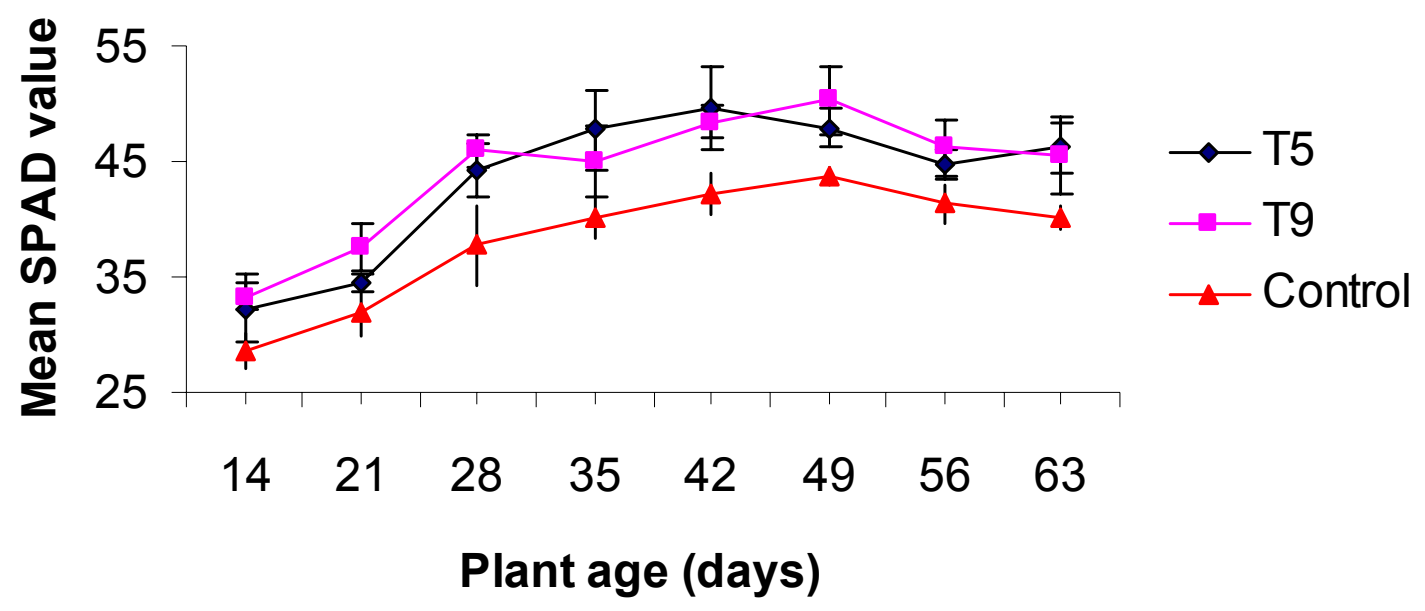

Figure 3.3. Average chlorophyll content during the course of plant maturation for transgenic plants (T5(1) and T9(1)) and non-transgenic controls. Each data point represents the mean chlorophyll content of three randomly selected plants. Vertical bars represent SD.

\subsubsection{Morphological, yield and quality traits of $\mathrm{T} 1$ transgenic plants}

No distinct difference in plant height was noted between the transgenic and non-transgenic plants during in vitro culture phase. However, under greenhouse conditions, a significant height reduction $(\sim 20 \%)$ was observed with transgenic plants at bolting, first flowering and at maturity (Table 3.4). 
Table 3.4. Morphological, yield and quality traits of $\mathrm{T} 1$ transgenic plants

\begin{tabular}{|c|c|c|c|}
\hline Parameter & T5 (1) & T9(1) & Control \\
\hline \multirow[t]{2}{*}{ Bolting (days) } & $23.3 *$ & $24.7 *$ & 27.6 \\
\hline & $(1.9)$ & $(2.4)$ & $(3.4)$ \\
\hline \multirow[t]{2}{*}{ 1st flowering (days) } & $35.3 *$ & $37.2 *$ & 43.7 \\
\hline & $(1.7)$ & $(2.8)$ & $(3.6)$ \\
\hline \multirow[t]{2}{*}{ Duration of flowering (days) } & 26.5 & 25.91 & 24.9 \\
\hline & $(3.9)$ & $(3.7)$ & $(2.7)$ \\
\hline \multirow[t]{2}{*}{ Plant height $(\mathrm{cm})$ At bolting } & 21.6 & $19.9 *$ & 24.9 \\
\hline & $(2.4)$ & $(4.3)$ & $(5.1)$ \\
\hline \multirow[t]{2}{*}{ 1st flowering } & $38.7^{*}$ & $38.1 *$ & 50.3 \\
\hline & $(6.0)$ & $(4.6)$ & $(2.2)$ \\
\hline \multirow[t]{2}{*}{ Maturity } & $90.4^{*}$ & $95.0 *$ & 113.9 \\
\hline & $(16.1)$ & $(15.3)$ & $(2.8)$ \\
\hline \multirow[t]{2}{*}{ No. siliques in main raceme } & 30.8 & 28.7 & 24.6 \\
\hline & $(8.5)$ & (7.8) & $(6.2)$ \\
\hline \multirow[t]{2}{*}{ Mean length of siliques $(\mathrm{cm})^{\mathrm{a}}$} & $7.1^{*}$ & $6.8^{*}$ & 6.2 \\
\hline & $(1.1)$ & $(0.9)$ & $(0.6)$ \\
\hline \multirow[t]{2}{*}{ No. of seeds per siliques ${ }^{a}$} & $25^{*}$ & $24 *$ & 20 \\
\hline & $(5.2)$ & $(5.7)$ & $(6.3)$ \\
\hline \multirow[t]{2}{*}{ Mean seed yield per plant (g) } & 1.7 & 1.4 & 1.8 \\
\hline & $(0.9)$ & $(0.7)$ & $(0.6)$ \\
\hline \multirow[t]{2}{*}{1000 kernel weight (g) } & $2.5^{*}$ & $2.4^{*}$ & 2.7 \\
\hline & $(0.21)$ & $(0.17)$ & $(0.19)$ \\
\hline
\end{tabular}

Data are means and standard deviation given in brackets

* denotes a statistically significant difference from the control at $\mathrm{P}=0.05,{ }^{\mathrm{a}}$ mean of five randomly selected siliques from the main raceme

There was no significant difference in number of siliques in the main raceme. Length of siliques and number of seeds per silique (mean value of five randomly selected siliques from the main raceme, for each plant) was significantly higher for transgenic plants than those of controls. No statistically significant difference was observed in seed yield per 
plant. Thousand kernel weight was significantly higher in control plants than in the two transgenic lines (Table 3.4). Analysis of mature seeds obtained from primary transformants (or T1 plants) showed no significant differences in major storage components, such as oil and protein content, when compared with non-transgenic controls. Seed glucosinolate content, oleic acid and linolenic acid content was significantly lower in transgenic plants (Table 3.5).

Table 3.5. NIRS analysis of T2 seeds (T1 plants)

\begin{tabular}{|c|c|c|c|c|c|}
\hline \multirow[b]{2}{*}{ Line } & \multicolumn{5}{|c|}{ Fatty acid profile $(\%)$} \\
\hline & Oil & Protein & GSL & C18:1 & C18:3 \\
\hline $\mathrm{T} 5(1)(\mathrm{n}=10)$ & 45.6 & 26.6 & $33.0 *$ & $76.7^{*}$ & $11.9 *$ \\
\hline T9(1) $(n=10)$ & 46.9 & 25.5 & $35.6^{*}$ & $76.8 *$ & $11.9 *$ \\
\hline $\operatorname{Control}(n=10)$ & 46.5 & 25.2 & 36.9 & 74.0 & 12.8 \\
\hline
\end{tabular}

\subsubsection{Hypocotyl elongation in $\mathrm{T} 2$ seedlings}

T2 seedlings of transgenic clones (T5 and T9) grown in vitro under complete darkness were indistinguishable from those corresponding non-transgenic control seedlings (Fig. 3.4). However, a significant inhibition of hypocotyl elongation was observed with in vitro transgenic seedlings when grown under 16/8 hours day/night light condition. This inhibition caused a pronounced short hypocotyl phenotype amongst transgenic seedlings (Fig.3.5). 


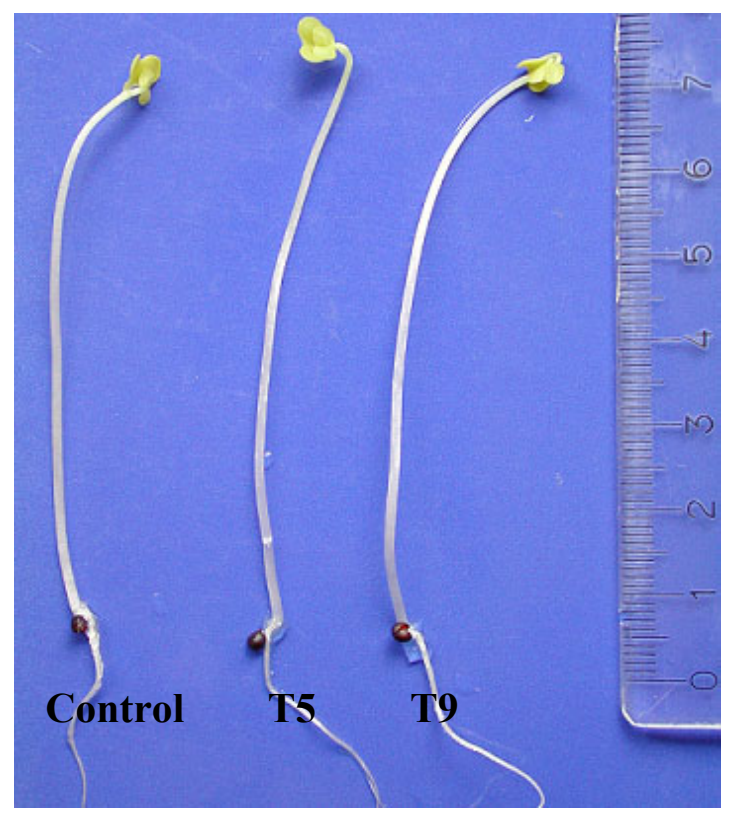

Figure 3.4. Appearance of transgenic and non-transgenic seedlings grown under continuous darkness for 7 days. C: non-transgenic control, T5(2) and T9(2): representative seedlings from two transgenic lines.

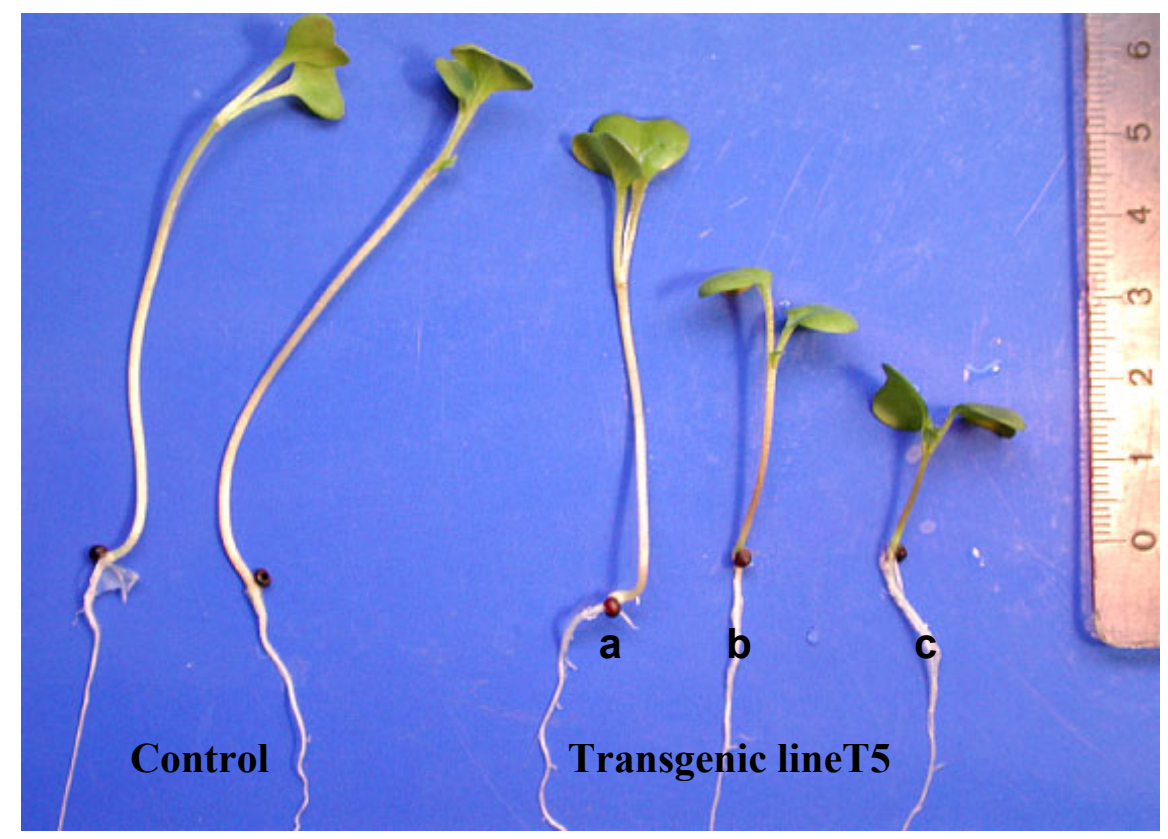

Figure 3.5. Appearance of non-transgenic and transgenic seedlings following 7 days of growth under white light regime of 16/8 hours day/night. From left to right, representative seedlings from non-transgenic control and seedlings from transgenic line T5(2) showing different degree of hypocotyl elongations (a: long, b: intermediate and c: short). 
Transgenic seedlings had three height groups; long seedlings which were indistinguishable from non-transgenic control seedlings (Fig. 3.5a), intermediate tall seedlings (Fig. 3.5b) and short seedlings (Fig. 3.5c). Short hypocotyls seedlings were characterized by fully expanded cotyledons and increased anthocyanine pigmentation at hypocotyls and at lower surfaces of cotyledons. Intermediate tall and short seedlings were grouped together and termed as short hypocotyl seedlings.

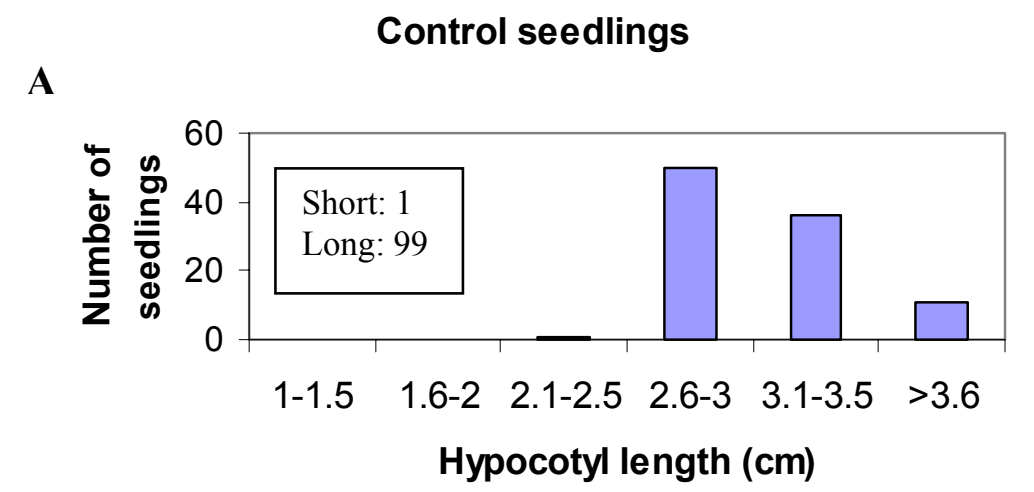

B T5(2) seedlings

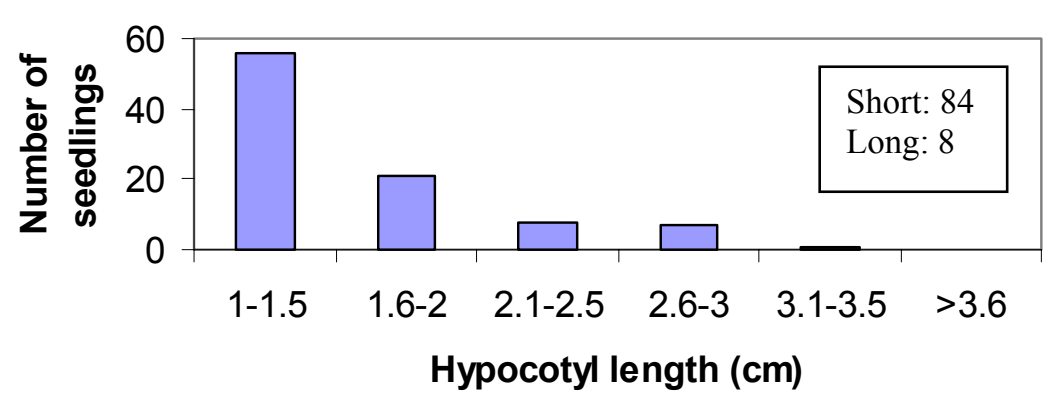

C T9(2) Seedlings

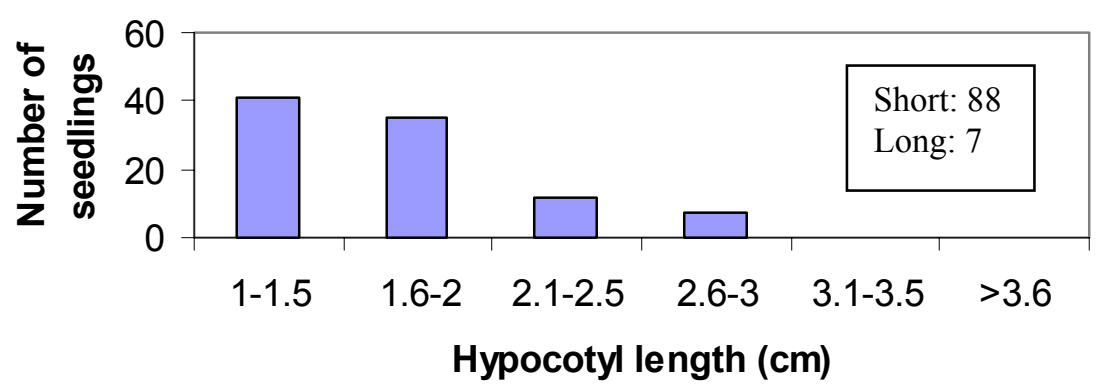

Figure 3.6. Hypocotyl length distribution of 7 days old in vitro grown seedlings of two transgenic lines; T5 (B) and T9 (C), and non-transgenic control seedlings (A). Absolute numbers of short and long hypocotyl seedlings are in the inserted box 
$99 \%$ of non transformed seedlings had a hypocotyl length of $>2.5 \mathrm{~cm}$ (Fig. 3.6A). A bimodal distribution of hypocotyl length was observed in transgenic line T5(2), with approximately $91 \%(84)$ of seedlings having hypocotyl length of $<2.5 \mathrm{~cm}$ and $9 \%(8)>2.5$ $\mathrm{cm}$ (Fig. 3.6B). The same tendency was observed with seedlings of transgenic line T9(2) in which 93\% (88) showing short hypocotyls $(<2.5 \mathrm{~cm})$ and $7 \%(8)$ showing long hypocotyls $(>2.5 \mathrm{~cm})$ (Fig. 3.6C).

\subsubsection{Kanamycin sensitivity of $\mathrm{T} 2$ seedlings}

In vitro grown transgenic seedlings segregating for a short hypocotyl phenotype also segregated for kanamycin resistance. Upon transfer into MS medium supplemented with $100 \mathrm{mg} / 1$ kanamycin, short hypocotyls seedlings showed resistance and grew further while those tall seedlings were kanamycin sensitive and died without further growth. Inheritance of kanamycin resistance gene amongst T2 seedlings indicated the presence of two transgenic copies in each of the transgenic line. As calculated chi-square $\left(\chi^{2}\right)$ values were below the tabulated value at $\mathrm{P}=0.05$, the null hypothesis of 15:1 segregation ratio could not be rejected (Table 3.5).

Table 3.6. Transgenic T2 seedlings segregating for kanamycin resistance

\begin{tabular}{lcccc}
\hline Line & Kan. ${ }^{\mathrm{S}}$ & Kan. $^{\mathrm{R}}$ & Segregation $\left(\chi^{2}\right)$ & Copy number \\
\hline $\mathrm{T} 5(2)(\mathrm{n}=92)$ & 5 & 87 & $15: 1\left(\chi^{2}=0.5\right)$ & 2 \\
$\mathrm{~T} 9(2)(\mathrm{n}=95)$ & 9 & 88 & $15: 1\left(\chi^{2}=0.1\right)$ & 2 \\
Control $(\mathrm{n}=100)$ & 100 & 0 & - & - \\
\hline
\end{tabular}

$\chi^{2}=3.84(5 \%, 1 \mathrm{DF})$

Amplification of total DNA extracted from ten shortest seedlings and ten intermediate tall seedlings (they were selected out from a seven days old, in vitro grown seedling population of 100 seedlings derived from transgenic line T5) with phyB primers resulted in an expected 800 bp band with all the seedlings tested. Amplification of total DNA extracted from ten tallest seedlings from the same population with phyB primers resulted in no amplification product with seven seedlings while three (shortest among the selected ten) showed the $800 \mathrm{bp}$ band (Fig 3.7). 


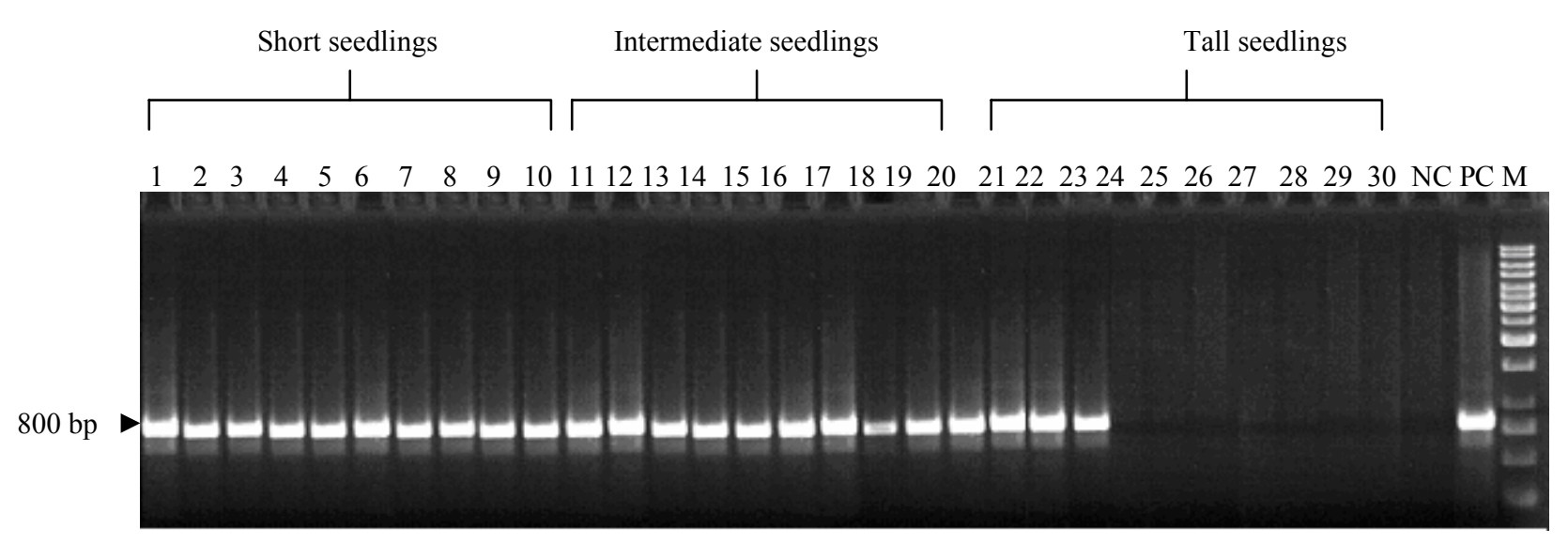

Figure 3.7. PCR analysis of total DNA amplified with Arabidopsis PHYB primers.

Lanes: 1 to 30 DNA extracted from selected in vitro grown seedlings of transgenic line T5(2). Seedlings are arranged in the ascending order, the shortest (lane 1) to the tallest (lane 30). NC: DNA from a untransformed seedling (negative control), PC: DNA from plasmid p35SA.thPhyB (positive control), M: DNA size marker

PCR analysis of selected greenhouse grown T2 plants (selection criteria was seedling height after one week) showed that $P H Y B$ gene was present in majority of plants. Contrary to the results obtained with in vitro grown seedlings, selected shortest and tallest plants from T5(2) and T9(2) populations grown under greenhouse conditions were shown to be equally transgenic (Table 3.7). Out of 20 selected tallest plants, 19 from T5(2) and all twenty from T9(2) 19 showed the presence of PHYB gene after PCR analysis.

Table 3.7. PCR detection of $P H Y B$ gene in greenhouse grown selected tall and short T2 plants

\begin{tabular}{lll}
\hline Line & PHYB $^{+}$seedlings & PHYB $^{-}$seedlings \\
\hline T5(2) selected tallest $(\mathrm{n}=20)$ & 18 & 2 \\
T5(2) selected shortest $(\mathrm{n}=20)$ & 19 & 1 \\
T9(2) selected tallest $(\mathrm{n}=20)$ & 20 & 0 \\
T9(2) selected shortest $(\mathrm{n}=20)$ & 19 & 1 \\
\hline
\end{tabular}

$\mathrm{n}=$ number of plants analysed 


\subsubsection{Plant height of $T 2$ transgenic plants}

Nineteen plants out of the 206 plant population of transgenic line T5(2) showed a phenotype and development distinct from the rest of the plants in the population. These 19 plants attained flowering much later than the rest of the 187 plants and were thus termed 'late-flowering' and described separately in comparisons. Nevertheless, these plants grew within the 206 plant population from the time of sowing until plants attained full maturity. After two weeks of growth under greenhouse conditions, seedlings of transgenic line T5(2) showed a significant height reduction than controls (Table 3.8).

Table 3.8. Comparison of plant height of $\mathrm{T} 2$ plant population at different developmental stages

\begin{tabular}{lcccc}
\hline & $\begin{array}{c}\text { Seedling height } \\
\text { Line }\end{array}$ & \multicolumn{3}{c}{ Plant height $(\mathrm{cm})$} \\
& $\begin{array}{c}\text { after two weeks } \\
\text { (cm) }\end{array}$ & At bolting & At flowering & At maturity \\
\cline { 3 - 5 } & & & & \\
\hline T5(2) population & $1.8^{*}$ & $18.4^{*}$ & $37.3^{*}$ & $107.0^{*}$ \\
$(\mathrm{n}=187)$ & $(0.5)$ & $(8.2)$ & $(9.1)$ & $(23.4)$ \\
Late-flowering plants of & $1.9^{*}$ & $18.7^{*}$ & $35.1^{*}$ & $81.4^{*}$ \\
T5(2) population (n=19) & $(0.6)$ & $(5.3)$ & $(6.2)$ & $(15.3)$ \\
Control & 3.2 & 23.0 & 46.4 & 110.9 \\
$(\mathrm{n}=30)$ & $(0.5)$ & $(3.1)$ & $(5.3)$ & $(11.2)$ \\
\hline T9(2)selected (tallest) & 2.4 & 21.7 & 45.5 & 113.0 \\
$(\mathrm{n}=50)$ & $(0.4)$ & $(8)$ & $(11.4)$ & $(17.5)$ \\
T9(2)selected (shortest) & $1.1^{*}$ & $16.0^{*}$ & $33.7^{*}$ & $92.8^{*}$ \\
$(\mathrm{n}=50)$ & $(0.2)$ & $(16.3)$ & $(9.6)$ & $(21.4)$ \\
Control & 2.7 & 24.6 & 50.2 & 110.7 \\
$(\mathrm{n}=10)$ & $(0.3)$ & $(4.3)$ & $(5.1)$ & $(10.7)$ \\
\hline Valnes & & & & \\
\hline
\end{tabular}

Values are means and standard deviations given in brackets, $n=$ number of individual plants * denotes a statistically significant difference from the control at $\mathrm{P}=0.05$

At the time of bolting (emergence of the main raceme) and at first flowering (appearance of first open flower), transgenic plants, except those selected tallest plants of the $T 9(2)$ population (selection criteria was seedling height after one week), displayed a significantly reduced plant height. For T5(2) population of 187 plants, reduction in plant height at first 
flowering was $20 \%$ when compared with non-transgenic control plants. Selected shortest T9(2) plants displayed a marked reduction in plant height at first flowering than corresponding control plants and the difference was 33\% (Table 3.8). No significant difference was observed between selected tallest T9(2) plants and the control plants. The difference in plant height between transgenic and control plants became narrow when plants attained maturity. Selected tallest plants grew even taller than the control plants. Nevertheless, those selected shortest plants of T9(2) population and 19 late-flowering plants of the T5(2) population remained significantly shorter than the controls after plants attained full maturity. Reduction in plant height of late-flowering plants at maturity was $27 \%$ than the controls (Table 3.8 )

\subsubsection{Bolting, first flowering and duration of flowering in $\mathrm{T} 2$ plants}

Bolting occurred about one week earlier for control plants than transgenic plants, in both lines, T5 and T9. Consequently, first flowering also took place about one week later for transgenic plants. There was no significant difference in the duration of flowering between transgenic and control plants (Table 3.9). However, the above mentioned 19 late-flowering plants out of the population of 206 T5(2) plants, displayed an extremely delayed bolting and first flowering. Bolting in these plants occurred at a mean of 114 days from sowing, at such time contemporaries from the same population attained full maturity (marked by siliques turning yellowish-brown), and first flowering occurred at a mean of 127 days (Table 3.9). 
Table 3.9. Comparison of days taken for bolting, first flowering and duration of flowering, in $\mathrm{T} 2$ transgenic plants

\begin{tabular}{|c|c|c|c|}
\hline Line & $\begin{array}{l}\text { Bolting } \\
\text { (days) }\end{array}$ & $\begin{array}{l}\text { First flowering } \\
\text { (days) }\end{array}$ & $\begin{array}{c}\text { Duration of } \\
\text { flowering (days) }\end{array}$ \\
\hline T5(2) population $(n=187)$ & $\begin{array}{l}42.6^{*} \\
(8.6)\end{array}$ & $\begin{array}{l}52.6 \\
(8.9)\end{array}$ & $\begin{array}{l}25.8 \\
(3.6)\end{array}$ \\
\hline T5(2) Late-flowering $(\mathrm{n}=19)$ & $\begin{array}{l}114.2 * \\
(19.6)\end{array}$ & $\begin{array}{l}126.6^{*} \\
(18.3)\end{array}$ & $\begin{array}{l}25.5 \\
(1.7)\end{array}$ \\
\hline Control $(n=30)$ & $\begin{array}{l}34.5 \\
(2.4)\end{array}$ & $\begin{array}{l}48.9 \\
(3.4)\end{array}$ & $\begin{array}{l}23.9 \\
(2.8)\end{array}$ \\
\hline T9(2) selected (tallest) $(\mathrm{n}=50)$ & $\begin{array}{l}44.2 * \\
(10.2)\end{array}$ & $\begin{array}{l}58.0^{*} \\
(11.1)\end{array}$ & $\begin{array}{l}24.6 \\
(1.9)\end{array}$ \\
\hline T9(2) selected (shortest) $(n=50)$ & $\begin{array}{r}43.2^{*} \\
(8.4)\end{array}$ & $\begin{array}{l}51.2 \\
(8.4)\end{array}$ & $\begin{array}{l}24.6 \\
(3.6)\end{array}$ \\
\hline Control $(n=10)$ & $\begin{array}{l}36.8 \\
(1.8)\end{array}$ & $\begin{array}{l}48.1 \\
(1.6)\end{array}$ & $\begin{array}{l}25.5 \\
(3.5)\end{array}$ \\
\hline
\end{tabular}

Values are means and standard deviations given in brackets, $n=$ number of individual plants

* denotes a statistically significant difference from the control at $\mathrm{P}=0.05$

\subsubsection{Phenotypic characteristics of late-flowering plants}

Apart from the unusual delayed flowering, the 19 late-flowering plants exhibited distinct dissimilarities in basic plant architecture when compared with other 187 plants in the same plant population and with those non-transgenic control plants. Average plant height, as measured at the $90^{\text {th }}$ day after sowing, was $17.5 \mathrm{~cm}$. At this stage the surrounding plants had reached a plant height of about $100 \mathrm{~cm}$ or more, and already were in a mature stage of plant development. All late-flowering plants showed reduced apical dominance with excessive branching where 2-3 parallel branches originated from the basal part of main stem and grew concurrently with the main stem. When these plants attained flowering, 2-3 blooming racemes could be seen (Fig. 3.8). 


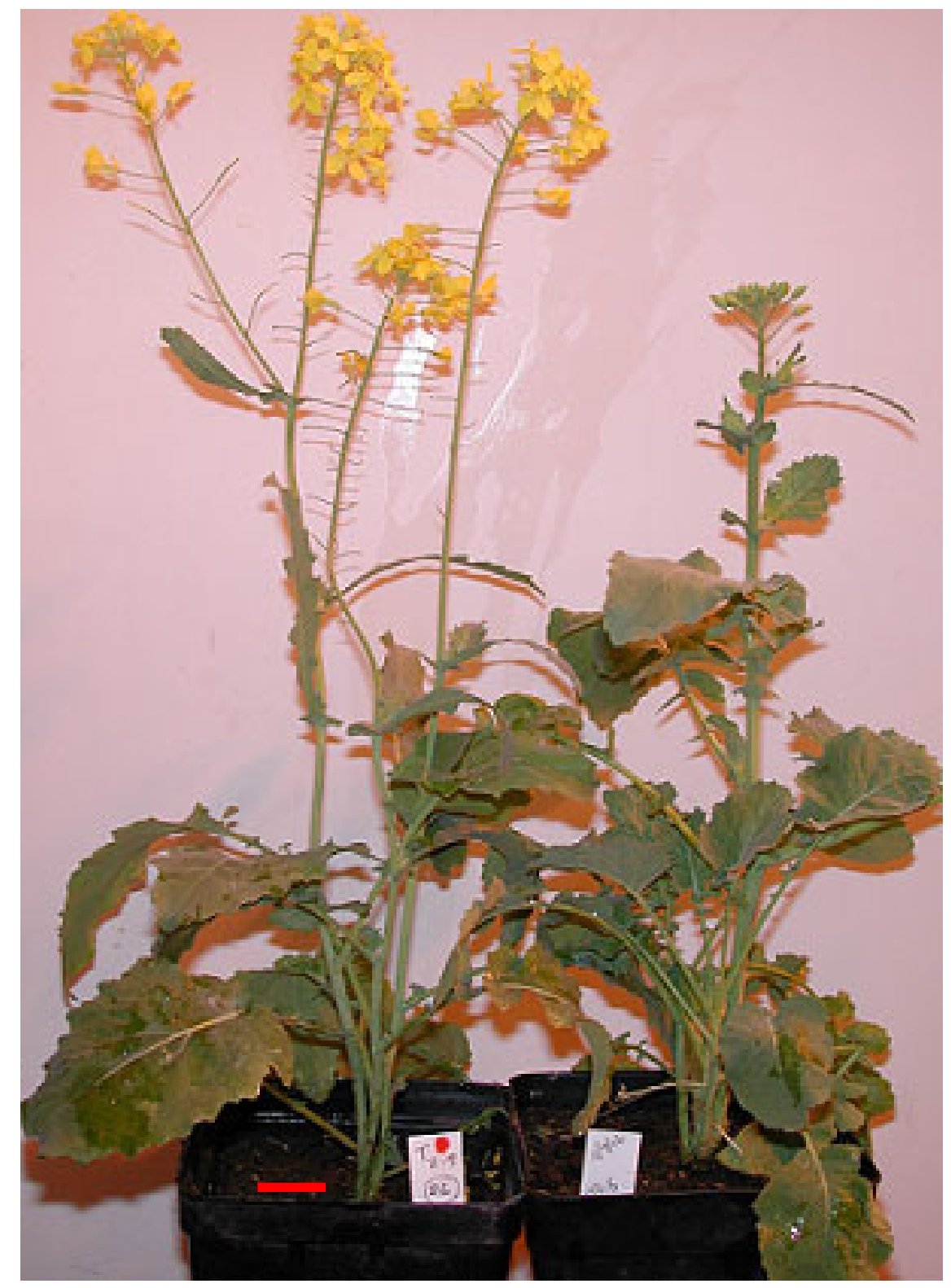

Figure 3.8. Two late-flowering plants of T9(2) (left) and T5(2) (right) transgenic lines showing excessive branching and higher number of leaves. Scale bar $=2 \mathrm{~cm}$

Late-flowering plants had comparatively smaller leaves, but the average number of leaves per plant at bolting and at first flowering was significantly higher than controls (Table 3.9). After neighbouring plants reached full maturity (at about 90 days from sowing) and their shading effects were diminished, late-flowering plants gained a thrust in plant growth, with increased branches, leaves and eventually entered from vegetative to reproductive state. Amplification (with $P H Y B$ primers) of total DNA extracted from these late-flowering plants revealed that Arabidopsis PHYB gene is present in all 19 plants tested. 
Table 3.10. Leaf chlorophyll content and average number of leaves per plant at bolting and at first flowering, in $\mathrm{T} 2$ transgenic plants

\begin{tabular}{lcccc}
\hline Line & \multicolumn{2}{c}{ Leaf chlorophyll content ${ }^{\mathrm{a}}$} & \multicolumn{2}{c}{ Average leaves per plant } \\
\cline { 2 - 5 } & at bolting & at flowering & at bolting & at flowering \\
\hline T5(2) population (n=187) & $44.2^{*}$ & $43.2^{*}$ & $6.6^{*}$ & $8.7^{*}$ \\
& $(3.4)$ & $(4.6)$ & $(1.3)$ & $(1.1)$ \\
T5(2) Late-flowering (n=19) & $47^{*}$ & $46^{*}$ & $9.6^{*}$ & $12.5^{*}$ \\
& $(2.7)$ & $(2.3)$ & $(2.1)$ & $(1.3)$ \\
Control (n=30) & 40.1 & 38.6 & 5.8 & 7.5 \\
& $(2.4)$ & $(2.2)$ & $(1.2)$ & $(1.4)$ \\
\hline T9(2)selected (tallest) $(\mathrm{n}=50)$ & $44.6^{*}$ & $43.8^{*}$ & 6.8 & $9.5^{*}$ \\
& $(3.6)$ & $(2.3)$ & $(1.2)$ & $(1.1)$ \\
T9(2)selected (shortest) $(\mathrm{n}=50)$ & $45.3^{*}$ & $45.0^{*}$ & 6.8 & $8.9^{*}$ \\
& $(2.2)$ & $(2.5)$ & $(1.3)$ & $(1.2)$ \\
& 41.5 & 37.8 & 6.4 & 7.9 \\
& $(2.3)$ & $(2.1)$ & $(1.4)$ & $(1.2)$
\end{tabular}

\footnotetext{
Values are means and standard deviations given in brackets, $\mathrm{n}=$ number of individual plants. ${ }^{\mathrm{a} C h l o r o p h y l l ~ c o n t e n t ~ r e p r e s e n t e d ~ b y ~ t h e ~ m e a s u r e d ~ S P A D ~ v a l u e ~}$ * denotes a statistically significant difference from the control at $\mathrm{P}=0.05$
}

Leaf chlorophyll content was significantly higher in transgenic plants than non-transgenic controls, which reached a maximum value at the time of bolting and started to decrease instantaneously when plants attended flowering. The highest average chlorophyll content was observed with late-flowering plants (Table 3.10). Chlorophyll degradation was fairly a decelerated process in the transgenic plants when compared with non-transgenic control plants, a phenomenon also observed with greenhouse grown primary transformants (T1plants). 


\subsection{Discussion}

The pronounced inhibition of hypocotyl elongation observed with in vitro seedlings (under light conditions) in this study resembles the short hypocotyl phenotype described for lightgrown transgenic tobacco seedlings (McCormac et al. 1993a, Halliday at al. 1997) and with transgenic Arabidopsis seedlings (Wagner et al. 1991), overexpressing either an Arabidopsis or a rice $P H Y B$ gene under the control of CaMV35S promoter. The short hypocotyl phenotype is strictly light-dependent as no significant difference in hypocotyl length was observed between transgenic and non-transgenic seedlings, when grown in complete darkness (see Fig 3.4). This observation is in agreement with Wagner et al. (1991) and Halliday et al. (1997). Exhibition of a light-dependent short hypocotyl phenotype in $B$. napus seedlings in this study could therefore be considered as an indirect proof of a successful integration of the Arabidopsis PHYB gene into the B. napus genome and production of biologically active phyB. Overexpression of oat PHYA cDNA in Arabidopsis (Bagnall et al. 1995) and in tobacco (Halliday et al. 1997) has also resulted in exaggerated shorting of hypocotyls, indicating both phytochromes, A and B, are capable of regulating hypocotyl elongation. However, more detailed physiological analysis of overexpressers and mutants have revealed distinct photosensory roles for these two phytochromes. Transgenic seedlings of tobacco and Arabidopsis overexpressing an oat PHYA cDNA displayed an enhanced sensitivity to prolonged exposure to FR with respect to the inhibition of hypocotyl elongation (McCormac et al. 1992, Whitelam et al. 1992). In contrast, transgenic Arabidopsis seedlings overexpressing either Arabidopsis or rice PHYB cDNA displayed wild-type responsiveness to prolonged FR, as do seedlings of the phyB mutant (McCormac et al. 1993a). Hence, responsiveness to prolonged FR would appear to be an intrinsic property of phyA which is not shared by phyB. The photophysiology of transgenic seedlings overexpressing a particular type of phytochrome appears to be the exact opposite of the photophysiology of mutants that are null for the same phytochrome. For instance, etiolated Arabidopsis seedlings overexpressing PHYB cDNAs displayed increased sensitivity to red light, with respect to the inhibition of hypocotyl elongation, which is in contrast with the selective lack of responsiveness to red light displayed by the phyB deficient $p h y B$ mutants (McCormac et al. 1993a). This complementary effect is not limited for hypocotyl elongation, but also for some other important photoresponses such as seed germination, chloroplast and leaf development, stem elongation and flowering (Reed et al.1993, McCormac et al. 1993b, Bagnall et al. 1995). 
The ein mutant in B. rapa was found to be partially dominant, where heterozygous EIN/ein seedlings displayed an elongation response which was intermediate between EIN/EIN (wild type) and ein/ein (mutant homozygous), under white light culture conditions (Devlin et al. 1997). EIN/ein was found to contain about 50\% of the level of immunochemically detectable phyB of equivalent wild type EIN/EIN seedlings. These observations provide evidence that the level of functional phyB produced is proportional to the number of copies of the PHYB gene present in the plant. In the same way, the photoresponses of the plant are proportional to the amount of biologically functional phyB. It appears that the amount of phyB produced by wild type $P H Y B$ allele is poised at a concentration that allows a plant the maximum sensitivity to changes in the light environment. Thus, any change to this steady state level of phyB could result in large elongation growth response under low R:FR ratio in which phyB is active.

Transgenic seedlings segregating for kanamycin resistance indicated the presence of two copies of the transgene (Arabidopsis PHYB) in each transgenic line, T5 and T9 (Table 3.6). Therefore, in the segregating plant population, there would be one non-transgenic plant for every 15 transgenic plants and one homozygous $(P H Y B / P H Y B)$ transgenic plant for every fourteen heterozygous $(P H Y B /-)$ transgenic plants. In this study, transgenic B. napus seedlings (grown in vitro under white light) segregating for short hypocotyls phenotype consisted of very short, intermediate and long hypocotyl seedlings (Fig. 3.5). The PCR analysis confirmed that all short and intermediate tall seedlings germinated in vitro were carrying the transgene while those displaying a hypocotyl elongation similar to nontransgenic control seedlings, did not (Fig. 3.7). Those intermediate seedlings could therefore be the heterozygous seedlings whilst those shortest could be homozygous. The amount of hypocotyl elongation (in this study under in vitro conditions) could be a true reflection of the genotypic state of transgenic seedlings, thus could be used as a phenotypic marker to identify potential transgenic plants. These observations are in agreement with findings of those of Devlin et al. (1997), where hypocotyl elongation was proportional to the number of $P H Y B$ gene copies present in the plant and the amount of phyB produced. However, success with such a selection criterion seems reliant on certain optimal culture conditions, such as intensity of light provided, duration of the light regime and culture temperature, since selected short and long hypocotyl seedlings in this study, under 
greenhouse conditions without controlled environment, proved to be equally transgenic (Table 3.7).

Contrary to greenhouse grown plants, T1 transgenic plants and corresponding nontransgenic plants did not show a noteworthy difference in plant height under in vitro culture conditions (however this was not studied in vitro in a replicated trial). The same observation has been made with transgenic potato (overexpressing Arabidopsis PHYB cDNA) grown under in vitro conditions where no significant difference in plant height was noted between transgenic and wild type plants (Thiele et al. 1999).

In the greenhouse, primary transformants ( $\mathrm{T} 1$ plants) showed $24 \%$ height reduction at flowering when compared with non-transgenic controls, but it was reduced to $20 \%$ at maturity (Table 3.4 ). In the T5(2) population, there was $22 \%$ and $20 \%$ height reduction at bolting and first flowering, respectively, but this dwarf nature was indeed provisional since at maturity transgenic plants averaged $96 \%$ of the non-transgenic control plants (Table 3.4). Similar results have been observed with transgenic potato overexpressing Arabidopsis $P H Y B$, under greenhouse conditions where the early semidwarf nature of transgenic plants diminished when plants attained maturity (Thiele et al. 1999, Schittenhelm et al. 2004). Observed increment in average plant height in the T5(2) plant population could be to some extent, due to the contribution by some elongated plants in the population. Since T5(2) represents a segregating plant population for transgene PHYB, it is composed of heterozygous, homozygous as well as non-transgenic plants. It is reasonable to assume that, non-transgenic plants, under dense plant population, would resort to typical shade avoidance responses, such as stem elongation and early flowering, to gain an upper hand over the other plants, thus creating an asymmetrical type of competition within the population. This asymmetrical competition may have stimulated transgenic plants to 'forage for light' by resorting to shade avoidance responses. However, it is obvious that transgenic plants responded to shade much later than those non-transgenic plants. This late response to shade is evident by the fact that transition from vegetative to reproductive state in transgenic plants occurred much later than in non-transgenic plants. The reason could be that increased phyB level in transgenic plants (as a results of overexpression) is capable of alleviating shading effects until the R:FR ratio drops under a certain threshold. This means increased phyB pool neither completely disables nor eliminates shade avoidance responses of transgenic plants, rather it restrains or delays shade avoidance responses. 19 lateflowering plants observed with T5(2) plants population could represent the homozygous 
fraction of the segregating population. Late-flowering plants may possess more $P H Y B$ gene copies and consequently could produce more functional phyB than those heterozygous counterparts. Increased concentration of phyB in late-flowering plants, could efficiently restrain shade avoidance responses much longer, even under a very low R:FR ratio. This is evident by the fact that, late-flowering plants remained in the vegetative state much longer than rest of the plants and resort to flowering only after the shade by the neighbouring plants is considerably reduced. Late-flowering plants remained significantly shorter than control plants at all developmental stages (Table 3.8). Similarly selected shortest plants of T9(2) population also remained significantly shorter than control plants at all times and reached only $83 \%$ of the non-transgenic plants at maturity. This may be a consequence of initial selection (even though it was found to be unsuccessful under the greenhouse conditions, Table 3.7 ), which may have allocated more potential homozygous plants into this group which remained significantly shorter reducing the average plant height at maturity.

Most of phenotypical and phenological changes which could be directly linked to $P H Y B$ overexpression were confined mainly to leaves, as it was observed in this study as well as in previous studies with transgenic potatoes (Thiele et al. 1999, Schittenhelm et al. 2004) and tobacco (Robson et al. 1996). Leaves of T1 plants were significantly thicker, heavier and yet comparatively smaller than those from non-transgenic control plants. Anatomical studies of leaves in transgenic potatoes overexpressing $P H Y B$ have revealed that increased leaf thickness was basically due to the increased length of palisade cells in leaf mesophyll, which were 19-30\% longer than the wild type palisade mesophyll cells (Thiele et al. 1999). Increased fresh leaf weight per unit area in transgenic plants in this study may be a direct consequence of thicker leaves and increased production of assimilates in leaves. Further studies, preferably with homozygous plants, would be necessary to establish whether increased thickness and fresh leaf weight is contributing positively to increase the total biomass of transgenic B. napus plants. In such a study, dry leaf weight would be a more reliable index than fresh leaf weight. A close relationship was observed between flowering time and number of leaves per plant. Plants that flowered late had a higher number of leaves than those plants flowered earlier. For instance, late-flowering plants had significantly a higher number of leaves than non-transgenic plants at bolting or at first flowering (Table 3.10). A similar observation has been made with transgenic phyB overexpressing Arabidopsis plants in which late-flowering plants (due to a low-fluence end 
of the day light treatment) were having significantly higher number of rosette leaves than those early flowering plants (Bagnall et al. 1995). Hence, increased leaf number could be a direct consequence of the prolonged vegetative phase experienced by transgenic plants.

Leaf chlorophyll content of transgenic plants remained significantly higher than nontransgenic plants, a trait that was observed in all transgenic plants in common. The highest concentration of leaf chlorophyll was registered by those late-flowering plants, which was $18 \%$ higher than the controls (Table 3.10). Chlorophyll degradation (initiated when plants shifted from vegetative to reproductive state) occurred at a much decelerated rate in transgenic plants than controls (Fig. 3.3). In transgenic potato, a decreased rate of chlorophyll degradation and 35\% more leaf chlorophylls production have been reported, when $P H Y B$ is overexpressed (Thiele et al. 1999). Transgenic tobacco plants overexpressing PHYA, has yielded 30\% more chlorophyll per unit leaf area than controls (Robson and Smith 1997). It has been well established that, synthesis of chlorophyll $a$ and $b$ is closely related with the far red absorbing form of phytochromes (Pfr) (Oelze-Karow and Mohr 1981). It is reasonable to suppose that, increased production of Pr due to phyB (or phyA) overexpression could elevate the total Pfr pool after absorbing red light during the day time. Pfr is involved in accumulation of an important upstream component (5aminolevulinate) of chlorophyll biosynthesis pathway which stimulates a higher production of chlorophyll (Kasemir and Mohr 1981). A higher photosynthesis rate in leaves of transgenic potatoes (overexpressing phyB) has been reported, where increased photosynthesis rate is proportional to the amount of chlorophyll produced (Thiele et al. 1999). However, the benefits of excess chlorophyll production would depend largely on the characteristics of chloroplast produced, since aberrant chloroplasts produced in transgenic tobacco overexpressing phyA, has hampered the photosynthesis performance of transgenic plants (Sharkey et al. 1991). How this increased chlorophyll pools effects photosynthesis performance in transgenic B. napus plants merits further investigations.

In Arabidopsis, it has been found that phyA and phyB regulate-flowering time in antagonistic manner. PhyA, which discriminates short days from long days, weakly promotes flowering in long day conditions whereas phyB acts to delay flowering under both long and short day conditions (Mouradov et al. 2002, Cerdán and Chory 2003). It has been suggested that phyB could have an inhibitory effect on PHYTOCHROME AND FLOWERING TIME1 or PFT1, a protein that supposed to act downstream of phyB, which 
could otherwise activate its downstream target FT (Flowering Locus T) (Cerdán and Chory 2003). In Arabidopsis phyB mutants, flowering has been accelerated due to the lack of functional phyB (Reed et al. 1993, Devlin et al. 1997). If the effects of overexpression are the antithesis of null-mutants (which was the case for other photomorphogenic responses such as, stem elongation and chlorophyll development) a late-flowering could be anticipated in phyB overexpressers. However, this was not clearly established in other studies carried out with phyB overexpressers and response to flowering may be speciesspecific. No significant difference in flowering has been observed between transgenic and wild type potato plants overexpressing phyB (Thiele et al. 1999). In transgenic Arabidopsis, phyA overexpressers flowered earlier under a high R:FR ratio, while phyB overexpressers exhibited a wild type response to flowering (Bagnall et al. 1995). Contrary to these observations, phyA and phyB overexpressors of day sensitive tobacco (short-day) have demonstrated an exaggerated delay in flowering (up to 8 months) under long day conditions than the wild type plants while under sort day conditions phyB overexpressors showed no significant difference than corresponding wild type plants. In response to a $30 \mathrm{~min}$ night break, phyB overexpressors caused a significant delay in flowering (Halliday et al. 1997). These observations demonstrate that responses to flowering depend mainly on the type of radiation provided and photoperiod to which plants was exposed. Apart from light signals, temperature is found to be the other most important environmental factor that regulates flowering time (Simpson and Dean 2002). It has been found that early flowering phenotype of phyB mutant in Arabidopsis was temperature dependent. When grown under constant temperature of $22^{\circ} \mathrm{C} p h y B$ showed an early flowering, while those $p h y B$ mutant plants grown under $16^{\circ} \mathrm{C}$ were late-flowering under both SD and LD conditions (Halliday et al. 1997). In this study flowering was significantly delayed in supposed homozygous B. napus plants (described as late-flowering plants), presumably with high phyB concentrations. Delayed flowering in these plants could be due to increased phyB pools, which would have down-regulated FT in a similar biological pathway described by Cerdán and Chory (2003). However, the effect of phyB overexpression seems mostly on flowering time but not on the duration of flowering, as no significant difference in duration of flowering was observed between late-flowering and corresponding controls plants (Table 3.9). In this study T1 transgenic plants flowered about one week earlier than controls (Table 3.4). The reason here could simply be a maturity or environmental effect rather than any detrimental effect by phyB to cause an early flowering. On the other hand the origin of T1 and T2 plants is also different, since T1 plants were vegetatively propagated while T2 were seed raised. 
Therefore flowering times of T1 and T2 plants could not be directly compared. Whether late-flowering phenotype observed in this study was a true manifestation of phyB overexpression or whether it is due to any other environmental factor, such as light intensity or temperature could be well established under controlled environmental conditions.

Nineteen late-flowering $B$ napus plants in this study, displayed the most of classical pleiotropic effects described previously for potato (Thiele et al. 1999) and tobacco (Halliday at al. 1997) after phyB overexpression. These included decreased apical dominance, excessive branching, small but large number of leaves and increased chlorophyll production which are the antithesis of null mutants of PHYB. However, these pleiotropic effects were not straightforward in T1 plants and 187 transgenic plants in the T2 segregating population. The main reason for this could be that, the endogenous production of phyB in these transgenic plants would not have been sufficient enough to make a big impact on biological and physiological processors of the plant to make drastic changes to the basic plant architecture. In transgenic potato, pleiotropic effects were found to be predominant in strong phyB overexpressing line Dara-12 but not in the moderately expressing line Dara-5 (Thiele et al. 1999). In a similar observation with Arabidopsis, photomorphogenic responses were closely related to the number of $P H Y B$ copies which in turn is proportional to the immunochemically detectable phyB level in the transgenic plants (Wester et al. 1994). These observations suggest a strong correlation between number of $P H Y B$ copies, amount of phyB produced and expression of pleiotropic effects.

Shade avoidance responses could be beneficial for individual plants in their natural environment, but could be deleterious for the growth of the crop in monoculture in modern agricultural setup. Despite strong selection for better yield, modern crops still react to a drop in photon fluence rate resorting to shade avoidance responses such as stem and petiole elongation (Ballaré et al. 1997). It is assumed that these elongation responses might tap assimilates that the plant would otherwise allocate to agronomically important storage organs. Therefore it has been proposed that disablement of shade avoidance responses or producing plants which are less sensitive to a low R:FR ratio would pay off to increase agricultural productivity, by reducing the wasteful resources allocation for stem elongation (Smith 1995, Ballaré et al. 1997). Transgenic manipulation of relative levels of phyA and phyB can markedly modify the allocation of assimilates in crop plants in the field has often 
been suggested; however experimental support for this is still emerging. Transgenic potatoes overexpressing phyB has resulted in higher photosynthesis performance, greater biomass production and extended underground organs with increased tuber yields (Thiele at al. 1999). In a separate study using the same transgenic plant materials Schittenhelm et al. (2004) reported most of the observations of Thiele at al. (1999) but found no significant difference in tuber and total biomass between transgenic and non-transgenic plants. In the present study, transgenic $B$. napus plants overexpressing phyB resulted in a higher number of relatively thicker leaves with higher chlorophyll content (Table 3.3). Number of seeds per silique in two transgenic lines; T5(1) and T9(1) was significantly higher than corresponding control plants (Table 3.4). However, there was no significant difference in seed yield per plant between transgenic and control plants. Thousand kernel weight was significantly lower in transgenic plants than in the controls (Table 3.4). These observations suggest that, even though there was an increase in number of seeds produced by transgenic plants, the actual size of a single seed is becoming smaller than those of controls. In other words, seed number in transgenic plants increased more than the seed yield with the consequent reduction in weight per seed. A similar observation has been reported with phyB overexpressing transgenic potatoes where transgenic plants resulted in higher number of small tubers with reduced weight (Boccalandro et al. 2003). It seems that phyB overexpression results in an increase number of sinks in transgenic plants. It has been suggested that increased photosynthesis observed with transgenic potato phyB overexpressers could be to meet the higher demand for assimilates by increased number of tubers (Boccalandro et al. 2003).

PhyB overexpression in B. napus had no significant effect on major seed storage components such as oil and protein content. Results obtained in this study also do not provide conclusive evidences to prove the hypothesis that phyB overexpression allocate more resources to reproductive and storage organs. The observed low response to shade displayed by transgenic B. napus plant in this study could pay off to improve total biomass of individual plants under increased planting densities, as a consequence of increased production of photosynthetically active leaves. PhyB overexpressing potatoes has resulted in increased tuber yield under high planting densities (Boccalando et al. 2003). When grown at low planting densities, transgenic tobacco expressing an oat PHYA cDNA and wild type had similar architecture, but when planting density was increased the transgenic PHYA expressers became shorter displaying less shade avoidance responses than wild type, 
which showed a greater response to shade at the expense of leaf development (Smith 1995). These observations suggest that best performance of phytochrome overexpressers could only be achieved at higher planting densities. Phytochrome overexpressers could therefore be used in breeding programs to shift optimum crop densities to higher values and to achieve an increase in number of individual plants per unit area, which may possibly result in proportional increment in crop yield.

In spite of possible advantages of disturbed photomorphogenic response by phytochrome overexpression, several negative effects have also been outlined. It has been found that plants lacking normal responses to R:FR ratio could simultaneously fail to optimize the positioning of light harvesting organs (Ballaré et al. 1997). Disabled shade avoidance of plants may be disadvantageous when facing intraspecific competition at high planting densities where FR insensitive plants undergo size structuring, which results in an asymmetrical type of competition within the plants population. This increased size structuring has shown to reduce the harvest index and crop yield (Ballaré and Scopel 1997). Even though, phyB overexpressing B. napus plants in this study resulted in reduced plant height which could reduce lodging under field conditions, presence of unfavourable traits such as small seed size and extremely delayed flowering make these plants difficult to fit in to a rapeseed breeding program.

\subsection{Conclusions}

Ectopic expression of Arabidopsis PHYB cDNA under the control of constitutive CaMV35S promoter in Brassica napus has resulted in photomorphogenic responses. A strictly light-dependent short hypocotyl phenotype was observed with transgenic seedlings under in vitro culture conditions. Exhibition of light-dependent short hypocotyl phenotype is considered to be the result of successful assembly of transgenically produced heterologous phytochrome apoproteins with endogenous chromophores to produce photoactive phyB. Photomorphogenic responses (such as hypocotyl elongation) seem closely associated with the transgene copy number and the level of phyB produced. Kanamycin sensitivity test and PCR analysis suggested the presence of two transgene copies in T5 and T9 transgenic lines. Supposed homozygous plants in the segregating population (T2) demonstrated a higher degree of pleiotropic effects under greenhouse conditions, such as reduced apical dominance, higher leaf chlorophyll content and extremely delayed flowering. There was no marked morphological difference between the 
rest of 187 plants in the T5(2) population and non-transgenic control plants. Observed semi dwarfism with transgenic plants was mostly restricted to early developmental stages and gradually diminished when plants attained maturity. 19 late-flowering plants in the T5(2) population produced relatively smaller but a higher number of leaves which could be attributed to their prolonged vegetative phase than corresponding non-transgenic control plants. Number of seeds in transgenic plants increased more than the seed yield with the consequent reduction in weight per seed. Decreased plant height observed with lateflowering plants could reduce lodging under field conditions, however extremely delayed flowering makes these plants difficult to fit in to a crop rotation in the field conditions. How these plants behave in a controlled environmental condition or at higher planting densities merit further investigations. Such studies may help to expose the true consequence of phyB overexpression in Brassica napus. 


\section{Summary}

Oilseed rape (Brassica napus L.) is a renowned crop worldwide for its edible oil as well as a source of protein in animal feed. Thus Brassica napus is an important target for crop improvements. Agrobacterium-mediated transformation has proved to work efficient for genetic engineering of this crop. However, transformation efficiency seems to vary among different genotypes, and the need to develop an improved transformation protocol still remains. The majority of successful transformation systems hitherto described for B. napus use diploid plant materials such as hypocotyls, cotyledons, and cotyledonary petioles. Owing to the diploid character of these materials, first generation transgenic plants $\left(\mathrm{T}_{1}\right)$ are hemizygous for the transformed gene(s). When multiple unlinked transgenic copies are present in the plants, much time and labour has to be invested to produce homozygous plants by repeated selfing or by applying the doubled haploid technology. The use of haploid cells and tissue explants could provide an alternative approach for efficient transformation of oilseed rape, since haploid transgenic plants will become homozygous in one step after colchicine treatment. This study reports the potential of using leaf and petiole explants of haploid plants propagated in vitro for an efficient Agrobacterium-mediated gene transfer. The haploid plants were obtained via microspore culture from Brassica napus $c v$. Drakkar.

Compared to a standard protocol for hypocotyl segments, significantly higher callus production $(\mathrm{P}=0.05)$ with leaf explants was achieved when cultured in callus induction medium CIM-L (MS basal medium supplemented with $1 \mathrm{mg} / 1$ BAP, $0.1 \mathrm{mg} / 1 \mathrm{NAA}, 0.1$ $\mathrm{mg} / 1 \mathrm{GA}_{3}, 5 \mathrm{mg} / \mathrm{l} \mathrm{AgNO} 3$ and solidified with $5 \mathrm{~g} / 1$ Agarose). For petiole explants CIM-P medium (MS basal supplemented with $2 \mathrm{mg} / 1 \mathrm{BAP}, 0.01 \mathrm{mg} / 1$ picloram, $5 \mathrm{mg} / 1 \mathrm{AgNO} 3$ and solidified with $5 \mathrm{~g} / \mathrm{l}$ Agarose) had a significant positive effect $(\mathrm{P}=0.05)$ on callus production. Highest shoot regeneration was achieved in DKW medium supplemented with $1 \mathrm{mg} / 1 \mathrm{BAP}, 0.1 \mathrm{mg} / 1 \mathrm{NAA}, 0.1 \mathrm{mg} / 1 \mathrm{GA}_{3}$, and $5 \mathrm{mg} / 1 \mathrm{AgNO} 3$ and solidified with $5 \mathrm{~g} / 1$ Agarose. Analysis of the ploidy showed that $96 \%$ of plantlets regenerated from leaf and 92\% from petiole explants remained haploid. Using Agrobacterium tumefaciens strain AGL0, which carried the binary plasmid pAK-UGI 9-1, a transformation efficiency of $1.8 \%$ and $2.9 \%$ was achieved for leaf and petiole explants, respectively. Presence of GUS gene in regenerated plantlets was confirmed by PCR. Results indicate that transformation of leaf and petiole explants derived from in vitro propagated haploid plants provides a suitable alternative for generation of homozygous transgenic plants in rapeseed. 
Lodging could be a serious problem in oilseed Brassica napus. Many current B. napus cultivars are prone to lodging inflicting heavy yield losses. Lodging could be decreased by reducing plant height. This study investigated the possibility of reducing plant height by overexpression of $A$. thaliana $P H Y B$ gene in B. napus plants. Ectopic expression of Arabidopsis PHYB cDNA under the control of constitutive CaMV35S promoter in Brassica napus caused pleiotropic effects such as decreased apical dominance, a higher number of small leaves and increased leaf chlorophyll content. Most of physiological and phenotypical changes, which could be directly linked to $P H Y B$ overexpression, were confined mainly to leaves. Leaves of primary transformants ( $\mathrm{T} 1$ plants) were significantly thicker and comparatively smaller than those from non-transgenic control plants. Leaf chlorophyll content was significantly higher in transgenic plants than in non-transgenic plants. However, no significant difference in seed yield per plant was observed with T1 plants when compared with non-transgenic control plants. A strictly light-dependent short hypocotyl phenotype was observed with transgenic seedlings under in vitro culture conditions. Supposed homozygous plants in the segregating population (T2) demonstrated a higher degree of pleiotropic effects under greenhouse conditions. These plants exhibited substantially modified plant architecture with reduced apical dominance and plant height. Beginning of flowering was delayed by 79 days when compared with control plants. Even though $P H Y B$ overexpressing plants resulted in reduced plant height, which could reduce lodging under field conditions, presence of unfavourable traits such as low seed yield and delayed flowering make these plants difficult to fit into a rapeseed breeding program. 


\section{References}

Akasaka-Kennedy Y, Yoshida H, and Takahata Y (2005) Efficient plant regeneration from leaves of rapeseed (Brassica napus L.): the influence of $\mathrm{AgNO}_{3}$ and genotype. Plant Cell Rep. 24:649-654

Altenbach SB, Kuo CC, Staraci LC, Pearson KW, Wainright C, Georgescu A, and Townsend J (1992) Accumulation of a Brazil nut albumin in seeds of transgenic canola results in enhanced levels of seed protein methionine. Plant Mol. Biol. 18:235245

Babic V, Datla RS, Scoles GJ, and Keller WA (1998) Development of an efficient Agrobacterium-mediated transformation system for Brassica carinata. Plant Cell Rep. 17:183-188

Bagnall D, King RW, Whitelam GC, Boylan MT, Wagner D, and Quail PH (1995) Flowering responses to altered expression of phytochrome in mutants and transgenic lines of Arabidopsis thaliana (L) Heynh. Plant Physiol. 108:1495-1503

Balandin $T$, and Castresana $C$ (1997) Silencing of a $\beta$ - 1,3-glucanase transgene is overcome during seed formation. Plant Mol. Biol. 34:125-127

Ballaré CL (1999) Keeping up with the neighbours: phytochrome sensing and other signalling mechanisms. Trends Plant Sci. 4:97-102

Ballaré CL, and Scopel AL (1997) Phytochrome signalling in plant canopies: testing its population-level implications with photoreceptor mutants of Arabidopsis. Func. Ecology 11:441-450

Ballaré CL, Scopel AL, and Sánchez RA (1997) Foraging for light: photosensory ecology and agricultural implications. Plant Cell Env. 20:820-825

Binns AC (1990) Agrobacterium-mediated gene delivery and the biology of host range limitations. Physiol. Plant. 79:135-139

Boccalandro HE, Ploschuk EL, Yanovsky MJ, Sánchez RA, Gatz C, and Casal JJ (2003) Increased Phytochrome B alleviates density effects on tuber yield of field potato crops. Plant Physiol. 133:1539-1546

Boulter ME, Simpson EC, Shields R, Croy RRD, and Shirsat AH (1990) Transformation of Brassica napus L. (Oilseed rape) using Agrobacterium tumefaciens and Agrobacterium rhizogenes-a comparison. Plant Sci. 70:91-99

Bullock WO, Fernandez JM, and Short JM (1987) XL1-Blue: a high efficiency plasmid transforming recA E. coli strain with ß-galactosidase selection. BioTech. 5:376-378 
Cardoza V, and Stewart CN (2003) Increased Agrobacterium-mediated transformation and rooting efficiencies in canola (Brassica napus L.) from hypocotyl segment explants. Plant Cell Rep. 21:599-604

Cardoza V, and Stewart CN (2004b) Brassica biotechnology: Progress in cellular and molecular biology. In Vitro Cell. Dev. Biol.-Plant 40:542-551

Cardoza, V and Stewart CN (2004a) Agrobacterium-mediated transformation of canola. In: Curtis IS (ed.) Transgenic crops of the world. Kluwer Academic Publishers, Netherlands, pp 379-387

Casal JJ, Aphalo PJ, and Sanchez RA (1987) Phytochrome effects on leaf growth and chlorophyll content in Petunia axilaris. Plant Cell Env. 10:509-514

Cerdán P, and Chory J (2003) Regulation of flowering time by light quality. Nature 423: $881-885$

Charest PJ, Holbrook LA, Gabard J, Iyer VN, and Miki BL (1988) Agrobacteriummediated transformation of thin cell layer explants from Brassica napus L. Theor. Appl. Genet. 75:438-445

Charest PJ, Iyer VN, and Miki BL (1989) Virulence of Agrobacterium tumefaciens strains with Brassica napus and Brassica juncea. Plant Cell Rep. 8:303-306

Clack T, Mathews S, and Sharrock RA (1994) The phytochrome apoprotein family in Arabidopsis is encoded by five genes: the sequences and expression of PHYD and PHYE. Plant Mol. Biol. 25:413-427

Damgaard O, Jensen LH, and Rasmussen OR (1997) Agrobacterium tumefaciensmediated transformation of Brassica napus winter cultivars. Transg. Res. 6:279-288

de Block M, and de Brouwer D (1991) Two T-DNAs co-transformed into Brassica napus by a double Agrobacterium tumefaciens infection are mainly integrated at the same locus. Theor. Appl. Genet. 82:257-263

de Block M, de Brouwer, D and Tenning P (1989) Transformation of Brassica napus and Brassica oleracea using Agrobacterium tumefaciens and the expression of the bar and neo genes in the transgenic plants. Plant Physiol. 91:694-701

Devlin PF, Somers DF, Quail PH, and Whitelam GC (1997) The Brassica rapa elongated internode $(E I N)$ gene encodes phytochromes B. Plant Mol. Biol. 34:537547

Downey RK, and Röbbelen G (1989) Brassica species. In: Röbbelen G, Downey RK, and Ashri A (Eds) Oil Crops of the World, McGraw-Hill Publishing Co., New York, pp. 339-362 
Dunwell JM (1981) In vitro regeneration from excised leaf discs of three Brassica species. J. Expt. Bot. 129:789-799

Eapen S, and George L (1997) Plant regeneration from peduncle segments of oilseed Brassica species: influence of silver thiosulfate. Plant Cell Tiss. Org. Cul. 51:229-232

FAO (2006) http: www.fao.org

Fletcher R, Coventry J, and Kott LS (1998) Double haploid technology for spring and winter Brassica napus. Technical Bulletin. University of Guelph, OAC publication

Foisset N, Delourme R, Barret P, and Renard M (1995) Molecular tagging of the dwarf BREIZH (Bzh) gene in Brassica napus. Theor. Appl. Genet. 91:756-761

Fry J, Barnason A, and Horsch RB (1987) Transformation of Brassica napus with Agrobacterium tumefaciens based vectors. Plant Cell Rep. 6:321-325

Fukuoka H, OgawaT, Matsuoka M, Ohkawa Y, and Yano H (1998) Direct gene delivery into isolated microspores of rapeseed (Brassica napus L.) and the production of fertile transgenic plants. Plant Cell Rep. 17:323-328

Furuya M (1993) Phytochromes: their molecular species, gene families, and functions. Annu. Rev. Plant Physiol. Plant Mol. Biol. 44:617-5

Gans W, Beschow H, and Merbach W (2000) Growth regulators for cereal and oil crops on the basis of 2,3-dichloroisobutyric acid and chlormequatchloride and residue analyses of both agents in the grain of oat. J. Plant Nutr. Soil Sci. 163:405-410

Godwin I, Todd G, Ford-Lloyd B, and H. John Newbury HJ (1991) The effects of acetosyringone and $\mathrm{pH}$ on Agrobacterium-mediated transformation vary according to plant species. Plant Cell Rep. 9:671-675

Greef JA (1996) Phytochrome research in whole plant physiology. Wild-type seedlings versus mutants and transgenic plants. Physiol. Plant. 98:377-380

Grimsley N, Hohn HBT, and Walden RM (1986) Agroinfection, an alternative route for viral infection of plants by using the Ti plasmid. Proc Natl. Acad. Sci. USA 83:32823286

Guerche P, Charbonnier M, Jouanin L, Tourneur C, Paszkowski J, and Pelletier G (1987) Direct gene transfer by electroporation in Brassica napus. Plant Science $52: 111-116$

Guivarc'h A, Cissard J-C, Brown S, Marie D, Dewitte W, Van Onckelen H, and Chriqui D (1993) Localization of target cells and improvement of Agrobacterium-mediated transformation efficiency by direct acetosyringone pre-treatment of carrot root discs. Protoplasma 174:10-18 
Halliday KJ, Koornneef M, and Whitelam GC (1994) Phytochrome B and at least one other phytochrome mediate the accelerated flowering response of Arabidopsis thaliana L. to low Red/Far-Red ratio. Plant Physiol. 104:1311-1315

Halliday KJ, Salter MG, Thingnaes E, and Whitelam GC (2003) Phytochrome control of flowering is temperature sensitive and correlates with expression of the floral integrator FT. The Plant J. 23:875-885

Halliday KJ, Tomas B, and Whitelam GC (1997) Expression of heterologous phytochromes $\mathrm{A}, \mathrm{B}$ or $\mathrm{C}$ in transgenic tobacco plants alters vegetative development and flowering time. The Plant J. 12:1079-1090

Hellens RP, Mullineaux P, and Klee H (2000) A guide to Agrobacterium binary Ti vectors. Trends in Plant Sci. 5:446-451.

Henzi MX, Christey MC, and McNeil DL (2000) Factors that influence Agrobacterium rhizogenes-mediated transformation of broccoli (Brassica oleracea L. var. italica). Plant Cell Rep. 19:994-999

Hu Q, Andersen SB, and Hansen LN (1999) Plant regeneration capacity of mesophyll protoplasts from Brassica napus and related species. Plant Cell Tiss. Org. Cul. 59:189-196

Hüsken A, Baumert A, Milkowski C, Becker HC, Strack D, and Möllers C (2005) Resveratrol glucoside (Piceid) synthesis in seeds of transgenic oilseed rape (Brassica napus L.). Theor. Appl. Genet. 111:1553-1562

Ingelbrecht I, Houdt HV, Montagu MV, and Depicker A (1994) Post-transcriptional silencing of reporter transgenes in tobacco correlates with DNA methylation. Proc. Natl. Acad. Sci. USA 91:10502-10506

Islam N, and Evans EJ (1994) Influence of lodging and nitrogen rate on the yield and yield attributes of oilseed rape (Brassica napus L.). Theor. Appl. Genet. 88:530-534

Jardinaud M-F, Souvre A, and Alibert G (1993) Transient GUS gene expression in Brassica napus electroporated microspores. Plant Sci. 93:177-184

Kasemir H, and Mohr H (1981) The involvement of phytochrome in controlling chlorophyll and 5-aminolevulinate formation in a gymnosperm seedling (Pinus sylvestris). Planta 152:369-373

Kazan K, Curtis MD, Goulter KC, and Manners JM (1997) Agrobacterium tumefaciensmediated transformation of double haploid Canola (Brassica napus) lines. Aust. J. Plant Physiol. 24:97-102 
Khan MR, Rashid H, Ansar M, and Chaudry Z (2003) High frequency shoot regeneration and Agrobacterium-mediated DNA transfer in Canola (Brassica napus). Plant Cell Tiss. and Org. Cul. 75:223-231

Kilby NJ, Leyser HMO, and Furrier IJ (1992) Promoter methylation and progressive transgene inactivation in Arabidopsis. Plant Mol. Biol. 20:103-112

Knutzon DS, Thompson GA, Radke SE, Johnson WB, Knauf VC, and Kridl JC (1992) Modification of Brassica seed oil by antisense expression of a stearoyl-acyl carrier protein desaturase gene Proc. Natl. Acad. Sci. USA 89:2624-2628

Kohno-Murase J, Murase M, Ichikawa H, and Imamura J (1995) Improvement in the quality of seed storage protein by transformation of Brassica napus with an antisense gene for cruciferin. Theor. Appl. Genet. 91:627-631

Lazo GR, Stein PA, and Ludwig RA (1991) A DNA transformation-competent Arabidopsis genomic library in Agrobacterium. Bio/Technol. 9:963-967

Mathews S, and Sharrock RA (1997) Phytochrome gene diversity. Plant Cell Env. 20:666-671

Matzke AJM, Neuhuber F, Park Y-D, Ambros PF, and Matzke MA (1994) Homology dependent gene silencing in transgenic plants: epistatic silencing loci contained multiple copies of methylated transgenes. Mol. Gen. Genet. 244:219-229

McCormac AC, Smith H, and Whitelam GC (1992) Light-grown plants of transgenic tobacco expressing an introduced oat phytochrome A gene under the control of a constitutive viral promoter exhibit persistent growth inhibition by far-red light. Planta 188: $173-181$

McCormac AC, Smith H, and Whitelam GC (1993b) Photoregulation of germination in seed of transgenic lines of tobacco and Arabidopsis which express an introduced cDNA encoding phytochrome A or phytochrome B. Planta 191:386

McCormac AC, Wagner D, Boylan MT, Quail PH, Smith H, and Whitelam GC (1993a) Photoresponses of transgenic Arabidopsis seedlings expressing introduced phytochrome B-encoding cDNAs: evidence that phytochrome A and phytochrome B have distinct photoregulatory functions. The Plant J. 4:19-27

Miki BL, Huang B, Bird S, Kemble R, Simmonds D and Keller W (1989) A procedure for the microinjection of plant cells and protoplasts. J. Tissue Cult. Meth. 12:139-144

Möllers C, Iqbal MCM, and Röbbelen G (1994) Efficient production of doubled haploid Brassica napus plants by colchicine treatment of microspores. Euphytica 75:95-104 
Moloney MM, Walker JM, and Sharma KK (1989) High efficiency transformation of Brassica napus using Agrobacterium vectors. Plant Cell Rep. 8:238-242

Mouradov A, Cremer F and Coupland G. (2002). Control of flowering time: Interacting pathways as a basis for diversity. Plant Cell Supplement.14: S111-S130

Muangprom A, Mauriera I, and Osborn TC (2006) Transfer of a dwarf gene from Brassica rapa to oilseed B. napus, effects on agronomic traits, and development of a 'perfect' marker for selection. Mol. Breed. 17: 101-110

Murashige T, and Skoog F (1962) A revised medium for rapid growth and bioassays with tobacco tissue cultures. Physiol. Plant. 15: 473-497

Nagatani A, Reed JW, and Chory J (1993) lsolation and initial characterization of Arabidopsis mutants that are deficient in phytochrome A. Plant Physiol. 102: 269-277

Neuhaus G, Spangenberg G, Scheid OM, and Schweiger H.-G (1987) Transgenic rapeseed plants obtained by the microinjection of DNA into microspore-derived embryoids. Theor. Appl. Genet. 75:30-36

Oelze-Karow H and Mohr H (1981) Phytochromes action on chlorophyll synthesis-A study of the escape from photoreversibilty. Plant Physiol. 70:863-866

Pechan PM (1989) Successful cocultivation of Brassica napus microspores and proembryos with Agrobacterium. Plant Cell Rep. 8:387-390

Pua E-C, Mehra-Palta A, Nagy F, and Chua N-H (1987) Transgenic plants of Brassica napus. Biotechnol. 5:815-817

Quail PH (1991) Phytochromes: a light-activated molecular switch that regulates plant gene expression. Annu. Rev. Genet. 25:89-109

Rademacher W (2000) Growth retardants: effects on gibberellin biosynthesis and other metabolic pathways. Ann. Rev. Plant Physiol. Plant Mol. Biol. 51:501-531

Radke SE, Andreas BM, Moloney MM, Crouch ML, Kridl JC, and Knauf VC (1988) Transformation of Brassica napus L using Agrobacterium tumefaciens: developmentally regulated expression of napin gene. Theor. Appl. Genet. 17:685-694

Reed JW, Nagpal P, Poole DS, Furuya M, and Chory J (1993) Mutations in the gene for the Red/Far-Red light receptor phytochrome B alter cell elongation and physiological responses throughout Arabidopsis development. The Plant Cell 5:147-157

Robsen PRH, McCormac AC, Irvine AS, and Smith H (1996) Genetic engineering of harvest index in tobacco through overexpression of a phytochrome gene. Nat. Biotechnol.14:995-998 
Robson PRH, and Smith H (1997) Fundamental and biological applications of phytochrome transgenes. Plant Cell and Env. 20: 831-839

Rockwell NC, Su Y-S, and Clark J (2006) Lagarias phytochrome structure and signalling mechanisms. Annu. Rev. Plant Biol. 57:837-58

Sangwan RS, Ducrocq C, and Sangwan-Norreel (1993) Agrobacterium-mediated transformation of pollen embryos in Datura innoxia and Nicotiana tabaccum: production of transgenic haploid and fertile homozygous dihaploid plants. Plant Sci. 95:99-115

Schittenhelm S, Menge-Hartmann U, and Oldenburg E (2004) Photosynthesis, carbohydrate metabolism, and yield of phytochrome-B-overexpressing potatoes under different light regimes. Crop Sci. 44:131-143

Schröder M, Dixellius C, Rahlen L, and Glimelius K (1994) Transformation of Brassica napus by using the aadA gene as selectable marker and inheritence studies of the marker genes. Physiol. Plant. 92:37-46

Sharkey TD, Vassey TL, Vanderveer PJ, and Vierstra RD (1991) Carbon metabolism enzymes and photosynthesis in transgenic tobacco (Nicotiana tabacum L.) having excess phytochrome. Planta 185:287-296

Sharrock RA, and Quail PH (1989) Novel phytochrome sequences in Arabidopsis thaliana: structure, evolution, and differential expression of a plant regulatory photoreceptor family. Genes Devel. 3:1745-1757

Simpson GG and Dean C (2002) Arabidopsis, the rosetta stone of flowering time? Science 296:285-289

Smith H (1992) Ecology of photomorphogenesis: clues to a transgenic programme of crop plant environment. Phytochem. Photobiol. 56:815-822

Smith H (1995) Physiological and ecological function within the phytochrome family. Annu. Rev. Plant Physiol. Plant Mol. Biol. 46:289-315

Smith H, and Whitelam GC (1997) The shade avoidance syndrome: multiple responses mediated by multiple phytochromes. Plant Cell and Env. 20:840-844

Smith H, Xu Y, and Quail PH (1997) Antagonistic but complementary actions of phytochromes A and B allow optimum seedling de-etiolation. Plant Physiol. 114:637641

Somers DE, Sharrock RA, Teppermaqa JM, and Quail PH (1991) The hy3 long hypocotyl mutant of Arabidopsis is deficient in phytochromes B. The Plant Cell $3: 1263-1274$ 
Statistical Graphics Corp. (1997) Statgraphics Plus 3.0, Statistical graphic System by Statistical Graphic Corporation, Rockville.

Stefanov IS, Bogre FL, Pauk J, Feher A, and Dudits D (1994) Differential activity of the manopine synthase and CaMV 35S promoters during development of transgenic rapeseed plants. Plant Sci. 95:175-186.

Stewart CN, Adang MJ, All JA, Raymer PL, Ramachandran S, Parrott WA (1996) Insect control and dosage effects in transgenic canola containing a synthetic Bacillus thuringiensis crylAc gene. Plant Physiol. 112:115-120

Stöger E, Fink C, Pfosser M, and Heberle-Bors E (1995) Plant transformation by particle bombardment of embryogenic pollen. Plant Cell Rep. 14:273-278

Swanson EB, and Erickson LR (1989) Haploid transformation of Brassica napus using an octopine-producing strain of Agrobacterium tumefaciens. Theor. Appl. Genet. $78: 831-835$

Thiele A, Herold M, Lenk I, Quail PH, and Gatz C (1999) Heterologous expression of Arabidopsis Phytochrome $\mathrm{B}$ in transgenic potato influences photosynthetic performance and tuber development. Plant Physiol. 120:73-81

Thomzik JE, and Hain R (1990) Transgenic Brassica napus plants obtained by cocultivation of protoplasts with Agrobacterium tumefaciens. Plant Cell Rep. 9:233236

Tsukayaki H, Kuginuki Y Aida R, and Suzuki T (2002) Agrobacterium-mediated transformation of a double haploid line of cabbage. Plant Cell Rep. 21:257-262

Utz HF (2001) A computer program for statistical analysis of plant breeding experiments. Institute of Plant breeding, University of Hohenheim, D-70593 Stuttgart, Germany

van Tuinen A, Kerckhoffs HJ, Nagatani A, Kendrick RE, and Koornneef M (1995) A temporarily red light-insensitive mutant of tomato lacks a light-stable, B-like phytochrome. Plant Physiol. 108:939-947

Vancanneyt G, Schmid R, O’Conner-Sanchez A, Willmitzer L, and Rocha-Sosa M (1990) Construction of an intron-containing marker gene: splicing of the intron in transgenic plants and its use in monitoring early events in Agrobacterium-mediated plant transformation. Mol. Gen. Genet. 220:245-50

Vaucheret H, Beclin C, Elmayan T, Feuerbach F, Morel J-B Mourrain P, Palauqui J-C, and Vernhettes S (1998) Transgene induced gene silencing in plants. The Plant J. 16:651-659 
Verwoert GS, van der Linden KH, Walsh MC, John H, Nijkamp J, and Stuitje AR (1995) Modification of Brassica napus seed oil by expression of the Escherichia coli fabH gene, encoding 3-ketoacyl-acyl carrier protein synthase III. Plant Molecular Biology 27:875-886

Verwoert IIGS, van der Linden KH, Walsh MC, Nijkamp HJJ, and Stuitje AR (1995) Modification of Brassica napus seed oil by expression of the Escherichia coli fabH gene, encoding 3-ketoacyl-acyl carrier protein synthase III. Plant Mol. Biol. 27:875886

Wagner D, Tepperman JM, and Quail PH (1991) Overexpression of phytochrome B induces a short hypocotyl phenotype in transgenic Arabidopsis. The Plant Cell 3:1275-1288

Wang YP, Sonntag K, Rudloff E, and Han J (2005) Production of fertile transgenic Brassica napus by Agrobacterium-mediated transformation of protoplasts. Plant Breed. 124:1-4

Wester L, Somers DE, Clack T, and Sharrock RA (1994) Transgenic complementation of hy3 phytochrome B mutation and response to PHYB copy number in Arabidopsis. The Plant J. 5:261-272

Whitelam GC, and Devlin PF (1997) Roles of different phytochrome in Arabidopsis photomorphogenesis. Plant Cell Env. 20:752-758

Whitelam GC, and Harberd NP (1994) Action and function of phytochrome family members revealed through the study of mutant and transgenic paints. Plant Cell Env. $17: 615-625$

Whitelam GC, McCormac AC, Boylan MT, Quail PH (1992) Photo-responses of Arabidopsis seedlings expressing an introduced oat phyA cDNA: persistence of etiolated plant type responses in light-grown plants. Photochem. Photobiol. 56:617621

Zanewich KP, Rood SB, Southworth CE, Williams PH (1991) Dwarf mutants of Brassica: responses to applied gibberellins and gibberellin content. Plant Growth Regul. 10:121-127

Zhang FL, Takahata Y, Watanabe M, and Xu JB (2000) Agrobacterium-mediated transformation of cotyledonary explants of Chinese cabbage (Brassica campestris L. ssp pekinensis). Plant Cell Rep. 19:569-575 


\section{Acknowledgments}

First of all I would like to extend my sincere thanks to Deutscher Akademischer Austausch Dienst (DAAD) for providing me with a scholarship as a gesture of friendship of German people, to come into their country and have a free education.

I would be grateful to Prof. Dr. Heiko Becker, first for accepting me as a $\mathrm{PhD}$ student under his supervision and secondly for providing me with all the facilities necessary to undertake my research in the Department of Crop Science. I highly appreciate your role as an academic supervisor and would always be thankful for your support, guidance, encouragements, valuable comments and corrections to improve my thesis.

My thanks and gratitude is for Dr. Christian Möllers, my immediate supervisor, for his invaluable help, guidance and encouragements throughout this study. This work would not have been realized without your help. I would be ever grateful to you for making possible my dream of having a $\mathrm{PhD}$. I highly value your professional approach in scientific affaires, research in the laboratory and enjoyed your kindness and friendliness all these years.

I would like to extent my sincere thanks to Dr MCM Iqbal first for introducing me to Prof. Dr. Heiko Becker and Dr. Christian Möllers and secondly for his efforts to initiate this research. I appreciate your help guidance and encouragements.

My special thanks are for Prof. Dr. Christiane Gatz of Albrecht-von-Haller-Institut für Pflanzenwissenschaften, University of Göttingen, Germany for providing me with the plant transformation vector containing A. thaliana Phytochrome B gene and Dr. Michael Wallbraun of Centrum Grüne Gentechnik, DLR Rheinpfalz, 67435 Neustadt/Wstr. for providing me with the plant expression vector pPNGUS.

I extend my thanks to Prof. Dr. Wolfgang Link for his suggestions in statistical analysis and also for supporting me with good recommendation letters necessary for extension of my scholarship by DAAD.

I thank Prof. Dr. Petr Karlovsky and PD Dr. Brigitte Maass first for accepting to be my academic referees and secondly for their corrections and valuable suggestions to improve my thesis.

My heartfelt thanks go to Ms. Rosemarie Clemens for her invaluable help and assistance in the laboratory during my study. You had been a great asset to me all these years to improve my laboratory skills. Your friendliness and kindness had always contributed to make a present environment in the laboratory.

I thank Ms. Gunda Asselmeyer and Ms. Maike Fischer for their valuable help during green house experiments. 
I extend my thanks to all the staff members of the Department of Crop Science, Faculty of Agriculture, University of Göttingen for their help, kindness and cooperation throughout my study.

I thank all my colloquies, Berisso, Mladen, Samiya, Mustapha, Lamiae, Oliver, Ofori, Ujjal, Nurhasanah, Franziska, Stijn, Sabine and Susane for their friendship and pleasant company.

Finally I thank my loving wife Chithrani, for her encouragements, help, patient and love throughout these three long years that served as a grate source of strength to achieve my goals. 


\section{Curriculum Vitae}

\section{Personal data}

Name $\quad$ Kolitha Bandara Wijesekara

Date of birth $\quad 25^{\text {th }}$ August 1970

Place of birth Kandy, Sri Lanka

Nationality Sri Lankan

\section{Educational qualifications}

2004 to date

$1999-2002$

1993-1997

1977-1990
Studying at the Department of Crop Science, Georg-August University, Göttingen, for the award of PhD. Degree in Plant Breeding

M.Phil. in Plant Reproductive Biology, at the Post Graduate Institute of Science, University of Peradeniya, Sri Lanka

B.Sc. degree in Biological Science from the University of Peradeniya, Sri Lanka

Elementary, secondary and high school education from Kingswood College, Kandy, Sri Lanka

\section{Professional career}

1998 to date

1997-1998
Working as a Research Assistant (Grade I) at the Department of Plant Biotechnology of Institute of Fundamental Studies, Hantana road, Kandy, Sri Lanka

Worked as an Assistant Lecturer in the Department of Botany, University of Peradeniya, Sri Lanka 
Filename: $\quad$ ThesisComplete.doc

Directory: $\quad \mathrm{E}$ :

Template: $\quad C:$ Documents and Settings $\backslash$ BERISO $\backslash$ Application

Data $\backslash$ Microsoft $\backslash$ Templates $\backslash$ Normal.dot

Title: Development of a haploid transformation system and overexpression of Phytochrome B gene in Subject:

Author: Rosmarie Hoffmann

Keywords:

Comments:

Creation Date: $\quad$ 7/31/2007 4:40 PM

Change Number: $\quad 485$

Last Saved On: $\quad$ 8/13/2007 3:30 PM

Last Saved By: kolitha

Total Editing Time: 3 Minutes

Last Printed On: $\quad$ 8/13/2007 5:01 AM

As of Last Complete Printing

Number of Pages: 91

Number of Words: $\quad 25,509$ (approx.)

Number of Characters: 145,403 (approx.) 